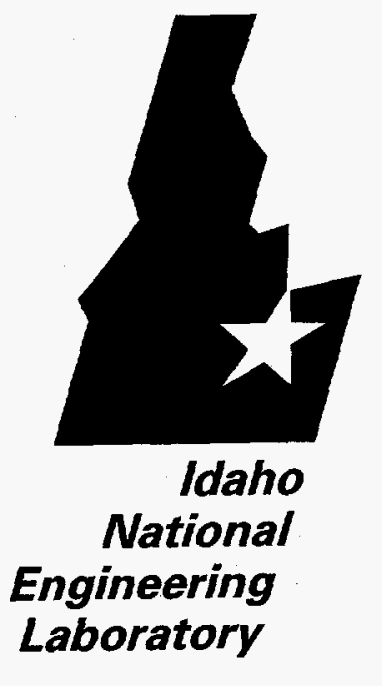

INEL-96/0143

April 1996

\title{
Pressure Grouting of Fractured Basalt Flows
}

Peter Shaw, Jerry Weidner

Idaho National Engineering Laboratory Lockheed Idaho Technologies Company

Steve Phillips, Jerry Alexander

Westinghouse Hanford Company

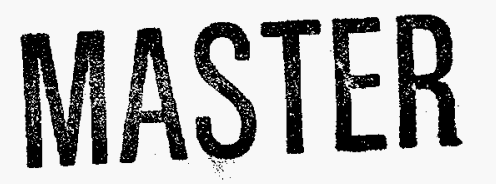

LOCKHEED MARTIN

MSTRIBUTION OF THIS DOCUMENT IS UNLIMITED, 


\title{
Pressure Grouting of Fractured Basalt Flows
}

\author{
Peter Shaw, Jerry Weidner \\ Idaho National Engineering Laboratory \\ Lockheed Idaho Technologies Company \\ Steve Phillips, Jerry Alexander \\ Westinghouse Hanford Company
}

Published April 1996

\section{Idaho National Engineering Laboratory Lockheed Idaho Technologies Company Idaho Falls, Idaho 83415}

Prepared for the

U.S. Department of Energy

Assistant Secretary for Environmental Management

Under DOE Idaho Operations Office

Contract DE-AC07-94ID13223 


\section{DISCLAMMER}

Portions of this document may be illegible in electronic image products. Images are produced from the best available original document. 


\begin{abstract}
This report describes a field trial of pressure grouting in basalt and the results of subsequent coring and permeability measurement activities. The objective was to show that the hydraulic conductivity of fractured basalt bedrock can be significantly reduced by pressure injection of cementitious materials. The effectiveness of the pressure grout procedure was evaluated by measuring the change in the hydraulic conductivity of the bedrock. The extent of grout penetration was established by analyzing postgrout injection drilling chips for the presence of a tracer in the grout and also by examining cores of the treated basalt. Downhole radar mapping was used to establish major lava flow patterns and follow water movement during a surface infiltration test. A site called Box Canyon, which is located northwest of the INEL, was chosen for this study due to the similarity of this surface outcrop geology to that of the underlying bedrock fracture system found at the Radioactive Waste Management Complex. This study showed that hydraulic conductivity of basalt can be reduced through pressure grouting of cementitious material.
\end{abstract}





\section{EXECUTIVE SUMMARY}

This report describes a field trial of pressure grouting basalt fractures and the results of subsequent coring and permeability measurement activities. The objective was to show that hydraulic conductivity of fractured basalt bedrock can be significantly reduced by pressure injection of cementitious materials. If successful, the grout material creates a barrier to water movement preventing transport of contaminants into or through the fractured bedrock geosystem.

The test program was undertaken because the buried waste pits and trenches of the Radioactive Waste Management Complex (RWMC) at the Idaho National Engineering Laboratory (INEL) are situated on the basaltic volcanic complex of the Eastern Snake River Plain. Bedrock permeability values in the Snake River Plain range through more than five orders of magnitude (i.e., $80-0.003$ darcies). Some regions within the basalt complex allow virtually unrestricted water flow while other regions are impermeable. The bedrock fracture systems are the natural conduits for the movement of surface waters to the aquifer at a depth of 580 feet below RWMC.

The effectiveness of the pressure grout procedure was evaluated primarily by measuring the change in the hydraulic conductivity of the bedrock. Extent of grout penetration was established by drilling and coring the basalt after treatment. Drilling chips were analyzed for the presence of a fluorescent dye in the grout. Intact angled cores of the pressure grouted basalt were examined for fill of fractures. Downhole radar mapping was tested in two of the holes before grouting as to its ability to establish major patterns of water flow into and within the lava flows. It also locates major lava flow patterns.

Implementability of in situ pressure grouting of fractured basalt beneath soil and buried waste was evaluated through field log data on cement injection volume, operational problems, photographic record, and by engineering assessments of the entire operation. From this the number of wells, their spacing and depth, and the cost of operation can be estimated for an actual operation such as sealing bedrock beneath a trench or storage tank for a hot spot removal action.

The Box Canyon Site is located northwest of the INEL and is geologically similar to the fractured basalt bedrock found at the RWMC. Three lithologically distinct zones are present at the test site. Two vertically stacked basaltic flows are separated by a layer of rubble. The bottom zone is the top of the base basaltic flow and is about 9 meters below the outcrop surface. The middle zone contains a layer of rubble about 5 meters below the outcrop surface. The top zone is above the intermediate rubble layer and is the bottom of the uppermost flow.

Twenty-four vertical holes were drilled in a semicircle array on a 16- meter radius. The hole depth was $8.4 \pm 0.5$ meters. The holes were characterized with a downhole video camera and by caliper logging followed by hydraulic conductivity measurements.

Hydraulic conductivity was measured using a 7.6-cm diameter straddle packer with 1.07 meters between packers at three points within each hole at average depths of $4.5,5.8$, and 7.1 meters. The packer was pressurized to isolate the section of the hole between packers. Water was injected into the volume between the packers until a steady state flow was achieved.

Flow volume was recorded as a function of time together with the total pressure of the system. Hydraulic conductivity (rkf) was calculated from the packer spacing (L), hole radius (r), pressure $(\mathrm{h})$ and flow $(\mathrm{Q})$ using the equation $\mathrm{rkf}=$ $\mathrm{Q} /(2 * p i * \mathrm{~h} * \mathrm{~L}) * \ln (\mathrm{L} / \mathrm{r})$. Hydraulic conductivity values averaged $5.6 \pm 9.3 \times 10^{-4}$ and range from $5.4 \times 10^{-3}$ to $8.7 \times 10^{-5} \mathrm{~cm} / \mathrm{sec}$ before grouting. The higher conductivities are typical of slightly impeded water flow through $1 / 2$ in. and larger cracks and at lava flow boundaries. The lower ones are those of tight basaltic formations.

For comparison, a small-scale surface infiltration test performed over a lava flow boundary in 
the same lava formations at the southeast end of the testing area before grouting. This $3 \mathrm{~m}^{2}$ area had a hydraulic conductivity of $5 \times 10^{-3} \mathrm{~cm} / \mathrm{sec}$. Hydraulic conductivity of $10^{-7} \mathrm{~cm} / \mathrm{sec}$ is the Environmental Protection Agency (EPA) guideline for a "sealed" liner or cap for landfill construction purposes. Conductivities lower than this are difficult to obtain in the field in situ and indicate that diffusion processes become the dominant contaminant transport mechanism.

Twenty four holes were drilled in a half radius pattern. Thirteen were grouted with Portland cement, nine with Microfine cement, and two with both cements. Portland cement was used premixed $1: 1$ by volume whereas Microfine was mixed onsite $3: 1$. A total of $23.4 \mathrm{~m}^{3}$ of cement, $22.2 \mathrm{~m}^{3}$ Portland and $1.2 \mathrm{~m}^{3}$ Microfine, was injected. The holes injected with Microfine cement contained the smallest fractures and were chosen based on the downhole video and caliper logs and low initial hydraulic conductivities $<3 x$ $10^{-4} \mathrm{~cm} / \mathrm{sec}$. A fluorescein dye tracer was also premixed with grout at about 1,000 parts per million (ppm) and injected with the grout. Five holes along a rough western line from the center of the radius accounted for $82 \%$ of the grout volume injected (i.e., $19.1 \mathrm{~m}^{3}$ ). One of these holes took $8.7 \mathrm{~m}^{3}$ of Portland cement or $37 \%$ of the total grout volume. These holes appear to be hydraulically connected to a large void or fracture. The remaining holes averaged $0.2 \mathrm{~m}^{3}, 0.3 \pm 0.2 \mathrm{~m}^{3}$ for Portland cement injection and $0.11 \pm 0.04 \mathrm{~m}^{3}$ for Microfine cement.

After the grouting campaign, 12 holes were vertically drilled between the grouted holes and to the same 8.4 meter depth. Six holes were 1 meter from the nearest grout injection point, four holes 2 meters away, and two holes were placed 4 meters away. During drilling, chip samples were collected every 1.5 meters, packaged, and analyzed for tracer presence by scanning with ultraviolet (UV) light. Every sample but one contained at least a trace of substance sensitive to UV light. Cross-contamination while drilling and the fact that some species in natural calcite are fluorescent made these tracer results less than definitive.
Hydraulic conductivity measurements were then made for the 12 holes in a similar fashion as before grouting. Hydraulic conductivity values were lower than the nearby pregrout holes in 10 of the 12 holes. The two holes along the zone of large grout injected volume had hydraulic conductivities higher than surrounding pregrouting holes by a factor of 2 to 3 . Values after grouting averaged $2.0 \pm 4.8 \times 10^{-4}$ ranging from $2.3 \times$ $10^{-3}$ to $6.2 \times 10^{-6} \mathrm{~cm} / \mathrm{sec}$. Using the 10 of 12 holes that showed hydraulic conductivity reductions, reduction factors ranged from 3 to 105 , averaging $29 \pm 38$ with a median of 10 .

Eight basalt cores were taken a year after the grouting test in the same location close to at least one grout injection point. Seven cores were water drilled at a 22-degree angle through areas of both high and low grout density. One core was air drilled outside the half circle testing area near the pivot point to obtain a directional core. The cores were analyzed for the presence of cement. About $22 \%$ of the fractures showed evidence of cement penetration. Within 3 meters of the ground surface, only $4 \%$ of the fractures showed evidence of cement. Beyond 9 meters of depth, 53\% of the fractures showed evidence of cement. The cement also pushed sediment already present in the fractures, which apparently assisted in the sealing the fractures.

The results of the test program indicate that, in general, the pressure grout effectively penetrated the fractured basalt. The top to bottom grout distribution indicates that the grout is now concentrated toward the lower portions of the basalt flows, suggesting that the grout flowed downward through the open channel ways due to gravity after the pressure injection.

A comparison of pre versus postgrout hydraulic conductivities indicates that the injection of grout has an $80 \%$ chance of decreasing hydraulic conductivity by a factor of two to three and a greater than $50 \%$ chance of decreasing it by an order of magnitude. The effective grouting diameter was estimated to be 2 meters in "average" fractured basalt although effects of grouting were 
observed at distances up to 4 meters in competent basalt.

However, the regions that initially had very high hydraulic conductivities were also the regions into which most of the grout was injected. The hydraulic conductivity of these regions was not affected by the grout injection. In one case, no hydraulic conductivity reduction was observed 1 meter away even after a half truckload of cement had been injected. The data suggest that these regions of very high conductivity were open, unconfined zones such as lava tubes, rubble zones, and very large fissures. This suggests that the grain size of the cement should be increased or otherwise changed, perhaps using concrete or a coarser grained aggregate as appropriate, so that the larger fractures and voids are sealed.

The correlation between high hydraulic conductivity values and the amount of cement injected is a useful way to predict those regions likely to require coarse grained grout materials and can be used in conjunction with systematic borehole characterization to select the grout material for a particular hole. Microfine cement seemed to enhance fill in fine fractures, particularly lowering conductivity at the lowest depths of treatment. Injecting most holes with Portland cement, or concrete as appropriate, and some select holes with Microfine cement is a feasible use of the more expensive Microfine cement.

Pressure grouting of basaltic fractures reduces hydraulic conductivity and can be implemented immediately. Hole drill rates ranged from
0.05-0.3 meters/min depending on the bit and stringer breakdown rate. Grouting rates range from $0.5-0.05$ meters/min depending on the "take" or about 0.25-2 hours for an 8-meter hole.

The cost of grouting large areas is difficult to estimate, but based on this field trial, a reduction in permeability of an order of magnitude could be achieved for roughly $\$ 500 / \mathrm{m}^{2}$ based on an 8-meter bedrock penetration and 4-meter hole spacing or $\$ 20 / \mathrm{m}^{3}$ of basalt treated. For $80 \%$ of the grouting, material costs are not critical but when large voids are encountered these costs can become a factor. This assumption does not include any contamination/radiological control expenses, assumes $95 \%$ of the grout will be Portland cement, and that the drilling and monitoring will be no more extensive than what was done in these field trials. Microfine cement seemed to enhance fill in fine fractures particularly lowering conductivity at the lowest depths of treatment and beyond.

Achieving a two orders of magnitude hydraulic conductivity reduction consistently with a closer hole spacing has not been demonstrated but appears achievable based on a conductivity decrease of this amount in one area in the field trial. Monitoring using downhole radar, video cameras, borehole hydraulic conductivity, and angled coring are valuable tools to verify fracture fill. Large voids such as vent tubes cannot be filled with this technique unless grout volumes are increased greatly or something large is used to plug these zones before further grouting. 


\section{CONTENTS}

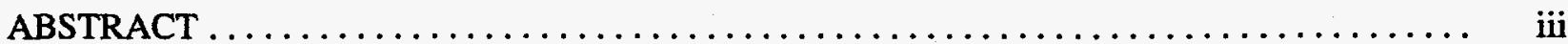

EXECUTIVE SUMMARY $\ldots \ldots \ldots \ldots \ldots \ldots \ldots \ldots \ldots \ldots \ldots \ldots \ldots \ldots \ldots \ldots \ldots \ldots$

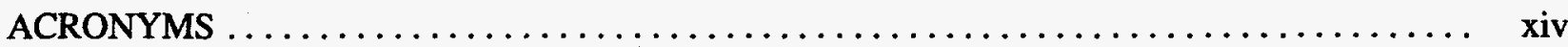

1. INTRODUCTION $\ldots \ldots \ldots \ldots \ldots \ldots \ldots \ldots \ldots \ldots \ldots \ldots \ldots \ldots \ldots \ldots \ldots \ldots \ldots$

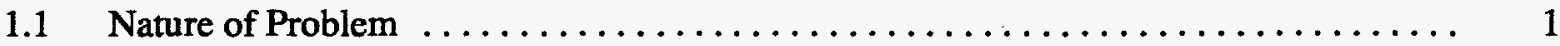

1.2 General Remediation Methods $\ldots \ldots \ldots \ldots \ldots \ldots \ldots \ldots \ldots \ldots \ldots \ldots \ldots \ldots \ldots \ldots \ldots$

1.3 Grouting Procedures and Application at the INEL $\ldots \ldots \ldots \ldots \ldots \ldots \ldots \ldots \ldots$

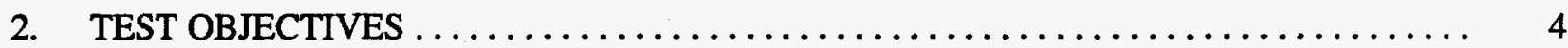

3. EXPERIMENTAL DESIGN AND PROCEDURES $\ldots \ldots \ldots \ldots \ldots \ldots \ldots \ldots \ldots \ldots \ldots$

3.1 Geology of Test Area $\ldots \ldots \ldots \ldots \ldots \ldots \ldots \ldots \ldots \ldots \ldots \ldots \ldots \ldots \ldots$

3.2 Pre and Postgrout Drilling Borehole Distribution Pattern $\ldots \ldots \ldots \ldots \ldots \ldots \ldots$

3.3 Hard Rock Drilling Equipment and Procedures $\ldots \ldots \ldots \ldots \ldots \ldots \ldots \ldots \ldots \ldots$

$3.4 \quad$ Hydraulic Conductivity Measurement Method $\ldots \ldots \ldots \ldots \ldots \ldots \ldots \ldots \ldots \ldots$

3.5 Description of Injection Materials $\ldots \ldots \ldots \ldots \ldots \ldots \ldots \ldots \ldots \ldots \ldots \ldots \ldots \ldots \ldots \ldots \ldots$

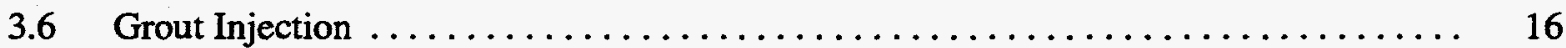

3.7 Cross-Hole Raytheon Subsurface Mapping Procedures $\ldots \ldots \ldots \ldots \ldots \ldots \ldots \ldots$

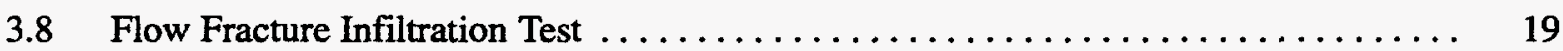

3.9 Postgrouting Angled Core Sampling $\ldots \ldots \ldots \ldots \ldots \ldots \ldots \ldots \ldots \ldots \ldots \ldots \ldots \ldots \ldots$

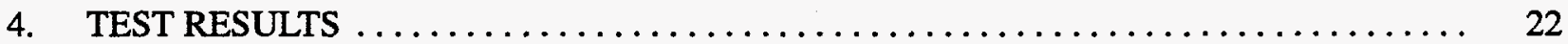

4.1 Grout Application and Water Conductivity in Fractured Basalt $\ldots \ldots \ldots \ldots \ldots \ldots 22$

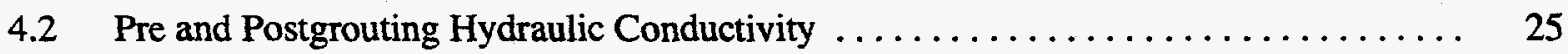

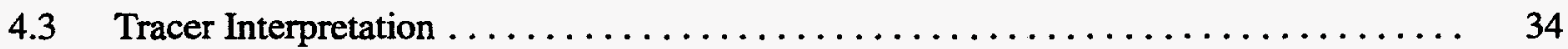

4.4 Downhole Radar, Surface Permeability, and Cross-Hole Subsurface Postgrouting

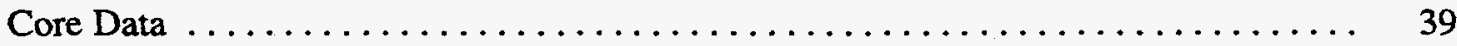

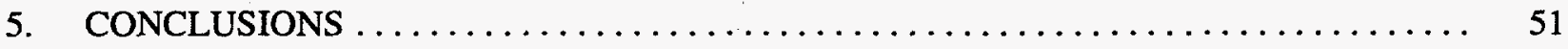

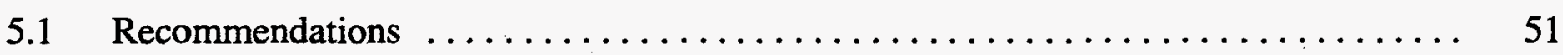

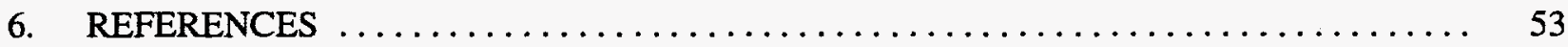

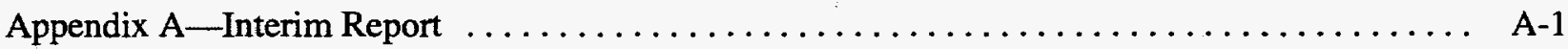




\section{FIGURES}

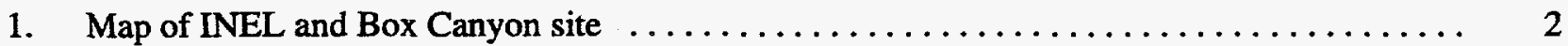

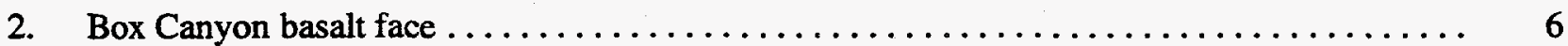

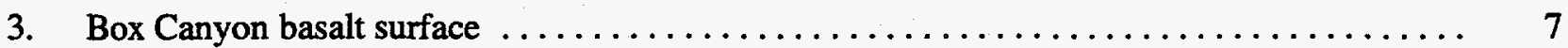

4. Schematic of Box Canyon lava flows $\ldots \ldots \ldots \ldots \ldots \ldots \ldots \ldots \ldots \ldots \ldots \ldots \ldots \ldots \ldots \ldots$

5. Idealized cross section of Box Canyon $\ldots \ldots \ldots \ldots \ldots \ldots \ldots \ldots \ldots \ldots \ldots \ldots \ldots \ldots$

6. Field sampling map hole and core locations $\ldots \ldots \ldots \ldots \ldots \ldots \ldots \ldots \ldots \ldots \ldots \ldots$

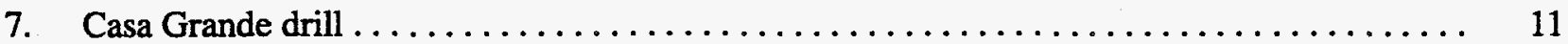

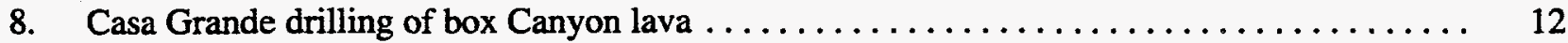

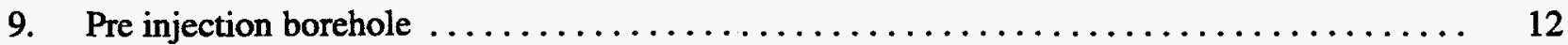

10. Hydraulic conductivity measurement packer assembly $\ldots \ldots \ldots \ldots \ldots \ldots \ldots \ldots \ldots$

11. Transport/mixing/shearing/pump module $\ldots \ldots \ldots \ldots \ldots \ldots \ldots \ldots \ldots \ldots \ldots \ldots \ldots$

12. Loading mixing/pump module with portland $\ldots \ldots \ldots \ldots \ldots \ldots \ldots \ldots \ldots \ldots \ldots$

13. Post injection borehole after closure $\ldots \ldots \ldots \ldots \ldots \ldots \ldots \ldots \ldots \ldots \ldots \ldots \ldots \ldots \ldots$

14. Water drilling post grout core at 22 degree $\ldots \ldots \ldots \ldots \ldots \ldots \ldots \ldots \ldots \ldots \ldots \ldots$

15. Vertical air drilling $\mathbf{C}-11$ post grout directional core $\ldots \ldots \ldots \ldots \ldots \ldots \ldots \ldots \ldots \ldots$

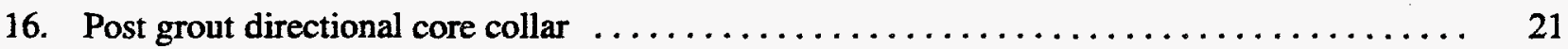

17. Map of grout volumes and grout types injected at Box Canyon $\ldots \ldots \ldots \ldots \ldots \ldots \ldots \ldots$

17a. Map showing region of high grout volumes injected at Box Canyon $\ldots \ldots \ldots \ldots \ldots \ldots$

18. Map of average grout and hydraulic conductivities $\ldots \ldots \ldots \ldots \ldots \ldots \ldots \ldots \ldots \ldots \ldots \ldots$

19. Comparison of average grout and water flow through basaltic rock fissures (log scale) .... 24

19a. Comparison of average grout and water flow through basaltic rock fissures (linear scale) ... 24

20. Comparison of grout and water flow through basaltic rock fissures at 4.5 meters depth .... 25

21. Comparison of average grout and water flow through basaltic rock fissures at

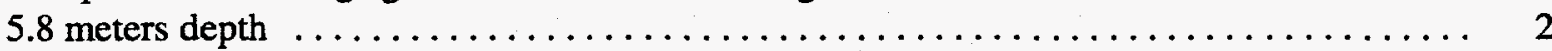

22. Comparison of average grout and water flow through basaltic rock fissures at

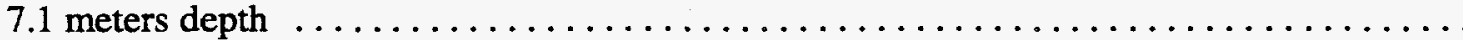


23. Average grout and water flow through basaltic rock fissures $\ldots \ldots \ldots \ldots \ldots \ldots \ldots \ldots \ldots$

24. Map of grout volumes and post grouting average hydraulic conductivities . . . . . . . . 29

25. Map of grout volumes and hydraulic conductivities reduction factors . . . . . . . . . . 29

26. Map of average pre and post grout hydraulic conductivities $\ldots \ldots \ldots \ldots \ldots \ldots \ldots \ldots$

27. Pre and post grouting average hydraulic conductivity $\ldots \ldots \ldots \ldots \ldots \ldots \ldots \ldots \ldots \ldots$

28. Comparison of pre and post grouting average hydraulic conductivity 4.5 meters deep ..... 31

29. Map of pre and post grout hydraulic conductivities 4.5 meters deep $\ldots \ldots \ldots \ldots \ldots \ldots \ldots$

30. Map of pre and post grout hydraulic conductivities 5.8 meters deep $\ldots \ldots \ldots \ldots \ldots \ldots \ldots$

31. Comparison of pre and post grouting average hydraulic conductivity 5.8 meters deep .... 32

32. Map of pre and post grout hydraulic conductivities 7.1 meters deep $\ldots \ldots \ldots \ldots \ldots \ldots$

33. Comparison of pre and post grouting average hydraulic conductivity 7.1 meters deep ..... 33

34. Comparison of average hydraulic conductivities based on mean distance from pressure grouting holes

35. Comparison of hydraulic conductivities 4.5 meters deep based on mean distance from

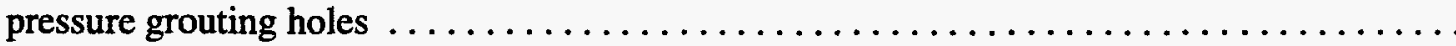

36. Comparison of hydraulic conductivities 5.8 meters deep based on mean distance from pressure grouting holes

37. Comparison of hydraulic conductivities 7.1 meters deep based on mean distance from

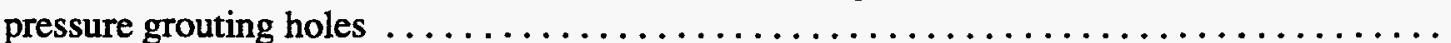

38. Grout selection effect on hydraulic conductivity $\ldots \ldots \ldots \ldots \ldots \ldots \ldots \ldots \ldots \ldots \ldots \ldots$

39. Borehole chip tracer presence by depth $\ldots \ldots \ldots \ldots \ldots \ldots \ldots \ldots \ldots \ldots \ldots \ldots \ldots$

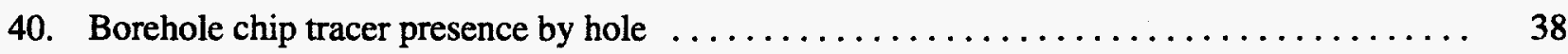

41. Core $\mathrm{C}-7$ at $4-7$ meter depth showing near vertical fractures $\ldots \ldots \ldots \ldots \ldots \ldots \ldots$

42. Core $\mathrm{C}-7$ at the $7-10$ meter depth showing rubblized zone $\ldots \ldots \ldots \ldots \ldots \ldots \ldots \ldots$

43. Close up core fragment showing portland grout penetration $\ldots \ldots \ldots \ldots \ldots \ldots \ldots \ldots$

44. Close up core fragment showing microfine grout penetration $\ldots \ldots \ldots \ldots \ldots \ldots \ldots \ldots .42$

45. Close up core fragment showing grout and sediment $\ldots \ldots \ldots \ldots \ldots \ldots \ldots \ldots \ldots \ldots \ldots$

46. Close up core fragment showing partial grout filling $\ldots \ldots \ldots \ldots \ldots \ldots \ldots \ldots \ldots \ldots$ 
47. Competent Basalt core $\mathrm{C}-114-7$ meter depth $\ldots \ldots \ldots \ldots \ldots \ldots \ldots \ldots \ldots \ldots \ldots \ldots \ldots \ldots \ldots \ldots \ldots$

48. Competent Basalt core $\mathrm{C}-117-9$ meter depth $\ldots \ldots \ldots \ldots \ldots \ldots \ldots \ldots \ldots \ldots \ldots$

49. Close up core fragment showing partial small fracture grout penetration $\ldots \ldots \ldots \ldots \ldots$

50. Close up core fragment showing partial large fracture grout penetration $\ldots \ldots \ldots \ldots \ldots$

51. Close up core fragment showing microfine grout penetration $\ldots \ldots \ldots \ldots \ldots \ldots \ldots \ldots$

52. Fracture frequency by depth $\ldots \ldots \ldots \ldots \ldots \ldots \ldots \ldots \ldots \ldots \ldots \ldots \ldots \ldots \ldots \ldots \ldots \ldots$

53. Fracture frequency range at various depths $\ldots \ldots \ldots \ldots \ldots \ldots \ldots \ldots \ldots \ldots \ldots \ldots$

54. Fracture fill percentage by depth $\ldots \ldots \ldots \ldots \ldots \ldots \ldots \ldots \ldots \ldots \ldots \ldots \ldots \ldots \ldots \ldots$

55. Companions of fracture fill percentage and hydraulic conductivity reduction by

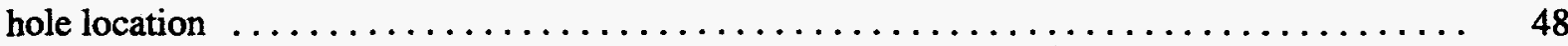

56. Map of average grout volumes injected and percentage of core fractures filled $\ldots \ldots \ldots .49$

57. Map of average hydraulic conductivity reductions and percentage of core fractures filled ... 49

\section{TABLES}

1. Grout pumping pressure determinations $\ldots \ldots \ldots \ldots \ldots \ldots \ldots \ldots \ldots \ldots \ldots \ldots \ldots \ldots$

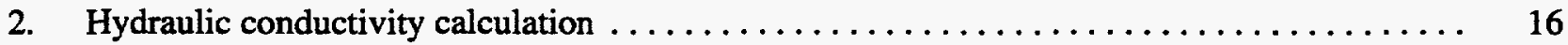

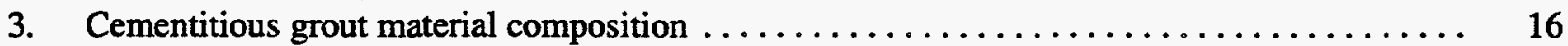

4. Hydraulic conductivity decrease after grouting at various depths $\ldots \ldots \ldots \ldots \ldots \ldots \ldots$

5. Hydraulic conductivity decrease after grouting by sector $\ldots \ldots \ldots \ldots \ldots \ldots \ldots \ldots$

6. Hydraulic conductivity reduction by grout type $\ldots \ldots \ldots \ldots \ldots \ldots \ldots \ldots \ldots \ldots$ 
xiii 


\section{ACRONYMS}

BLM Bureau of Land Management

DOE Department of Energy

EPA Environmental Protection Agency

HEPA high-efficiency particulate air

INEL Idaho National Engineering

Laboratory

LDRD Laboratory Directed Research and Development
ORNL Oak Ridge National Laboratory

OTD Office of Technology Development

RWMC Radioactive Waste Management Complex

TTP Technical Task Plan

USGS United States Geological Survey

UV ultraviolet

WHC Westinghouse Hanford Company 


\section{INTRODUCTION}

This report describes a field trial of pressure grouting in basalt and the results of subsequent coring and permeability measurement activities. All work was carried out near the Radioactive Waste Management Complex (RWMC) but outside the Idaho National Engineering Laboratory (INEL) boundary at the Box Canyon Site. The primary field activity called "Monolithic Confinement of RWMC Contaminated Geologic Material" was designed to demonstrate that hydraulic conductivity of fractured basalt bedrock can be significantly reduced by pressure injection of cementitious materials. ${ }^{1}$ This creates a barrier to water movement preventing transport of contaminants found both above the rock in waste and in the underlying rock.

The Office Of Technology Development (OTD), Technical Task Plan (TTP-RL421212), Environmental Restoration and Laboratory Directed Research and Development (LDRD) supported the work during the summer of 1994 and subsequent 1995 coring activities. ${ }^{1}$ A map of the test site in relationship to the INEL is shown in Figure 1. The site is 8 miles northwest of the RWMC, has the same volcanic basalt features and the same Lost River basin drainage as the RWMC. This site has been used for various infiltration studies. ${ }^{2,3}$ This included a demonstration of cross-borehole radar technology where permeability of a single, major flow fracture was determined. The preliminary report is given in Appendix A.

The cross-borehole radar technology is a promising method for characterizing grout injection performance and, for that reason, was field tested in conjunction with the grout program described here. Subsurface coring to determine cement penetration was performed the following year and is included in this report. Field core descriptions and notes are given in Appendix B. INEL personnel from the Environmental Restoration and Technology Development groups, Westinghouse Hanford Company (WHC), several private vendors, and Boise State University were involved in various aspects of basalt grouting and in the pre and post characterization activities.

\subsection{Nature of Problem}

Technical interest in the application of grout materials to reduce the permeability of fractured bedrock arose from buried waste at facilities that are situated on highly fractured bedrock such as that found at the INEL. The INEL RWMC is situated on the fractured basalt complex of the Eastern Snake River Plain, which includes the Snake River Plain Aquifer at a depth of about 580 feet. ${ }^{3}$ The bedrock above the water table is a sequence of basalt lava flows, which may locally be massive, fractured, and/or vesicular, and three sedimentary interbeds, which vary in thickness up to about 4 meters. ${ }^{4}$ Bedrock permeability values range through more than five orders of magnitude indicating that some regions within the basalt complex allow virtually unrestricted water flow while other regions are impermeable. ${ }^{5}$ The bedrock fracture systems are the natural conduits for the movement of surface waters to the aquifer.

Approximately $2,000,000 \mathrm{ft}^{3}$ of waste has been buried in pits and trenches at the RWMC with the potential for contamination of over $6,000,000 \mathrm{ft}^{3}$ of soil. ${ }^{6}$ Though rain water does not flow directly through surface soils through the waste, runoff does follow surface basalt conduits. This type of runoff may percolate to leach contaminants from overlying waste and contaminate the basaltic bedrock in the zone directly below the waste pits and trenches. Possible contamination of the aquifer could occur by continued downward movement of contaminated waters through the fractures in the basalt to the aquifer. Similar buried waste problems exist at other Department of Energy (DOE) sites situated on fractured bedrock complexes, though the problems are less severe in dry arid climates (like the INEL) than in humid, wet climates [like Oak Ridge National Laboratory (ORNL)]. ${ }^{7}$

In addition to the buried waste problem described above, there is a remote chance that injection wells drilled into fractured geologic 


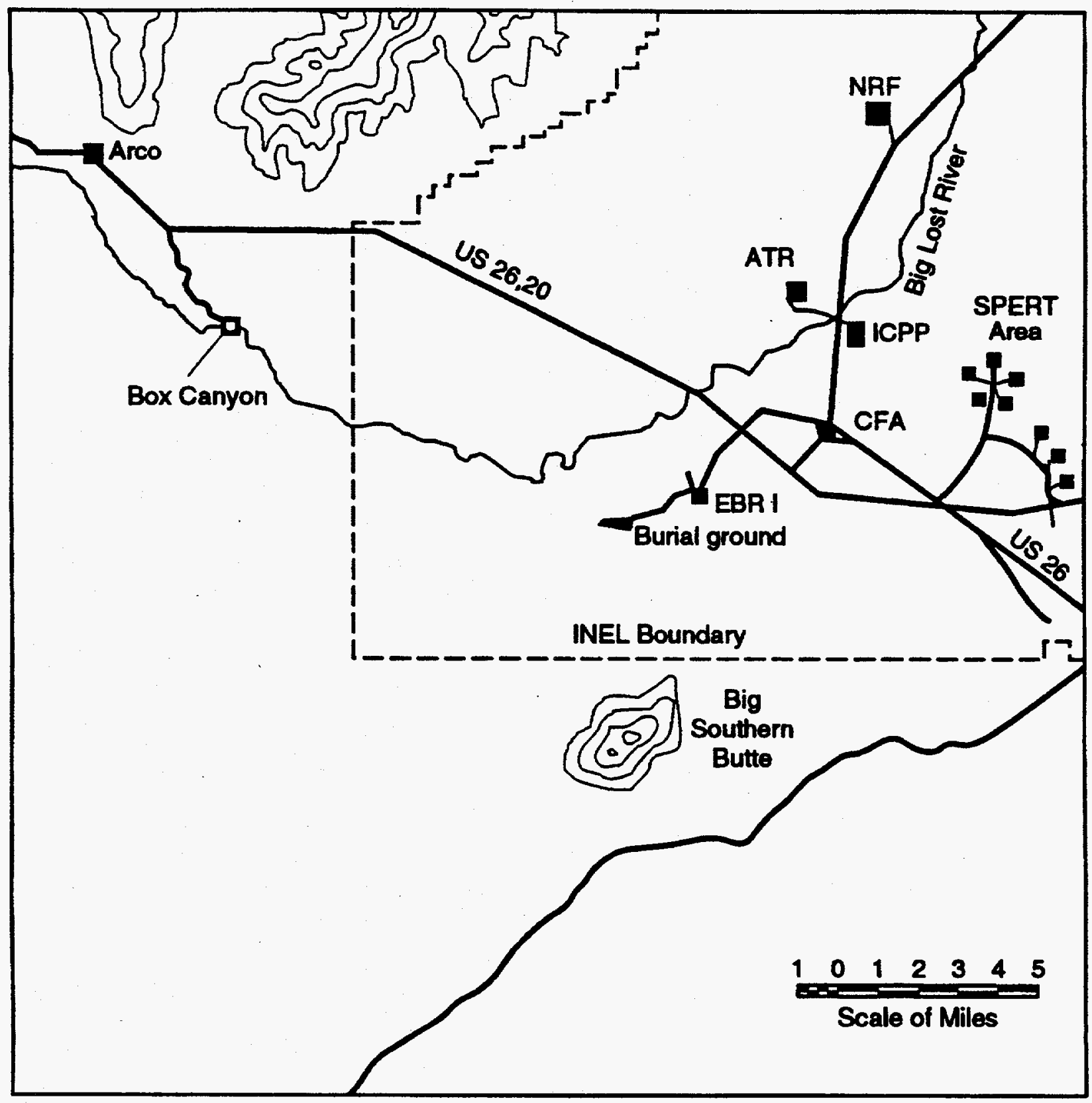

M96 0251

Figure 1. Map of INEL and Box Canyon site.

materials have contaminated bedrock and are a source of potential contamination of the ground water system. In this case, treatment options are much more limited, but the fundamental problem remains the same: can contaminated bedrock be successfully encapsulated and isolated from the natural environment?

\subsection{General Remediation Methods}

Two general approaches have been suggested for the remediation of sites such as the RWMC. One approach is to remove and treat all of the contaminated material, including the contaminated 
portions of the overburden, underburden, and bedrock. ${ }^{7}$ The other approach is to treat the waste in place and isolate it from the environment for geologic time periods, if necessary. If the bedrock is contaminated, a slight potential exists for contamination of the ground water system. Also injection wells drilled into fractured geologic materials might have resulted in possible contamination of bedrock, thus leading to potential contamination of the ground water system. Removing and treating bedrock is prohibitively expensive and not an option. ${ }^{8}$ Even if the bedrock is not contaminated, virtually all the in situ waste treatment processes would be improved if the water pathways below the waste site were eliminated, thus reducing the risk of ground water contamination if the primary in situ treatment failed.

The possibility of ground water contamination can be virtually eliminated if the bedrock fracture system is closed to water percolation and the contaminated bedrock is effectively encapsulated and isolated from the environment. A possible waste isolation and encapsulation method is the injection of cement so that the fractures and void spaces are filled with impermeable material and the hydraulic conductivity of the bedrock is reduced to an acceptable level. In general, a hydraulic conductivity value of about $10^{-7} \mathrm{~cm} / \mathrm{sec}$ or less is the goal because this is the Environmental Protection Agency (EPA) regulatory limit and the value below which diffusion is the dominant transport mechanism. ${ }^{9}$

\subsection{Grouting Procedures and Application at the INEL}

The grouting procedures discussed in this report are processes that seal and remove the natural water conduits in fractured bedrock by filling the fractures with cement (or some other suitable material), thus converting the bedrock into an impermeable, monolithic material in which the waste components are isolated from the natural environment. ${ }^{10}$ In general, grouting procedures can be separated into two classes: the so called dynamic, i.e., pressure grouting, and static or gravity grouting. The first case applies to processes in which the grout slurry is pumped at elevated pressure (up to about 8,000 psi) into the matrix. ${ }^{11}$ Gravity grouting relies strictly on the pressure generated by gravity acting on the grout slurry to flow into waste or voids. The use of pressure grouting is preferred for systems that require that maximum grout penetration and void filling be achieved.

Both gravity and pressure grouting have been field demonstrated at the INEL. In 1986, an in situ grouting demonstration at the INEL used dynamic compaction and gravity injection of a particulate, Microfine cement grout into a simulated buried waste pit using a Richland Hanford Operations technique. ${ }^{12}$ About $60 \%$ of the total voids in the pit were filled $(90 \%$ of the waste voids and $<5 \%$ of the soil voids). A monolithic structure was not created, thus the process could not be recommended for buried waste. Particulate grout will not penetrate the voids in clay soil under simple gravity pressure with no mixing.

In contrast, a recent INEL study demonstrated that the vigorous mixing by the high pressure of jet grouting of Portland cement can penetrate buried waste and surrounding soil. ${ }^{13}$ The use of jet grouting gave maximum grout penetration in the soil and void filling of waste containers. The grout slurry was pumped at $6,000 \mathrm{psi}(0.58 \mathrm{~kb})$ through a rotating orifice as the drill retracted. That study used the same drill as was used in this study to both penetrate underlying soil and waste and deliver the grout. Portland cement grout filled the soil and waste voids while simultaneously locking contaminants (tracers) deposited with the waste material. ${ }^{14}$

The jet grouting operation successfully created a monolithic structure filling virtually $100 \%$ of the void space in both soil and buried waste. Given the success of the jet grout method when used to encapsulate simulated buried waste in soil, the application of grout under pressure to fractured bedrock appeared to be highly feasible and is the subject of this report. 


\section{TEST OBJECTIVES}

The objectives of the test program were to demonstrate pressure grout injection of Portland and Microfine cement into fractured basalt. The effectiveness and implementability of pressure grouting fractures in basalt will be used to assess remediation feasibility for site or smaller "hot spot" use at the INEL. The field activity was designed to test pressure grouting of hydraulic cements into fractured bedrock so that the hydraulic conductivity of such material would be significantly reduced. A reduction of two orders of magnitude should significantly retard the dissolution and transport of possible waste components.

The effectiveness of the pressure grout procedure was evaluated by measuring several variables. The change in permeability of the basalt due to grouting was determined by measuring the hydraulic conductivity of the bedrock before and after the injection of cement. The extent of grout penetration was established by analyzing postgrout injection drilling chips for the presence of a tracer in the grout and also by examining cores of the treated basalt.
The effectiveness of injecting Portland and Microfine cement into fractured basalt was measured by the reduction in water permeability, integrity of the basalt grout bond, and the effect of contaminants on grout. This is evaluated by: (a) measuring the hydraulic conductivity to assess change in permeability of the basalt due to grouting, (b) examining cores of the grouted basalt for the presence of Portland and Microfine cement and the tightness of fractured basalt crack filling, and (c) obtaining data from the literature on the compatibility of various contaminants with the grouted basalt.

The implementability of applying grout in situ beneath buried waste and soil under pressure to seal fractured bedrock basalt was assessed through log data on cement "take," log of operational problems, photographic record, and by engineering assessment of entire operation. From this assessment, the number of wells, their spacing and depth, and the cost of operation was estimated to treat underlying bedrock at the INEL. The results can be extrapolated for using this technique in a saturated zone. 


\section{EXPERIMENTAL DESIGN AND PROCEDURES}

The experimental design and method, including site selection, equipment setup, procedures, and expected operations are described below and also in the Test Plan draft, Monolithic Confinement of Radioactive Waste (12/93) and Revised Draft Test Plan, Monolithic Confinement of RWMC Contaminated Media (5/94).

\subsection{Geology of Test Area}

The INEL lies within the boundary of the Eastern Snake River Plain, which is a broad, nearly flat plain underlain by approximately $1 / 2$ miles of basalt lava flows, interspersed with sediment, that were deposited during several episodes in the geologic past. The basalt lava flows may locally be massive, fractured and/or vesicular. Between some major series of flows are sedimentary interbeds which vary in thickness up to about 4 meters.

Field permeability values of basalt measured in the monitoring wells beneath the RWMC range from more than 80 darcy to $3 \times 10^{-3}$ darcy. 2,3 Hydraulic conductivity values range from $10^{-1}$ to $10^{-6} \mathrm{~cm} / \mathrm{sec}^{4,14,15}$ The higher flows are virtually unimpeded water flow through $1 / 2$ inch and larger cracks. The lower flows are those of tight basaltic formations. A flow of $10^{-7} \mathrm{~cm} / \mathrm{sec}$ is the EPA guideline for a "sealed" liner or cap for landfill construction purposes and is the limit after which diffusion processes become significant. The ultimate goal is to grout the basalt sufficiently to obtain this hydraulic conductivity.

The Box Canyon Site is located northwest of the INEL, on Bureau of Land Management (BLM) land, 6 miles southeast of the town of Arco, Idaho. A reconnaissance survey of the Box Canyon Site ${ }^{3,4}$ is shown on a generalized map (Figure 1) and a site map (Figure 2). The photographs in Figures 3 and 4 show surface and outcrop geology with two vertically stacked basaltic flows separated by a rubble zone that is present in the drilling site. Bedrock fracture systems such as those located at this site are found at the RWMC and are the primary natural conduits for the movement of surface waters to the aquifer.

Three lithologically distinct zones are identified and can be seen on the accompanying photograph. The bottom zone is the top of the base basaltic flow (Flow F) and is about 9 meters below the outcrop surface. The middle zone contains a rubble zone about 5 meters below the outcrop surface. The top zone is above the intermediate rubble zone and is the bottom of the uppermost flow (Flow B). A third flow (Flow A) is present in the area with a high angle contact of unknown character with Flow B. The entire lithology underlying the RWMC is described in detail from numerous test wells and a 3-dimensional simulation. 2,3 The buried waste at the RWMC is in soil covered pits and trenches approximately 7 to 10 meters deep, which overlays this series of volcanic/basalt rock.

The Box Canyon Site has been selected for evaluating water flow though basalt in conjunction with environmental scientists, regulatory representatives, and hydrogeologists from INEL and Hanford sites. The site selection was based on its lithology, rock and interbed general mineralogy, geologic structure, fracture-joint configuration, morphology, use for previous infiltration testing, and accessibility with heavy equipment.

\subsection{Pre and Postgrout Drilling Borehole Distribution Pattern}

The boreholes distribution pattern was designed to give the maximum amount of coverage and information with the minimum amount of holes. The hole arrangement was used to help determine the efficiency of the overall process in sealing a large area of rock, the effect of adjacent holes on one another, most effective distance for sealing large and small fractures, and narrow interbeds. Under actual operation, a standard grid would be used. The radial arrangement allowed hole distances of 2,4 , and 8 meters to be 


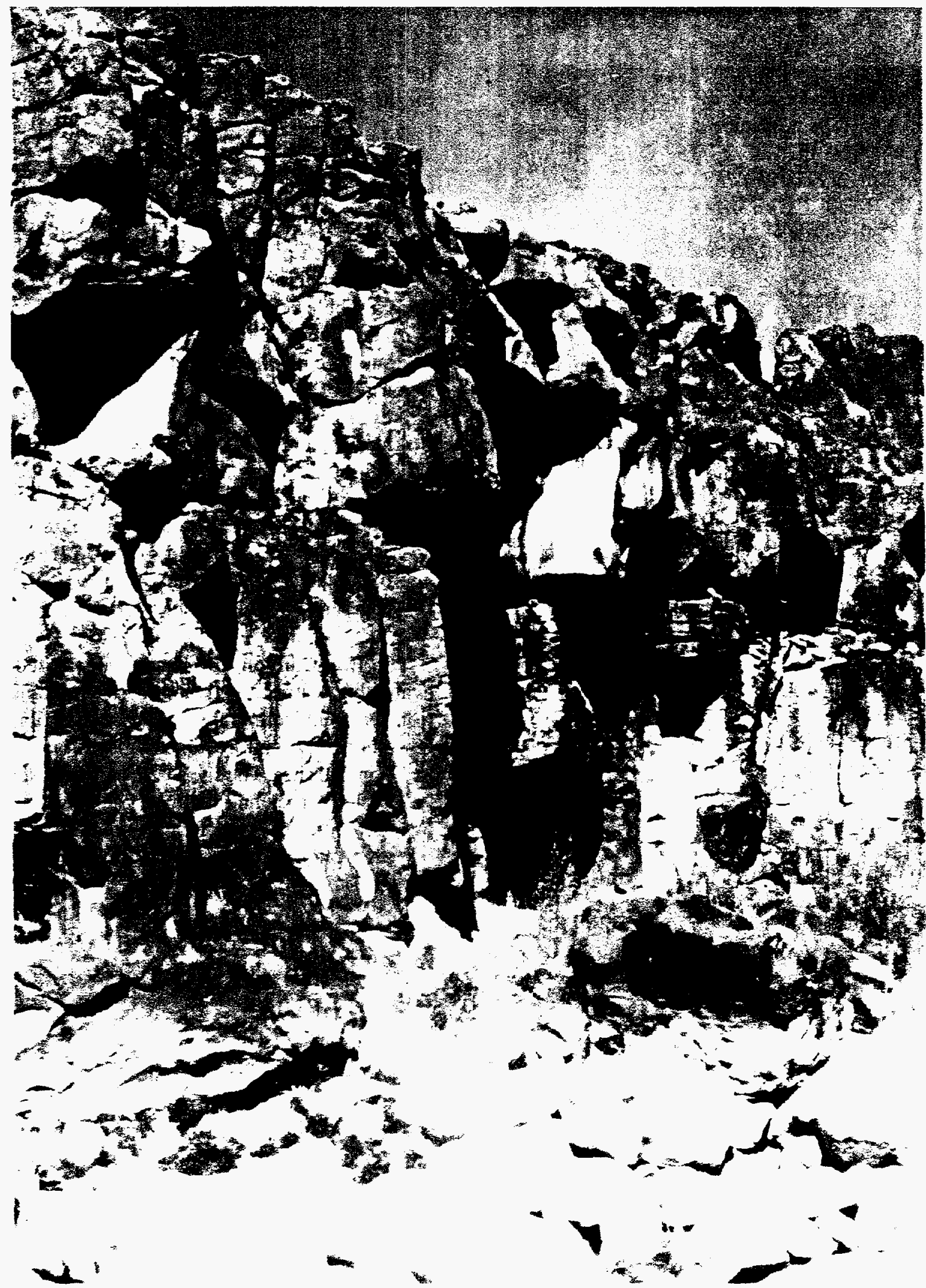

Figure 2. Box Canyon basalt face. 
compared. Injecting 8 to 9 meters deep means grout will penetrate to the top of the lower basalt flow. Having three injection/permeability zones will roughly match this lower flow, the intermediate rubble zone, and top basalt flow.

The photograph of Box Canyon (Figure 2) shows these zones as viewed from the now dry Lost River bed floor. The arrows drawn in mark the zones. A similar series of basalt flows underlies the RWMC, which is 8 miles downriver. The surface of the site is shown in Figure 3 with markers where some of the holes are to be drilled. This type of volcanic basalt is covered with about 7 meters of soil at the RWMC where the waste has been buried.

Figure 4 shows the flows schematically in relation to major basalt flows with some of the hole locations marked that were used for both grouting and the infiltration/radar testing. Figure 5 gives a scaled vertical schematic of the basalt flows on the east side of the site. Vertical holes were drilled through these flows as shown in Figure 5 to per- mit a 16-meter radius, half cylinder matrix to be grouted. Figure 6 shows all the holes drilled for this study for injection and verification, along with the lateral and radial measurement lines. Holes were chosen on four concentric rings from a central "pivot" point. The original scope of a 32-meter radius, half cylinder with five rings was reduced for time, budgetary, and operational permit reasons. Postgrouting holes and core locations are also shown in Figure 6. The location of these holes provided diagnostic information of grout penetration and sealing performance.

Each half ring was located twice the distance from the center as the previous ring, 2, 4, 8, and 16 meters, respectively, and labeled numerically with the distance. Seven laterals for the 4,8 , and 16-meter distances were chosen at about 30-degree intervals with the label and direction from the center as follows: "A" $S S E$, "B" $S$, "C" $S S W$, $D$ " $S W$, "E" $S W W$, ,F" $W$, and "G" $N W W$. Only three holes were drilled at the 2-meter distance following the $S S E, S W$ and $N W W$ laterals.

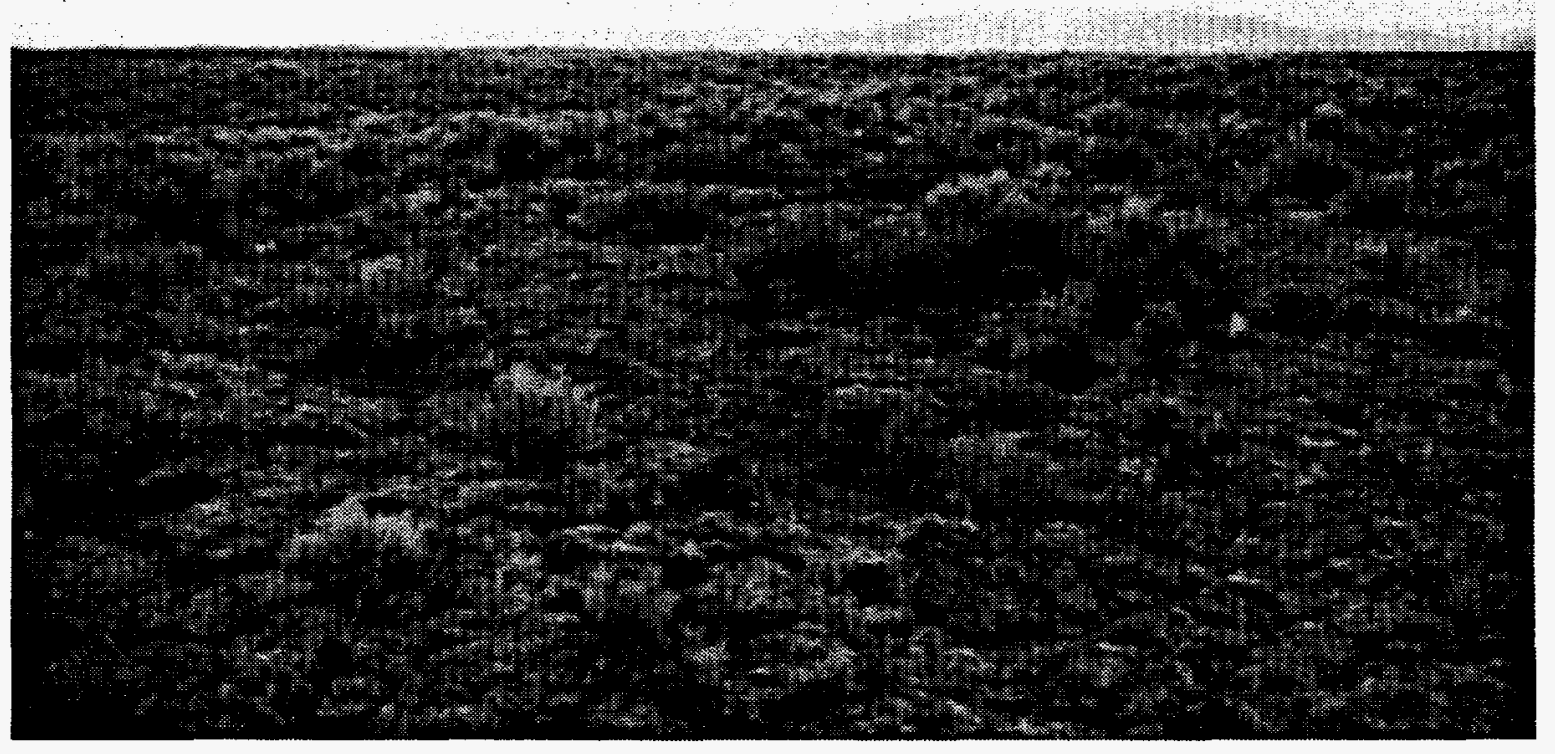

Figure 3. Box Canyon basalt surface. 


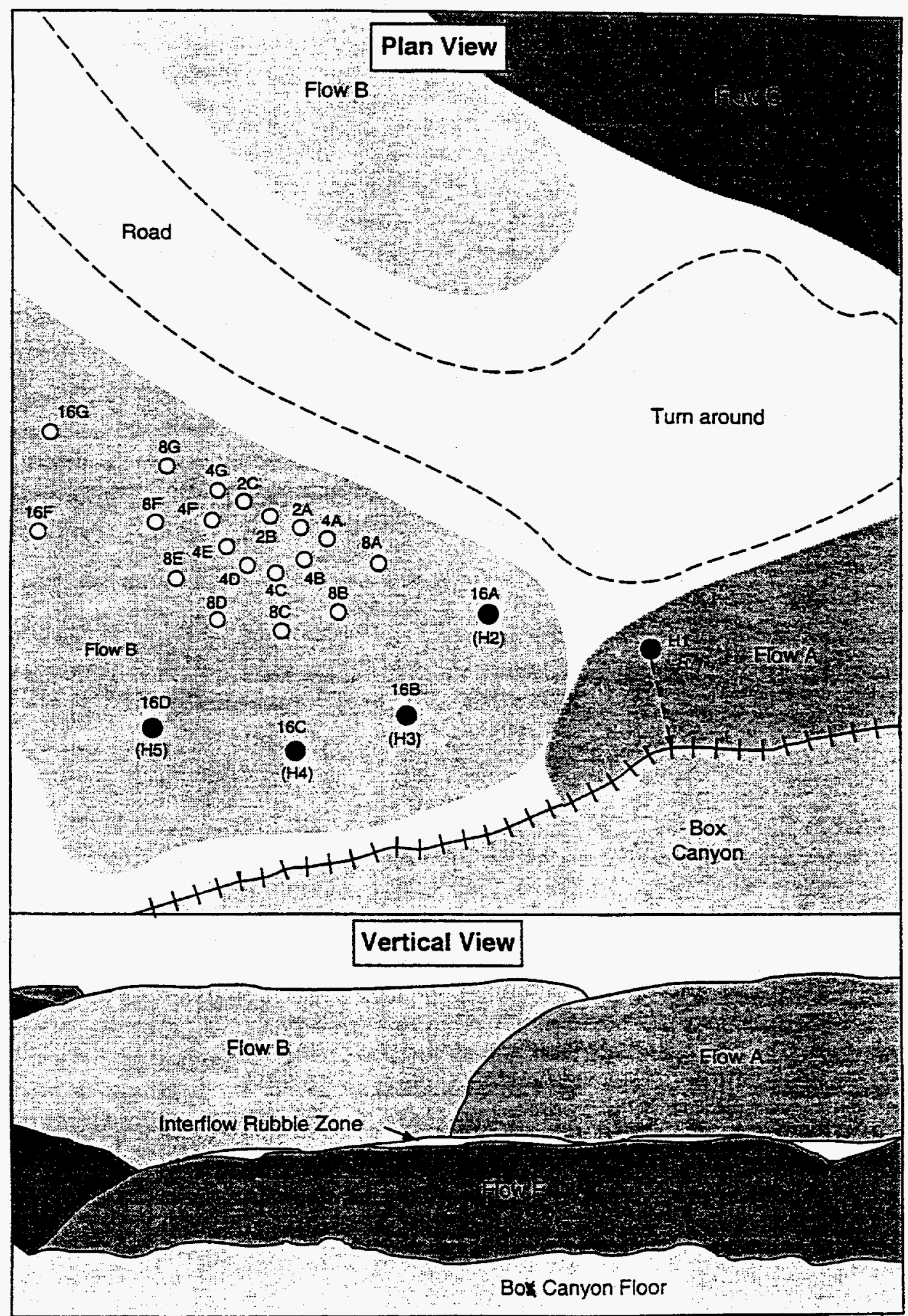

M94 0394

Figure 4. Schematic of Box Canyon lava flows. 


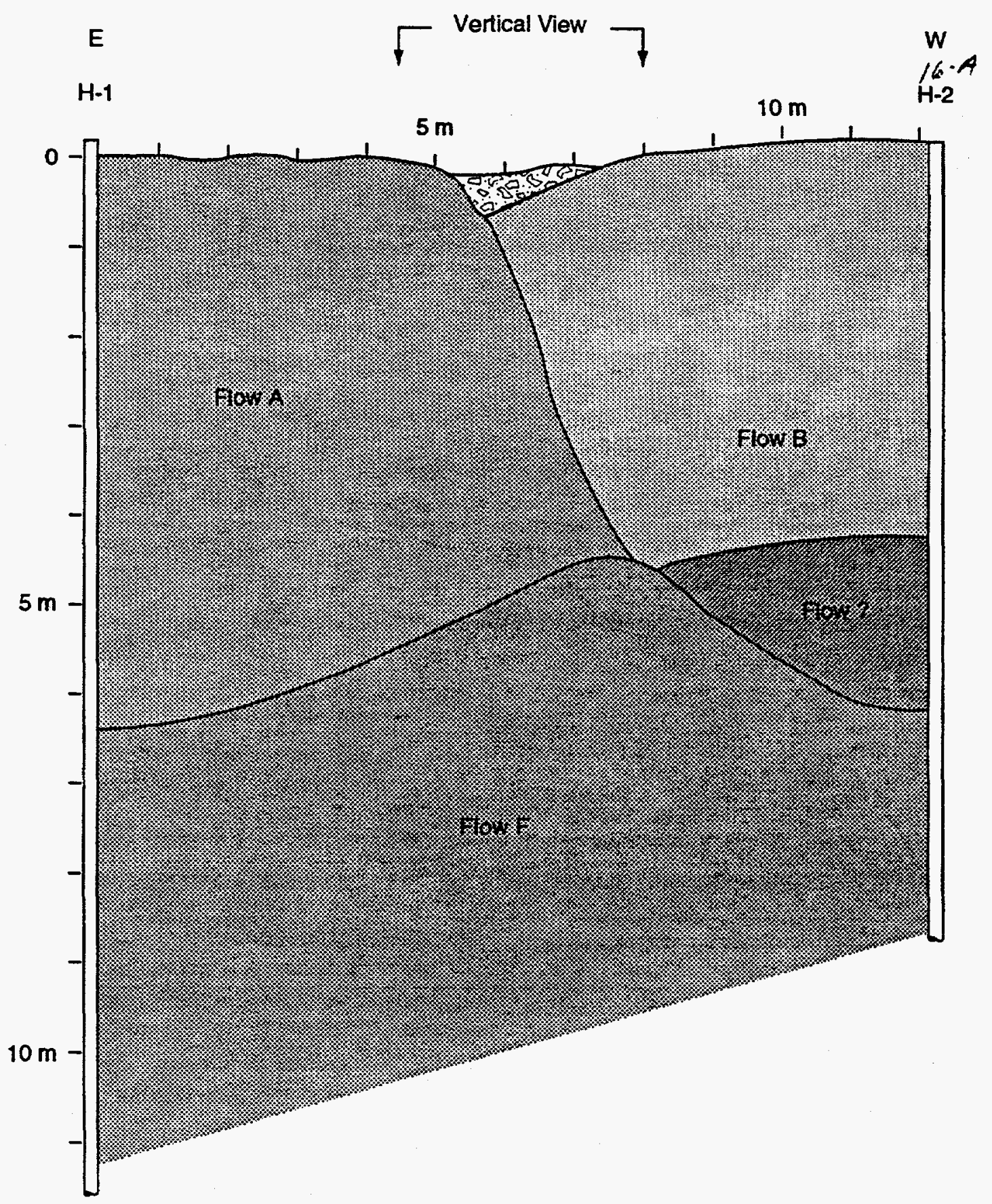

$M 940395$

Figure 5. Idealized cross section of Box Canyon. 


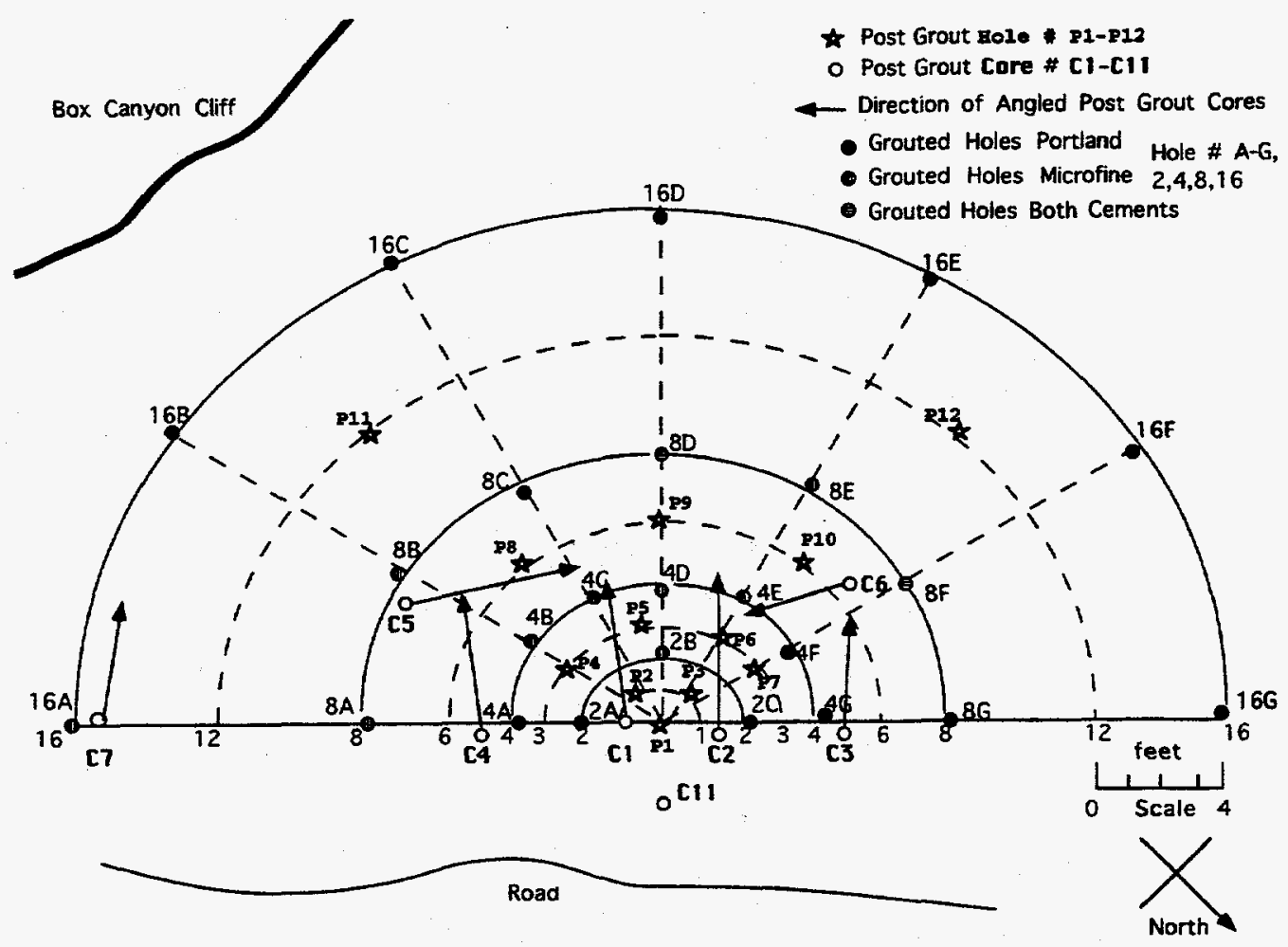

Figure 6. Field sampling map hole and core locations.

The holes were numbered by their radial distance in meters (i.e., 2, 4, 8, and 16) from the center pivot and the lateral direction from southeast to northwest in 30-degree increments (A-G): 2A-2C, 4A-4G, 8A-8G, 16A-16G. Thus, a total of 24 holes were drilled, measured for permeability, and pressure grouted.

After the grouting of these 24 holes, 12 holes were drilled among them to a depth of approximately 8.5 meters. Three holes were drilled: one on the pivot position and two, 1 meter away on either side. Four holes were drilled 3 meters from the center close to one of the lateral lines (B,C,E,F). Three holes were drilled 6 meters from center to assess grouting effects 1 meter from any of the grouting holes; one on Lateral D, and two between Lateral Lines $B$ and $C$ and $E$ and F. Two holes were drilled to assess permeability reduction 2 meters away from any of the grouting holes. These two holes were drilled 12 meters away from the pivot between Lateral Lines $B$ and $C$ and $E$ and F. Figure 4 shows the placement of pregrouting holes, such as Hole $\mathrm{H}-1$, which remained from pre- vious studies. ${ }^{4}$ Figure 6 depicts both pre and postgrouting holes and postgrouting cores.

A year later, eight intact cores were taken within this same region to provide samples of cement-filled basalt and to visually determine grouting effectiveness. The core hole distribution pattern and direction of penetration for angled cores is also shown on the map (Figure 6). Seven cores were taken at 22 degrees $(22.6 \pm 2.1$ degrees) as shown angling into the grouting area. The water drill apparatus shown in Figure 6 was angled while coring and gave a 2.5 -inch core. These cores are labeled on the map, video log, and on the photographs as $\mathrm{C} 1-\mathrm{C} 7$. Basically five of these cores are along the baseline of the radial grid angling S-SW into the grouted region. The other two holes are 4 meters from this line and angle NW and SE into the matrix.

Hole locations were selected so some cores (C1-C4) would access heavily grouted areas while others, cores (C5-C6) go through areas of less grout density. The core start is shown on the maps as open circles with the direction and hori- 
zontal distance of penetration indicated by an arrow. The first two core starts angled south and are close to four grout holes closely spaced (about 1 meter), the next two core starts are near two holes spaced at 2 meters, the third set of core starts angled east near three holes spaced 2 meters apart, and the last core starts is near one hole extending up to 10 meters away from the grout application hole.

Three more cores were not drilled (C8-C10) because of budget cuts. These holes would have been located further out in the less grouted region of the grid. The 8th vertical core was taken 2 meters from the pivot. This core, labeled C11, was a 3-inch diameter core. The drilling device uses a scribing indent shown in the photograph to keep the orientation in the hole fixed. This core was located outside the grid pattern and accessed primarily horizontal fractures. The previous angled holes crossed some vertical fractures.

\subsection{Hard Rock Drilling Equipment and Procedures}

A Casa Grande drill was used to drill the required holes. It is shown in Figure 7 with the special high-efficiency particulate air (HEPA) filtration system attached in the rear. The CG drill is a trac mounted, special purpose oil field/mineral type drill that can penetrate underlying soil, rock, and waste and also deliver grout. A special 4-in. $(10-\mathrm{cm})$ hard rock bit is required is to penetrate the volcanic basalt rock underlying most of the INEL.

Figure 8 shows the drill in relation to the Lost River basalt outcropping and Figure 9 shows a typical borehole. The drill rig was driven from hole to hole (east to west) and leveled for vertical, 90-degree drilling. The holes were drilled to a depth of $8.4 \pm 0.5$ meters. This depth allowed injection into the top of the lower basalt flow as well as the intermediate rubble zone, and top

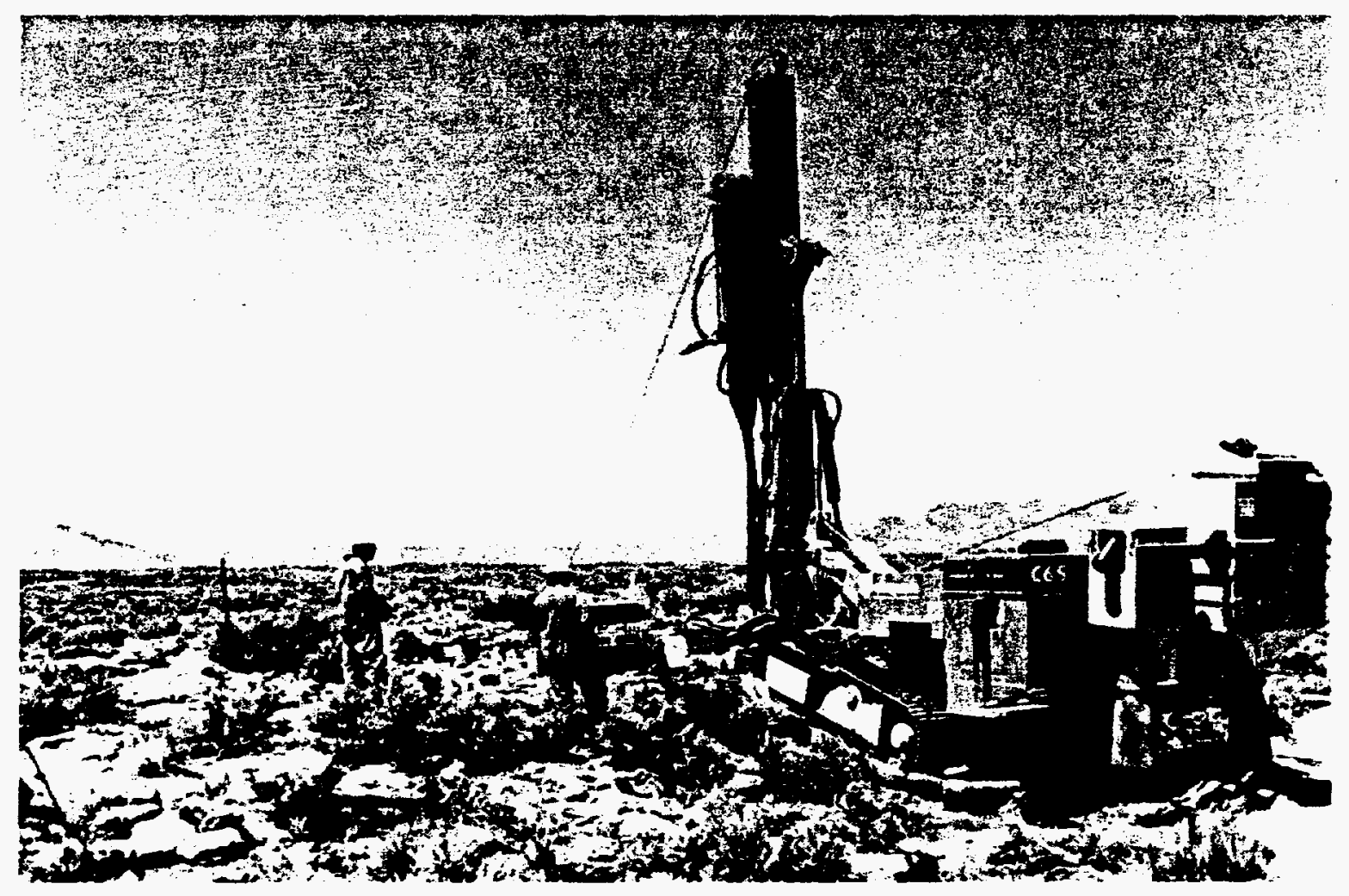

Figure 7. Casa Grande drill. 


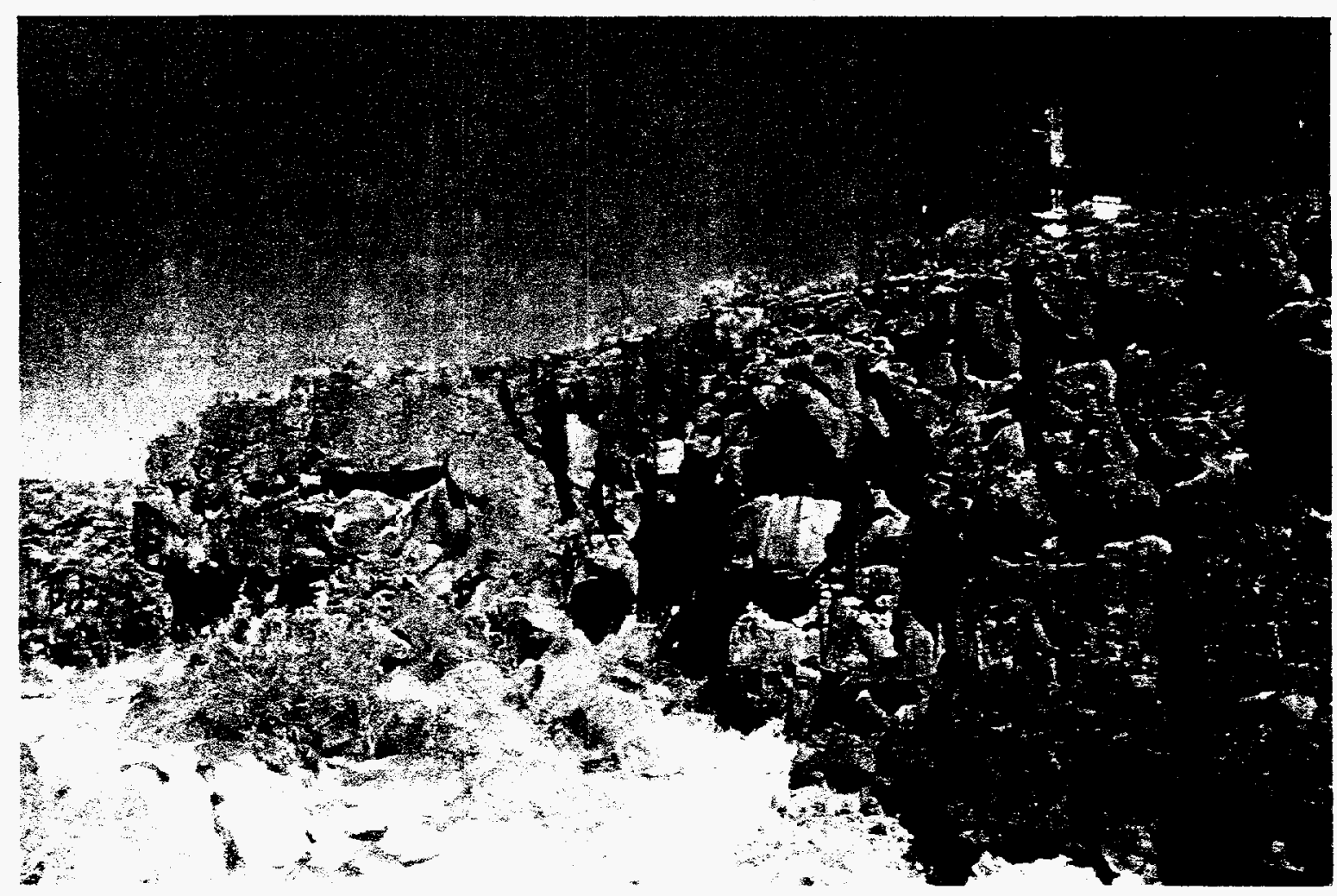

Figure 8. Casa Grande drilling of box Canyon lava.

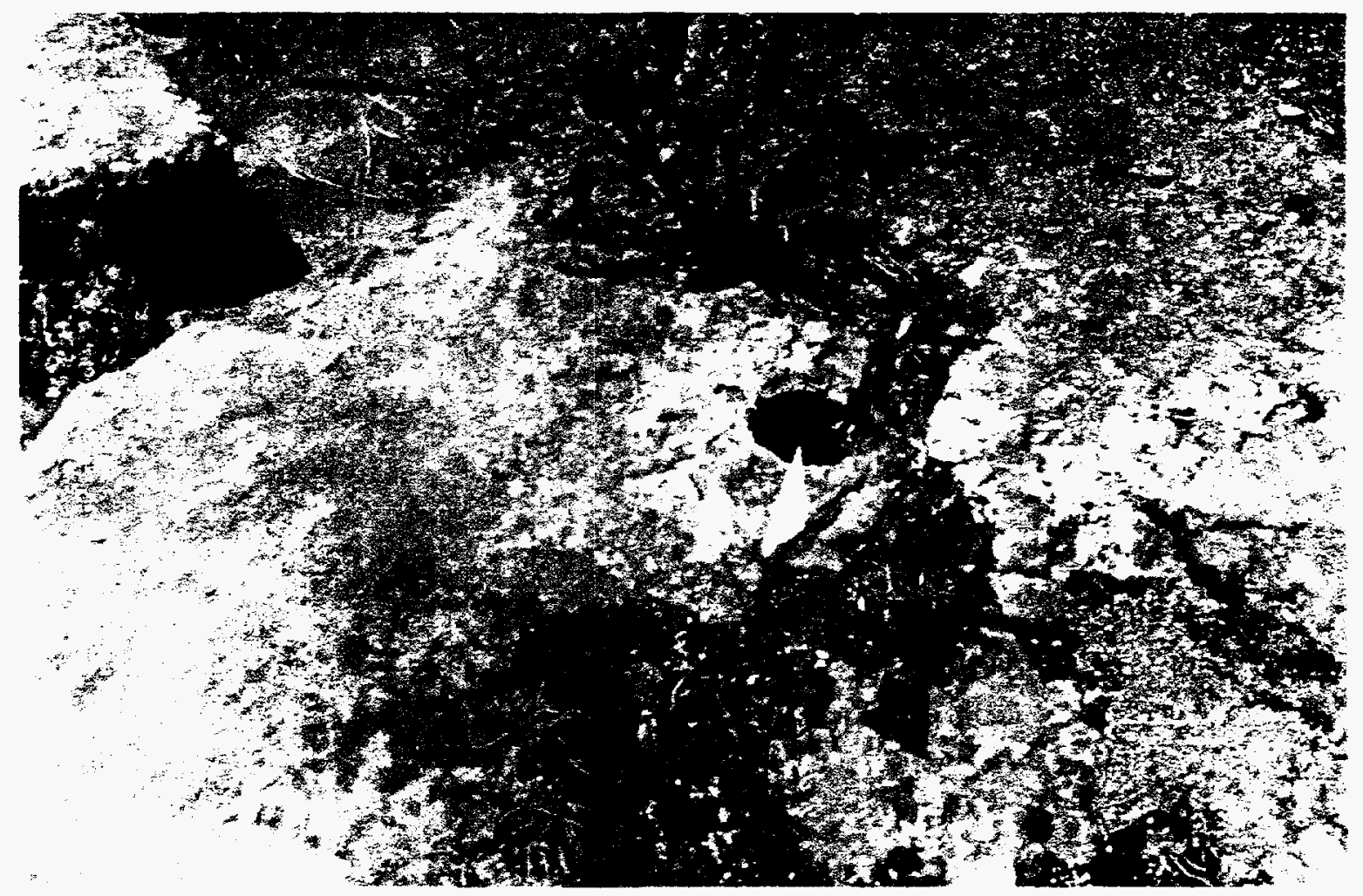

Figure 9. Pre injection borehole. 
basalt flow. Only water was used as a drilling fluid. No drilling bentonite or drilling mud was used to prevent any sealing of the natural fractures by materials other than the injected cements. The final hole diameters were about $11 \mathrm{~cm}(11.4$ $\pm 0.4 \mathrm{~cm}$ )

Problems were encountered in drilling the first four holes (16A, B, C, and 8B). Four bits were lost down these holes and five drill string stubs twisted off. The drilling rate for these holes was roughly $0.05 \mathrm{~m} / \mathrm{min}$. To speed drilling and reduce stress on the drill string and connecting drill string tubes, a $400 \mathrm{cfm} 200$ psi air powered, downhole hammer (rather than the top hole hammer) was used on subsequent holes. The hole depths are under 8 meters for Holes $2 \mathrm{C}, 8 \mathrm{~B}, 8 \mathrm{C}$, and $8 \mathrm{~F}$, in which either water circulation was lost or the drill bit broke off. This factors either stopped the penetration or indicated a large void, which effectively extended the hole into a large void area such as a rubble zone. The depth profile was standardized on Hole $8 \mathrm{D}$ (the $\mathrm{D}$ lateral dividing the two quadrants), which was 0.76 meters above the center pivot point.

The remaining holes were drilled at an overall rate of about $0.3 \mathrm{~m} / \mathrm{min}$. The hole drilling sequence was from the center outward in a radial array (Figure 6) and is described in Section 3.2. Hole drilling was started from the east side (A, B, and $C$ ) of the 16-meter radial working in towards the 2-meter radial holes. The west quadrant $(E, D$, and F) was drilled outward from the inside radial to 16 meters from the pivot point. The final array and cement used is also shown in Figure 6. A summary of the hole drilling pressures is given in Table 1 and grout volumes are given in the Results Section.

Each borehole was surveyed using a video camera and caliper logged by the United States Geological Survey (USGS). These data provide qualitative measurements of the properties of the boreholes, including interfaces between lithologic zones, the presence of large fractures, roughness of the hole wall, and actual hole diameter. The survey information was used to help decide which type of grout would be injected. After this survey, each hole was also tested for hydraulic conductivity before grout injection. Data for both pre and post permeability data are given in the Appendix C.

After completing grout injection through 24 holes into the fractured rock, 12 postinjection holes were drilled. Drilling and permeativity testing was performed in a similar manner as in the preinjection holes. These holes were also vertical and about 8 meters deep ( $8.3 \pm 0.5$ meters). The pivot hole lost circulation after 7 meters. The drilling sequence for postinjection holes generally followed a pattern placing holes between radials $(0,2,4,8$, and 16 meters) and laterals $(A, B, C, D$, E, F, and G). Drilling started from the hole matrix pivot and moved outward drilling two or three holes, 1, 3, 6, and 10 meters. The drilling sequence for these postgrouting holes is indicated by their hole number (see Figure 6) starting from the pivot and moving outward $1,3,6$, and 12 meters.

Table 1. Grout pumping pressure determinations.

\begin{tabular}{llc}
\hline \multicolumn{1}{c}{ Pressure Type } & \multicolumn{1}{c}{ Description } & \multicolumn{1}{c}{$\begin{array}{c}\text { Pressure } \\
\text { used in PSI }\end{array}$} \\
\hline Lithostatic pressure $+10 \%$ & $\begin{array}{l}\text { Dependent on depth of hole/elevation of } \\
\text { packer })\end{array}$ & $20-35$ \\
Fracture pressure $-10 \%$ & $\begin{array}{l}\text { Fracturing was observed on several occasions } \\
\text { beyond this pressure } \\
\text { Mean pressure }\end{array}$ & $\begin{array}{l}\text { Mean of the maximum and minimum } \\
\text { pressures }[(\mathrm{L}+0.1 * \mathrm{~L})+(\mathrm{F}-0.1 * \mathrm{~F})] / 2\end{array}$ \\
\hline
\end{tabular}


Drill cutting samples were taken from the edge of each post injection hole starting at the surface down to seven meters. Six samples were taken every 1.5 meters of drilling. Samples were placed in a container and labeled with the borehole number, and depth and stored in lockable field office. The cutting samples were analyzed in the Hanford Geotechnical Laboratory by ultraviolet light to determine the presence or absence of the dye mixed with the injected grout. The natural calcite $^{8}$ in the basalt fractures might also have fluorescent substances in them possibly confounding the ultraviolet light detection of grout. Holes were left open for caliper/video logging in a manner similar to preinjection holes. Caliper logs are in Appendix $\mathrm{D}$ and video logs have been archived with the project file.

\subsection{Hydraulic Conductivity Measurement Method}

The hydraulic conductivity was measured in each zone for each hole using a double packer as shown in Figure 10. This $7.6-\mathrm{cm}$ diameter straddle packer was used to measure each hole at depths of $4.5,5.8$, and 7.1 meters. The packer spacing was 1.07 meters (see Section 3.1 for description of zones). The packers were pressurized to isolate the section of the hole between packers. Water was injected into the volume between the packers until a steady state flow was achieved. Flow volume was recorded as a function of time together with the total pressure or "head" of the system.

Hydraulic conductivity was calculated from the packer spacing $(L)$, pressure head $(h)$, radius (r), and flow (Q) and is given in $\mathrm{cm} / \mathrm{sec}$ (see Table 2). The formula for hydraulic conductivity is $\mathrm{rkf}=\mathrm{Q} /\left(2 * p i^{*} \mathrm{~h} * \mathrm{~L}\right) * \ln (\mathrm{L} / \mathrm{r})$. Pressure was converted from psi to meters of water $(1.43 \mathrm{psi}=1$ meter of water) for the calculation and the final result was converted from meters/min to $\mathrm{cm} / \mathrm{sec}$ to match values from standard permeation devices.

See Appendix E for further details of the procedure used and construction of the packer. ${ }^{11,12}$ The relationship between field and laboratory hydraulic conductivity measurements and permeability is given in standard texts such as Fluid Flow in Porous Media. 13

\subsection{Description of Injection Materials}

A standard Type I/I Portland cement was used for most of the injections into the fractured basalt. Microfine cement was used to fill a portion of the smaller fractures because it has a much smaller mean particle size than Portland cement. Physical and chemical comparisons of the two materials is given in Table 3. Microfine cement has a higher aluminum and silicon content, is four times smaller in mean particle size and has a larger surface area, than Portland cement. It is also about 10 times more expensive than ordinary Portland cement $(0.06 \$ / 1 b$ vs. $0.6 \$ / / b)$.

The borehole integrity, fracture depth, fracture spacing, hydraulic conductivity, and fracture inclination was evaluated for each injection hole and zone of interest to determine whether Portland or Microfine cement was to be used. This information was taken from the hydraulic flow data and an examination of the caliper and video logs. The caliper logs are included in the Appendix D.

In general, Microfine cement was used in those sections of the boreholes that contain only small fractures, lacked extensive rubble zones, and had hydraulic conductivity usually below $2 \times 10^{-4} \mathrm{~cm} /$ sec. Nine holes were exclusively injected with Microfine cement, 13 with Portland cement, and two were inject with both. The Portland cement was used at the lower depths (i.e., 6 and 7.25 meters) and the Microfine cement was used at depths of 4.25 meters.

A fluorescein disodium salt dye, sensitive to ultraviolet (UV) light was mixed with the grout before pumping. The dye concentration was thousand $\mathrm{pp}$, by volume. This facilitated later identification of cement penetration in postgrout drill cuttings and cores. Cross-contamination and potential natural calcite fluorescence made verification of cement penetration by the presence of the tracer not completely reliable. 


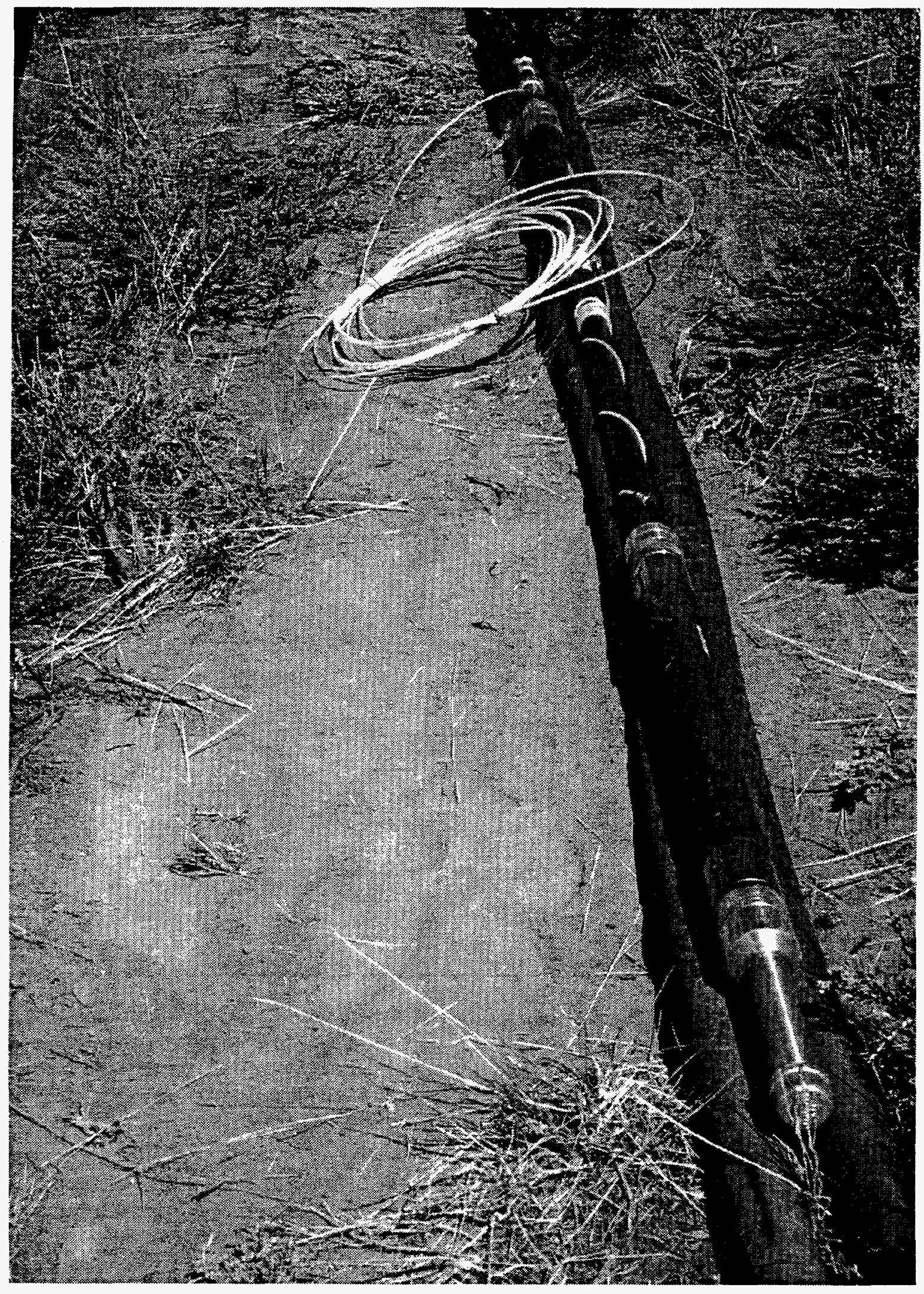

Figure 10. Hydraulic conductivity measurement packer assembly. 
Table 2. Hydraulic conductivity calculation.

\begin{tabular}{llcl}
\hline \multicolumn{1}{c}{ Variable } & \multicolumn{1}{c}{ Measurement Unit } & Symbol & Precision \\
\hline Volume & liter & $\mathrm{V}$ & $\pm 2 \mathrm{~L}$ \\
Time & minute & $\mathrm{t}$ & $\pm 0.1 \mathrm{~min}$ \\
Flow & liter per min & $\mathrm{Q}$ & $\pm 2.5 \mathrm{l} / \mathrm{min}$ \\
Hole Radius & centimeter & $\mathrm{r}$ & $\pm 1 \mathrm{~cm}$ \\
Packer Length & meter & $\mathrm{L}$ & $\pm 0.01 \mathrm{~m}$ \\
Pressure & pounds per square inch & $\mathrm{h}$ & $\pm 5 \mathrm{psi}$ \\
Hydraulic Conductivity & centimeters per second & $\mathrm{rkf}$ & $\pm 30 \% \mathrm{~cm} / \mathrm{sec}$ \\
\hline
\end{tabular}

Table 3. Cementitious grout material composition.

\begin{tabular}{lll} 
& Oxide Analysis & \multicolumn{2}{c}{ Microfine } & \multicolumn{2}{c}{ Portland } \\
\cline { 2 - 3 } & \multicolumn{2}{c}{ Composition Percent } \\
\hline $\mathrm{SiO}_{2}$ & 30.6 & 21.5 \\
$\mathrm{Al}_{2} \mathrm{O}_{3}$ & 12.4 & 5.4 \\
$\mathrm{Fe}_{2} \mathrm{O}_{3}$ & 1.1 & 2.5 \\
$\mathrm{CaO}$ & 48.4 & 63.9 \\
$\mathrm{MgO}$ & 5.8 & 2.3 \\
$\mathrm{SO}_{3}$ & 0.8 & 1.7 \\
$\mathrm{Na}_{2} \mathrm{O}$ & 0.4 & 0.3 \\
$\mathrm{Physical} \mathrm{Parameter}_{\mathrm{Specific} \mathrm{Gravity}}$ & & \\
Bulk Density (g/cc) & 3.0 & 3.15 \\
Blaine Specific Area (cm & \\
50\% grain size (micron) & 1.0 & 1.2 \\
Estimated Minimum Permeation Hole size (mm) & 8150 & 3170 \\
\hline
\end{tabular}

\subsection{Grout Injection}

The transport/mixing/shearing pumping module used to stage grout mixture and pump into the predrilled holes is shown in Figure 11. This module is a series of hoppers mounted on a flat bed truck, which includes a traditional 0-200 psi cement pump. The Microfine cement was mixed in the hoppers and pumped into the holes. The Portland cement was ordered redimix and was poured into the hopper from the truck before being pumped into the holes (see Figure 12). High pressure was not used due to hydrofracturing of the rock during injection. Portland cement was delivered mixed $1: 1$ by volume with water or $448 \mathrm{Kg} / \mathrm{m}^{3}$. Microfine cement formulation was a $3: 1$ by volume mixture " 8 sack neat" mix and was batched in the module.

Holes were injected from the bottom up in stages to match the three lithologic zones described above in Section 3.1. A single head packer was used to isolate 1.3-meter hole lengths in these zones. Grout was pumped at three pressures ranging between 20-110 psi as listed in Table 1. Figure 13 depicts a borehole after grout injection. 


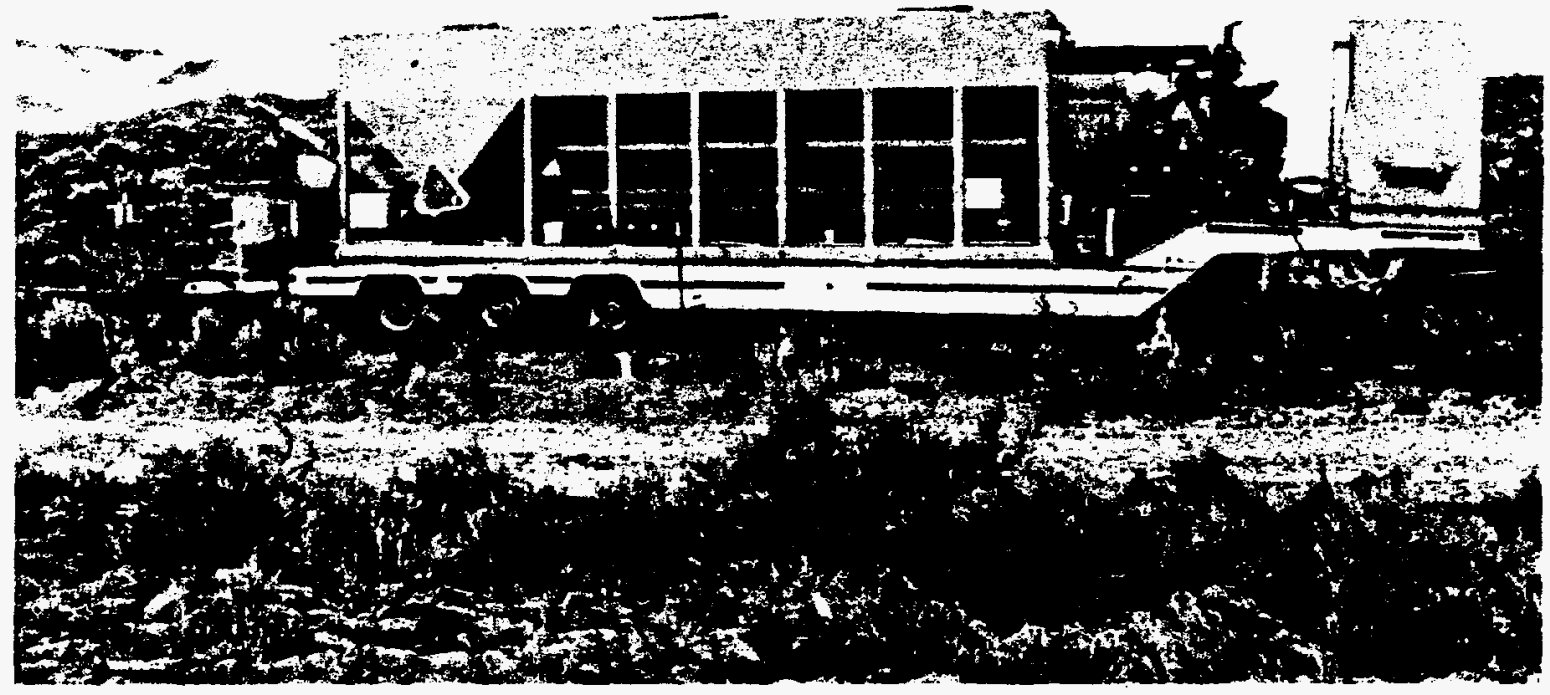

Figure 11. Transport/mixing/shearing/pump module.

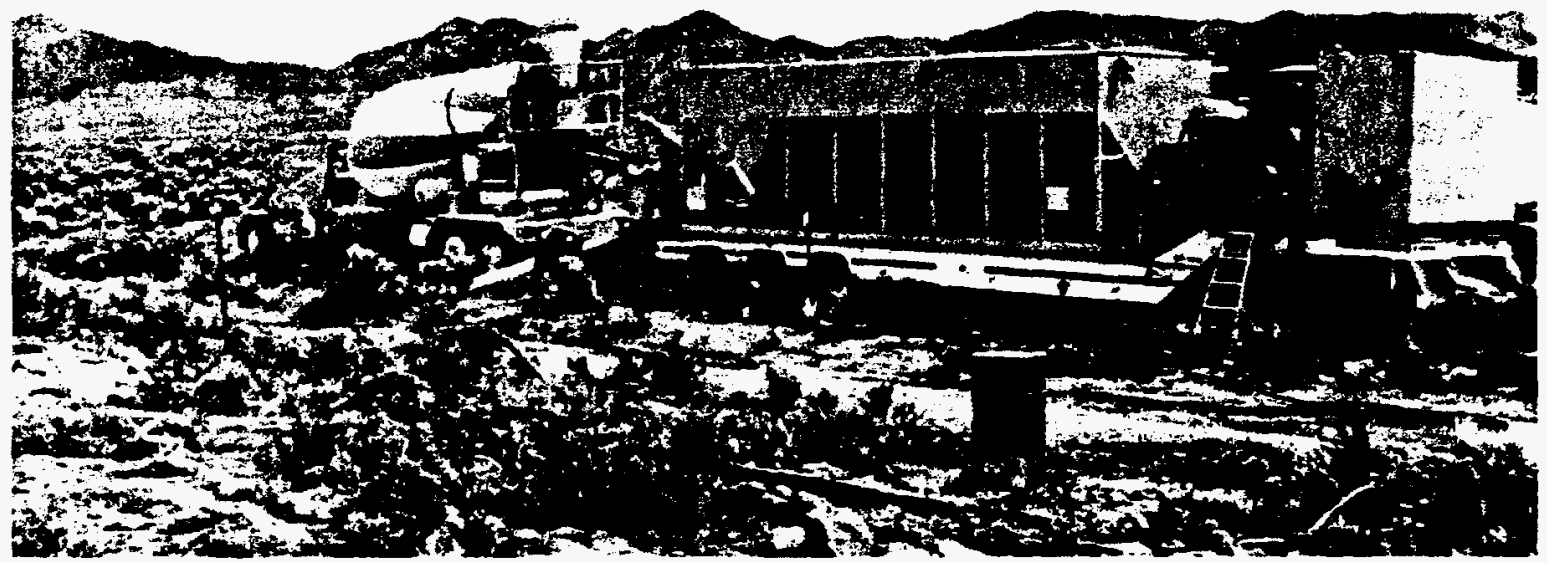

Figure 12. Loading mixing/pump module with portland. 


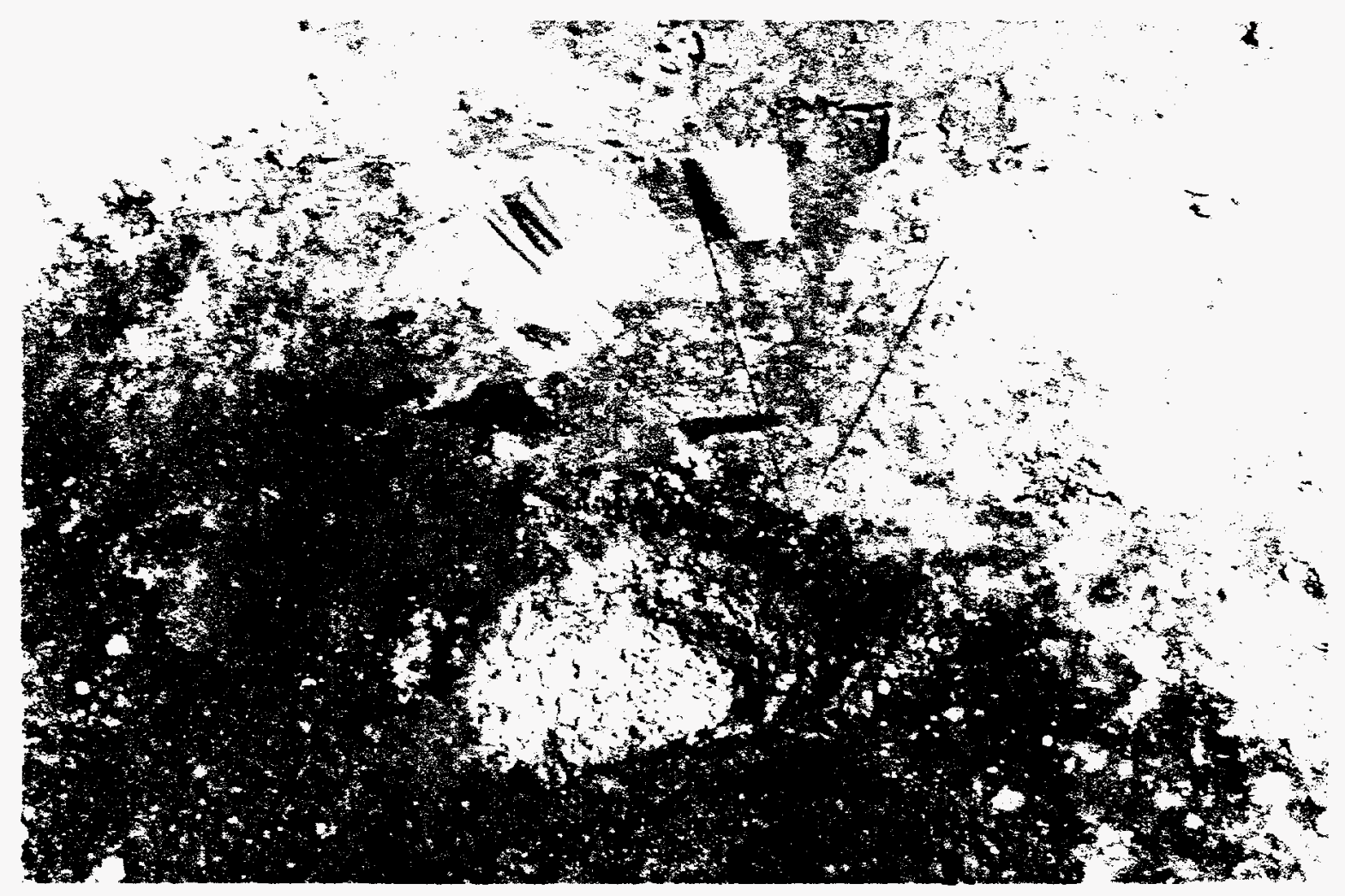

Figure 13. Post injection borehole after closure.

The depth profile was standardized on Hole $8 \mathrm{D}$ (in the middle of the lateral dividing the two quadrants of the grouting area) and 0.76 meters above the center of pivot point. After injection. 12 holes were drilled to assess grouting efficiency from both multiple overlapping and single injections and in different permeation bedrock. A summary of the cement injection data is mapped in Figure 6 . The grout take for some holes was more than sufficient to fill the inner granular cracks in the basalt and flowed beneath the formation into large rubble zones.

\subsection{Cross-Hole Raytheon Subsurface Mapping Procedures}

Borehole radar surveys were carried out on four holes on 16-meter radial in the first quadrant (A-D) of the Box Canyon Site as shown on the map. The borehole radar manufactured by ABEM is an automatic. two component unit. The system has two computer controlled draw works and a software program that automatically positions the sending and receiving sondes in two boreholes and records and processes data steam.

The system can operate in a single or multiple sonde mode. In the single sonde mode. the orientation of the reference direction for the sonde is set with a magnetic location. The system records the average of four sets of reflected signals taken at a 90-degree azimuth at each depth station. The effective depth in the single mode is from 1 meter below the casing to 2 meters above the borehole bottom. For the receiver in the multiple mode. the maximum record depth is 4 meter above the bottom of the hole.

The transmitter and receiver were moved in 1/4-meter steps down the hole. The transmitter sends about three hundred, $30 \mathrm{Mhz}$ radar pulses. The receiver captures each pulse, and averages and then stores them. Well-to-well tomograms were obtained to follow water infiltration from a 2-meter diameter pool and investigate the maximum useable transmission distance. Single tomograms were used to map the basalt flows of the Box Canyon Site. Further discussion and photographs are included in the Results Section. 


\subsection{Flow Fracture Infiltration Test}

An infiltration test was run on fractures from two major basalt flows in the Box Canyon area and monitored by the cross-hole radar. A pool was constructed on a fractured basalt outcrop between a USGS well and hole at the farthest east of the half circle drilling area, hole 16A. A 2-meter wading pool with the bottom removed was placed on a tarp weighted with sand to seal the pool against the rock.

The pit/pool was filled with water from a water truck and kept full for 3 hours and 17 minutes. Nine flow measurements were taken about every 15 minutes until 832 gallons had passed. Water flows started high and decreased throughout the test. The final series of flows were considered indicative of the actual fracture flow. The water front was tracked with the radar showing the high attenuation expected from the high dielectric coefficient of water as it fills fractures. Figure 5a depicts this pool and a schematic water penetration.in the lava flow joint. Photographs and a complete description of the pool and schematic water penetration and are given in the Results Section.

\subsection{Postgrouting Angled Core Sampling}

In August of 1995, diamond drilling was used to obtain eight intact cores within the Box Canyon grouted zone region. These cores provided samples to visually determine the grouting effectiveness and quantitate fracture fill. The core hole distribution pattern has been described in Section 3.2.2 and shown in Figure 6. Seven cores were drilled at 22 degrees off vertical (22.6 \pm 2.1 degrees) with a water drill. Figure 14 is a photograph of the drill in action. The direction of penetration and extent of horizontal subsurface coverage is also shown on the map in Figure 6. The 8th vertical core $(C-11)$ was taken with a directional air drill that preserves the orientation of the core. This drill is shown in Figure 15 and the marked collar device to preserve direction of the core is shown in Figure 16. Standard coring procedures used in the oil industry were used in obtaining, labeling, and archiving all cores. Photographs of core samples from both types of drills are shown in the Results Section. Further core descriptions and data are presented in Appendix F.

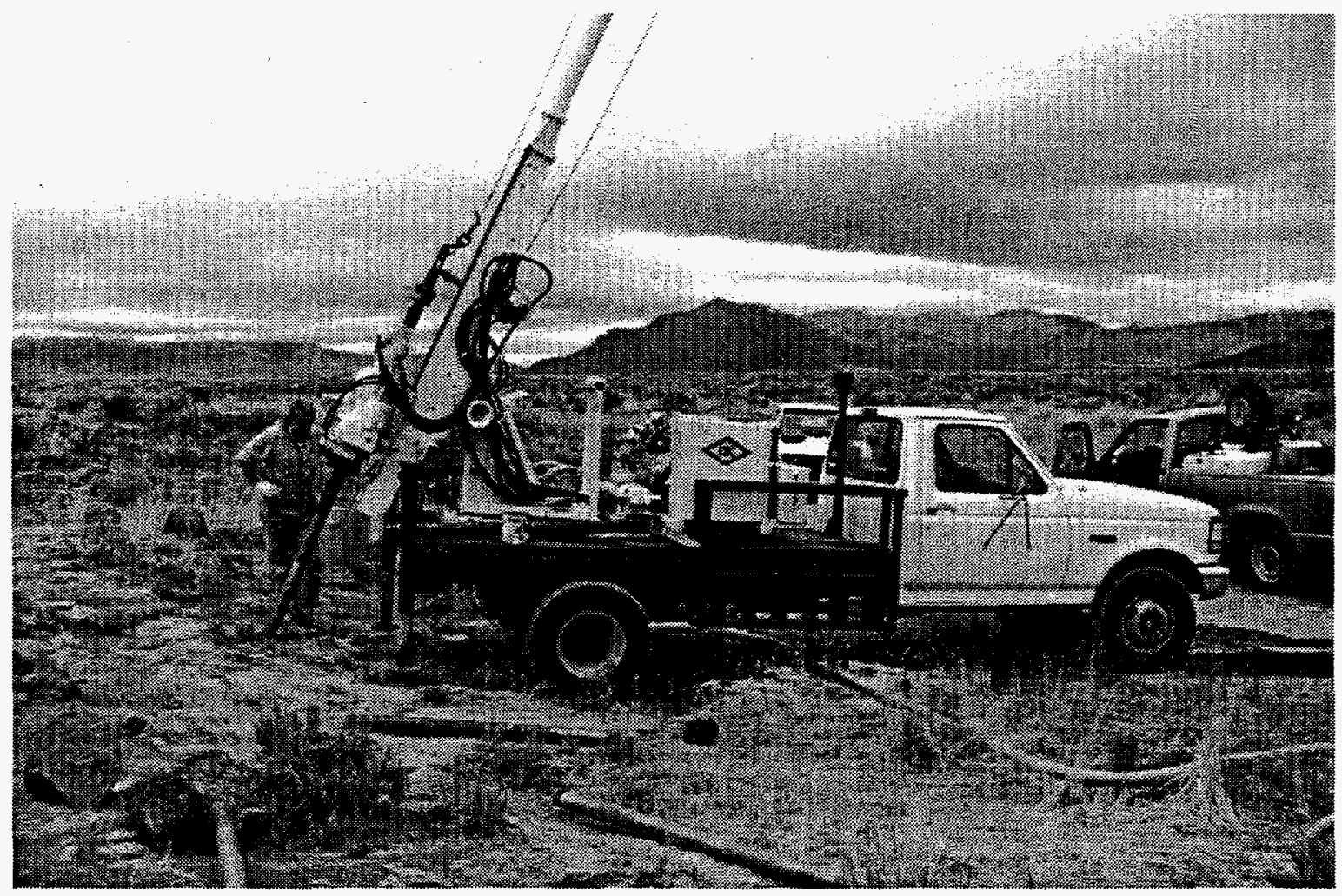

Figure 14. Water drilling post grout core at 22 degree. 


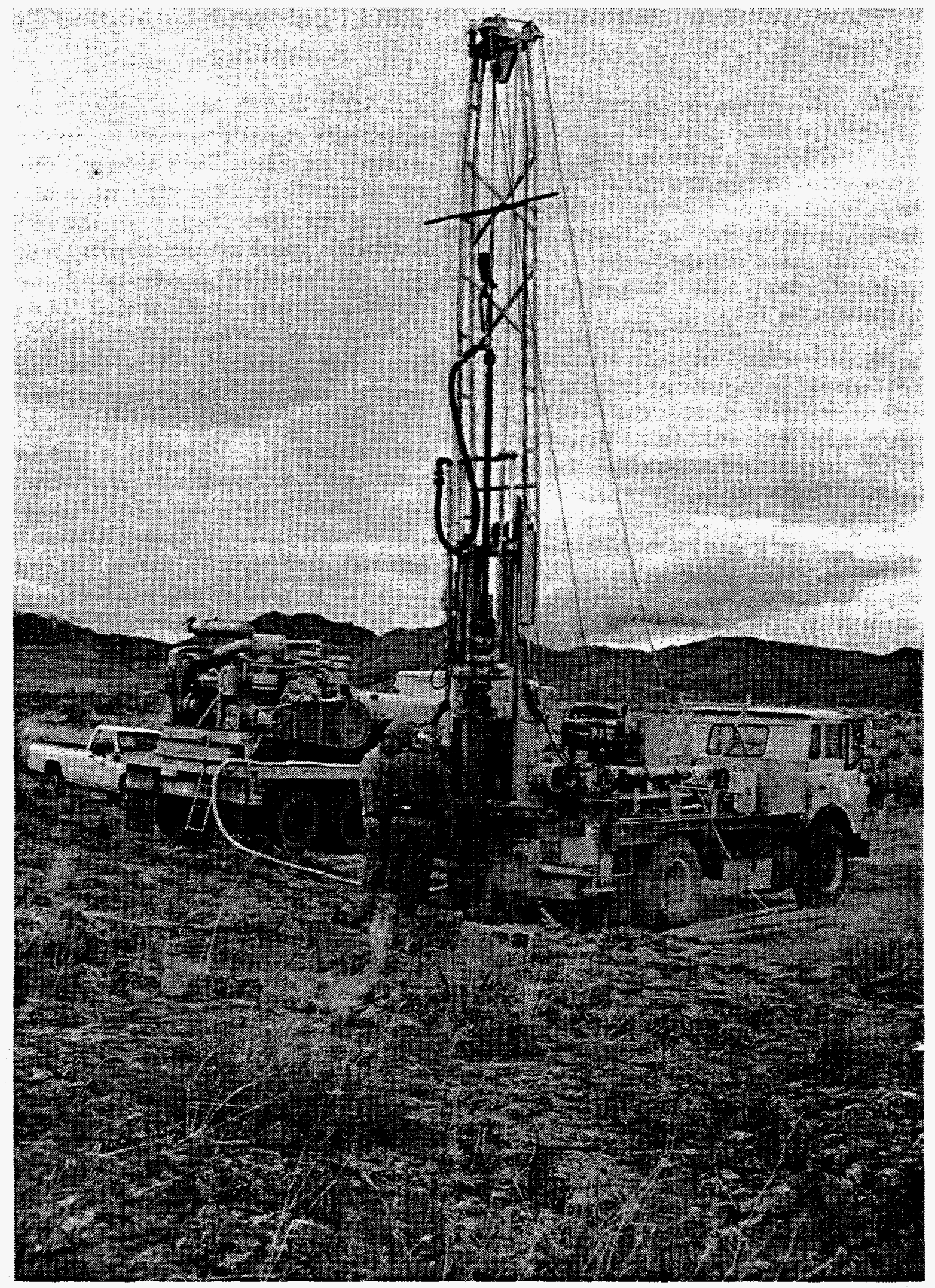

Figure 15. Vertical air drilling C-11 post grout directional core. 


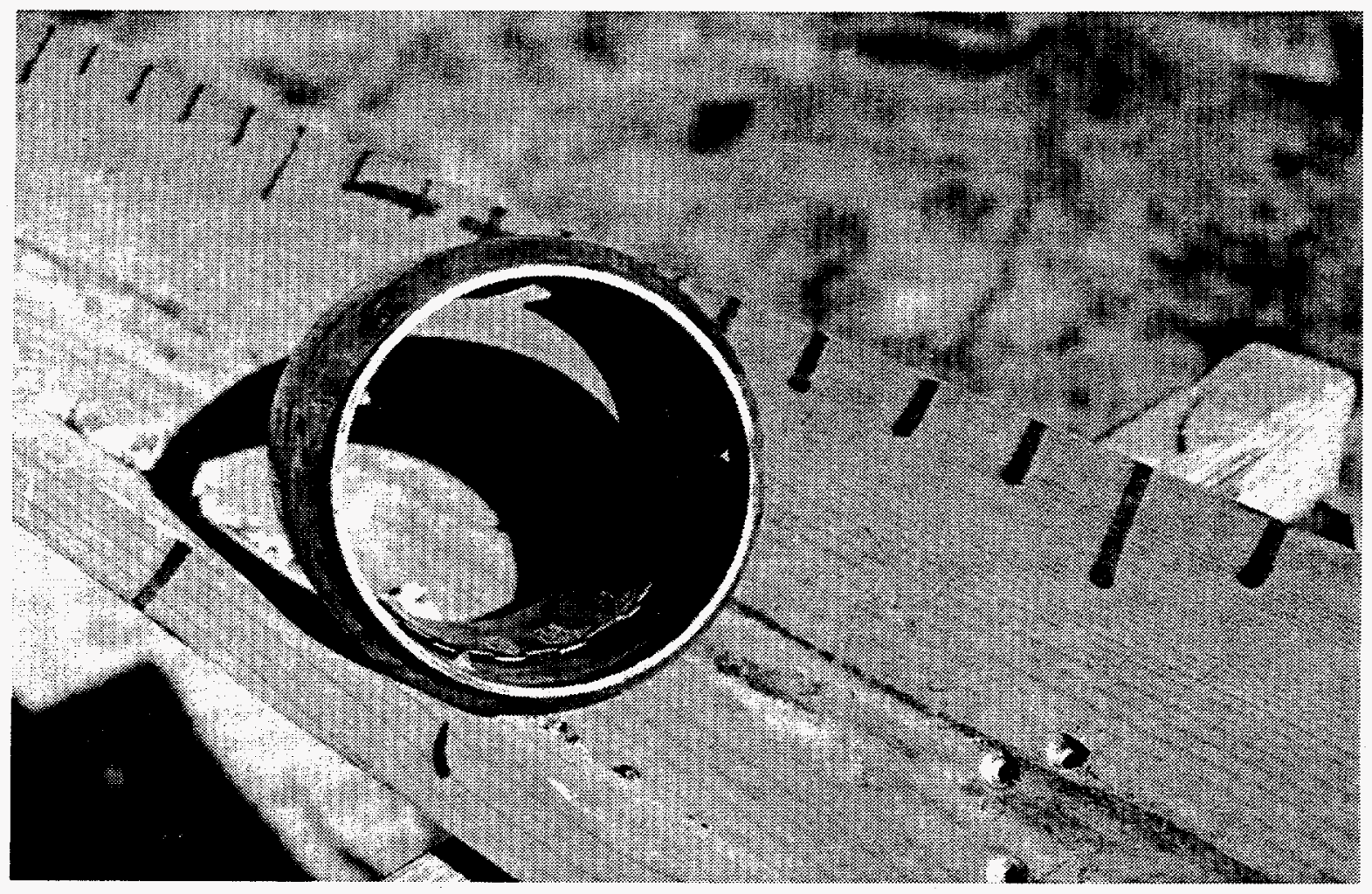

Figure 16. Post grout directional core collar. 


\section{TEST RESULTS}

Methods used to measure the effectiveness of the pressure grouting included: postgrouting permeability data, tracer presence, grout presence in cross-hole cores. The implementability of Monolithic Confinement by Pressure Grouting of Basalt was assessed qualitatively based on drilling and operational logs. The most important evidence of grouting success was the decrease of water conductivity noted in most of the postgrouting holes.

\subsection{Grout Application and Water Conductivity in Fractured Basalt}

At total of $23.3 \mathrm{~m}^{3}$ of cement was injected into Box Canyon in this demonstration.; 95\% of this was Portland cement. Microfine cement was injected completely in nine holes and partially in two holes. Figure 17 shows the distribution of grout quantity and type injected. The $1.2 \mathrm{~m}^{3}$ of Microfine cement injected was distributed fairly evenly in each hole (i.e., $0.11 \pm 0.04 \mathrm{~m}^{3}$ ). By far the largest amount of cement, $19.2 \mathrm{~m}^{3}$, was injected along the $F$ lateral, northwest from the pivot, in five holes as shown in Figure 17a. This amounts to $82 \%$ of the total cement injected. In one hole, almost half of the total amount, $8.67 \mathrm{~m}^{3}$, was injected. The remaining 10 Portland cement holes averaged $0.3 \pm 0.2 \mathrm{~m}^{3}$ per hole, ranging from 0.13 to $0.64 \mathrm{~m}^{3}$ of cement pumped.

Figure 18 compares (on a sample map) the average grout conductivity with the hydraulic conductivity at all depths without correcting for the greater density and viscosity of the cement. Figures 19 and 19a show these values graphically on linear and $\log$ scales. Average values for all depths correlate well, particularly at the radial 8 meters from the pivot point. Seven holes showed a correlation between water and grout flows at all depths based on a positive correlation coefficient for flows at comparable depths greater than 0.7 meters. The correlation coefficient between all the water and grout flow measurements was 0.65 .

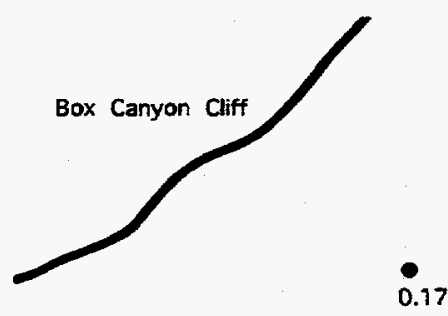

- Grouted Holes Portland Total Grout Volume in $\mathrm{M}^{3}$

- Grouted Holes Microfine is:a: Craw: Volume is M $^{3}$

- Grouted Holes Both Cements

0.19 0.08

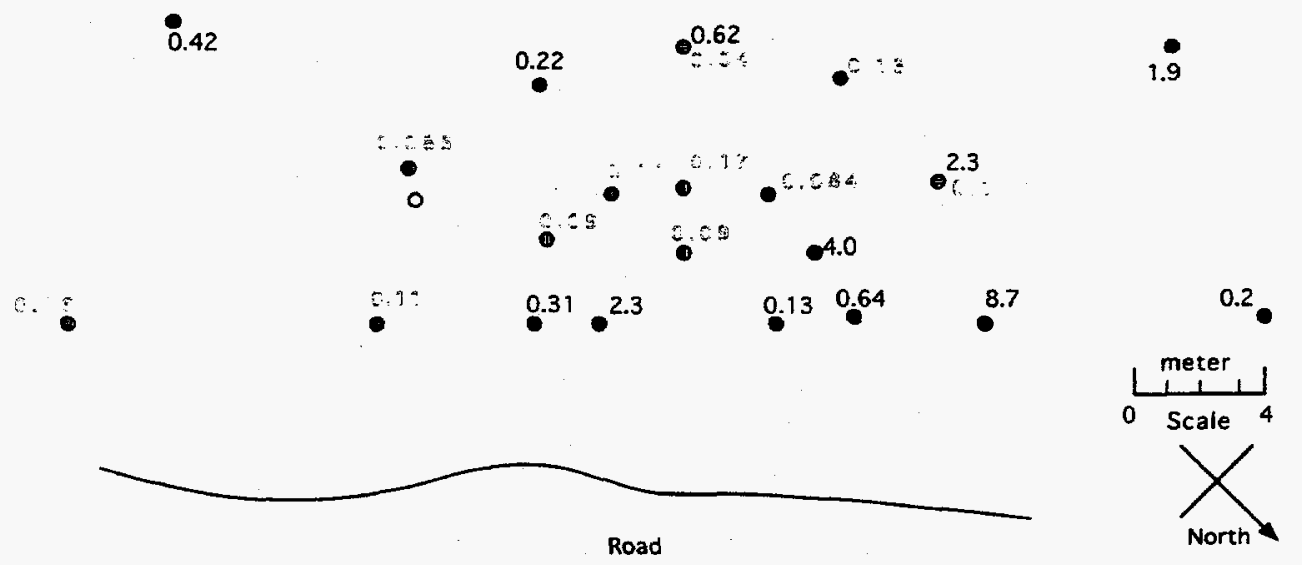

Figure 17. Map of grout volumes and grout types injected at Box Canyon. 


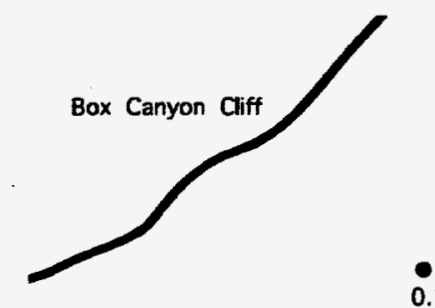

$\stackrel{0.19}{0.17}$

- Grouted Holes Portland Total Grout Volume in $M^{3}$

- Grouted Holes Microfine

Tera. Grow Ve.wre : $p^{3}$

- Grouted Holes Both Cements

0.42

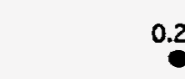

0.22

$e_{3.2}^{0.62}$

c.is

1.9

5.05

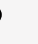

$-$

58

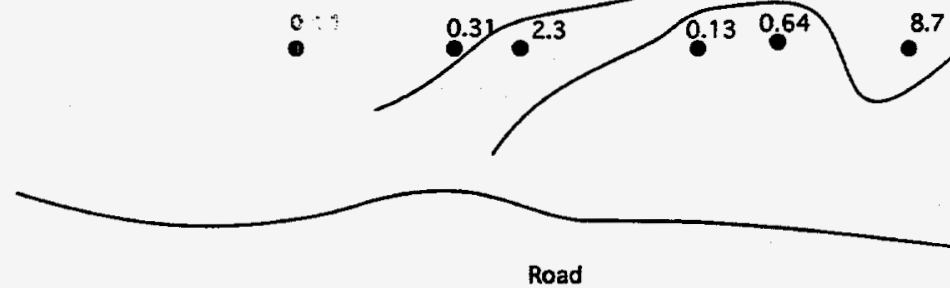

8.7
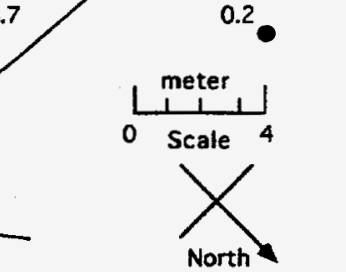

Figure 17a. Map showing region of high grout volumes injected at Box Canyon.

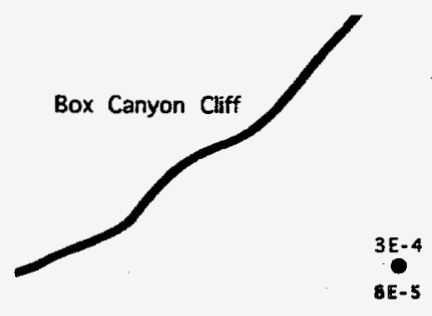

- Portland Grout Injected

- Microfine Grout Injected Hydraulic Conductivity $\mathrm{cm} / \mathrm{sec}$ Grove Conouetivity $\mathrm{cm} / \mathrm{sec}$

$\begin{array}{ccc} & 3 E-4 & \\ 3 E-4 & 0 & \\ 0 & 9 E-5 & \\ 8 E-5 & & 1 E-4 \\ & & 8 E-5\end{array}$

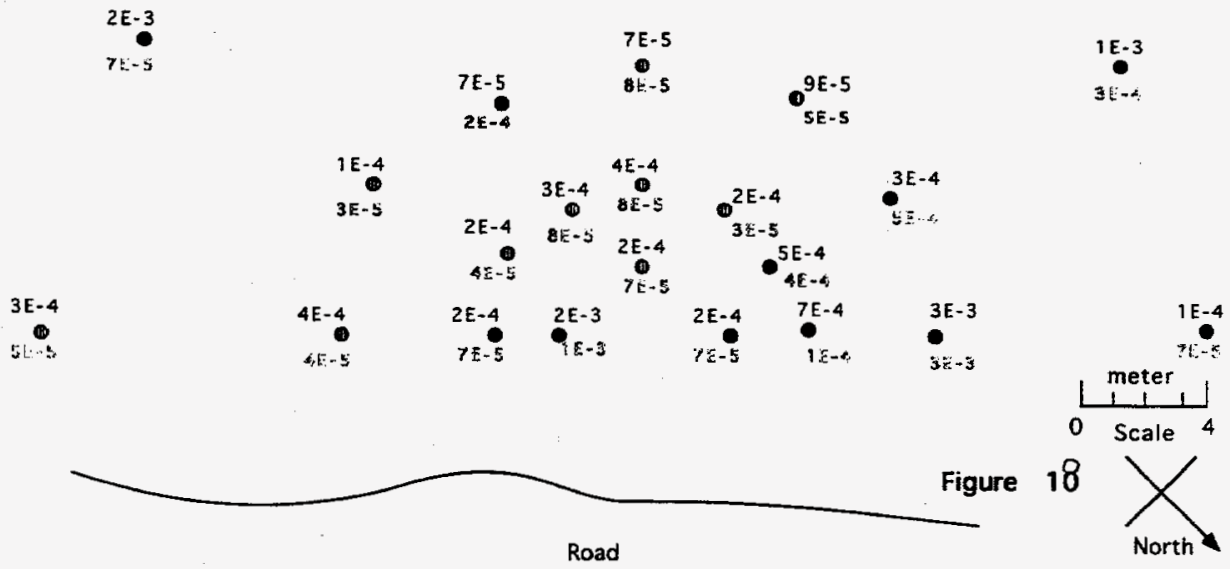

Figure 18. Map of average grout and hydraulic conductivities. 


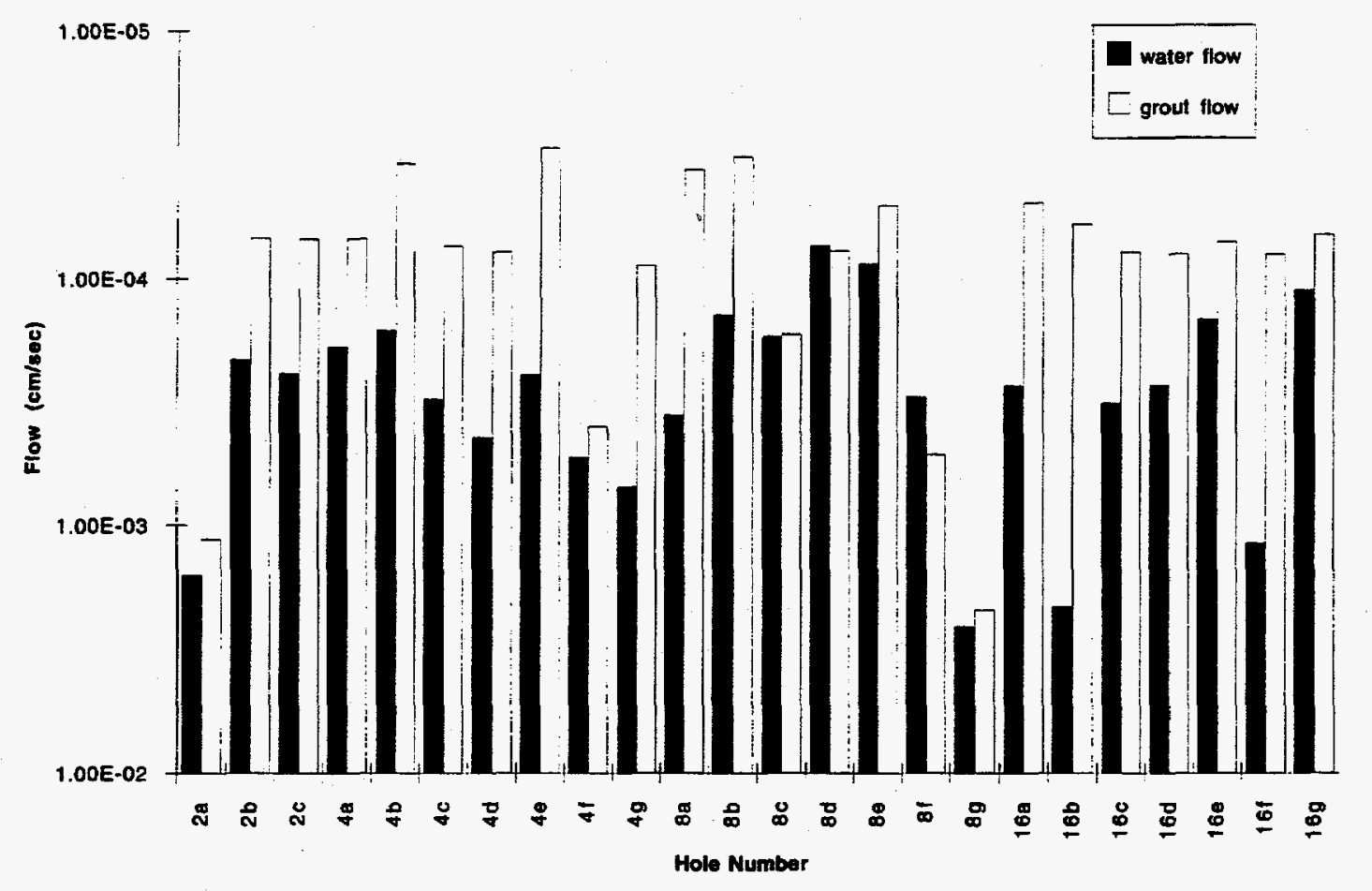

Figure 19. Comparison of average grout and water flow through basaltic rock fissures (log scale).

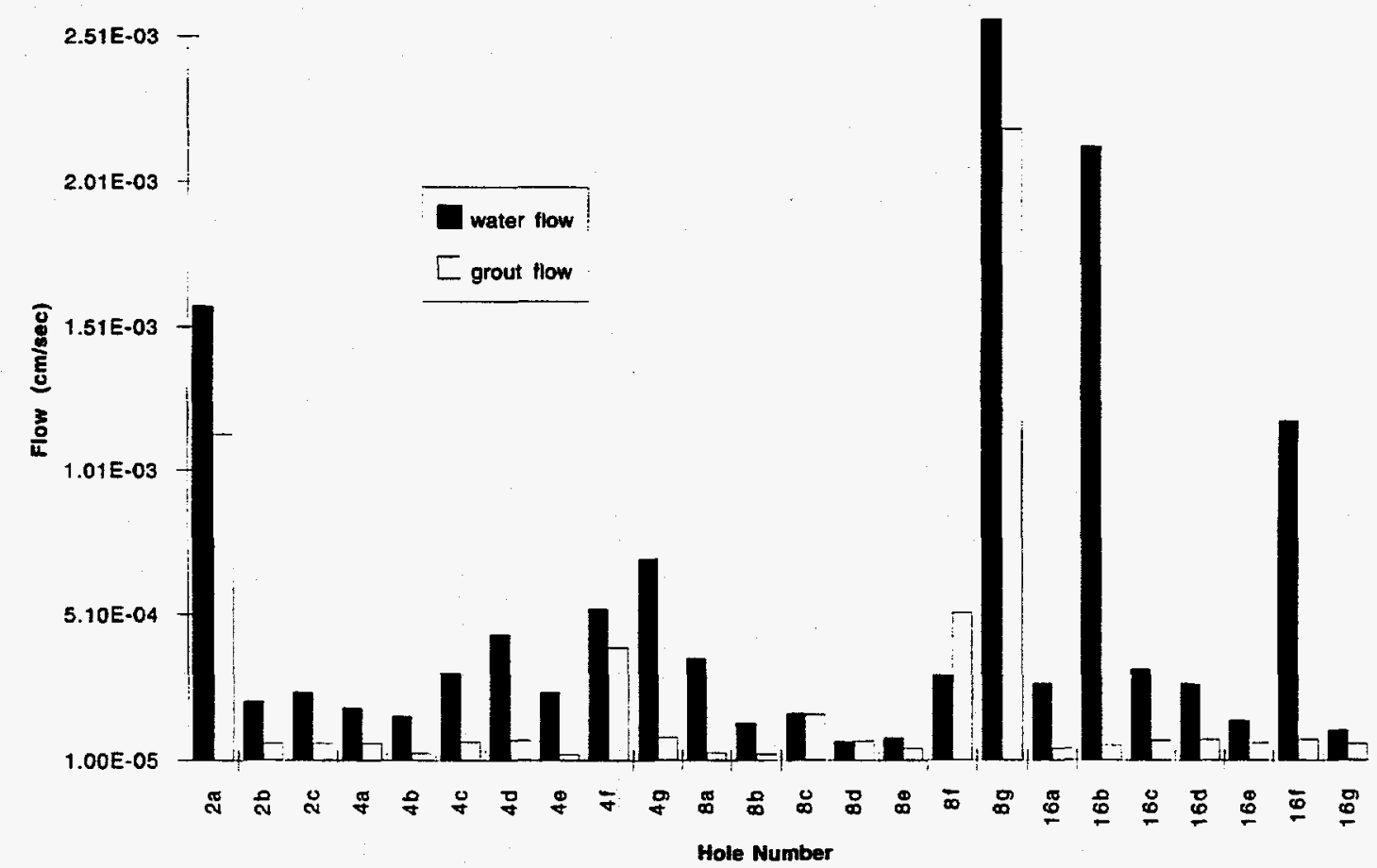

Figure 19a. Comparison of average grout and water flow through basaltic rock fissures (linear scale). 
This is fairly good considering that the depths for measuring conductivity and injecting grout did not always line up exactly and the length of the region for measuring water conductivity was 1.07 meter while that of pumping grout was 1.33 meters.

Grout and hydraulic conductivities at individual depths are compared graphically in Figures 20-23. The depths, 4.5, 5.8, and 7.1 meters are the average depth for the permeation measurements and grout injection at that level. The correlation of grout and hydraulic conductivities are closer near the bottom of the hole at 7.1 meters then further up at 4.5 meters. The discrepancies in the data such as in Hole 16a on the east side (incidently the same one used for downhole radar in the water infiltration test) probably have to do with sediment being pushed along by the water and blocking holes from the grout, or the increased viscosity of the grout makes it unable to flow though small fractures.

\subsection{Pre and Postgrouting Hydraulic Conductivity}

Table 4 compares the average hydraulic conductivity of all the pre and postgrout holes at average depths of $4.5,5.8$, and 7.1 meters. The overall conductivity decreased by a factor of $3 \pm 1.4$, with the greatest decrease at the bottom region of the hole, which was 7.1 meters from surface. The uncertainty of each measurement is $20-50 \%$ and the uncertainty from averaging all measurements at a specific depth is $130-210 \%$. The relative standard deviation of all the postgrouting hydraulic conductivities is $\pm 240 \%$. The standard deviation of all the pregrouting conductivities is $\pm 170 \%$. The post grouting conductivities had a larger range than pregrouting ones particularly at the 5.8-meter depth with both the highest $\left(1 \times 10^{-3} \mathrm{~cm} / \mathrm{sec}\right)$ and lowest $\left(6 \times 10^{-6} \mathrm{~cm} /\right.$ $s e c)$ hydraulic conductivity values.

Table 5 shows the average hydraulic conductivity for each radial sector both before and after grouting. Except for two holes on the northwest side of the site, which were located 3 and 6 meters

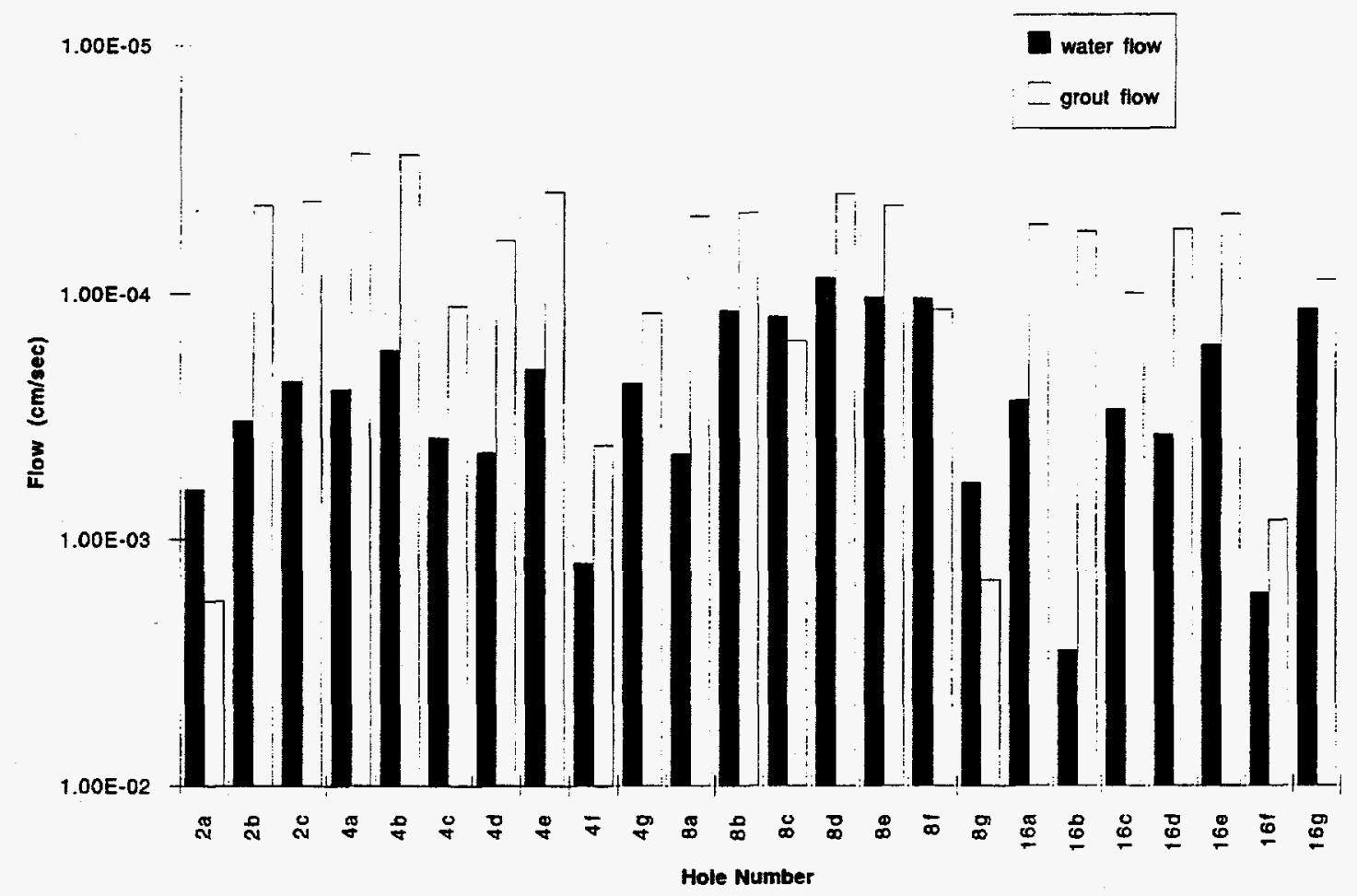

Figure 20. Comparison of grout and water flow through basaltic rock fissures at 4.5 meters depth. 


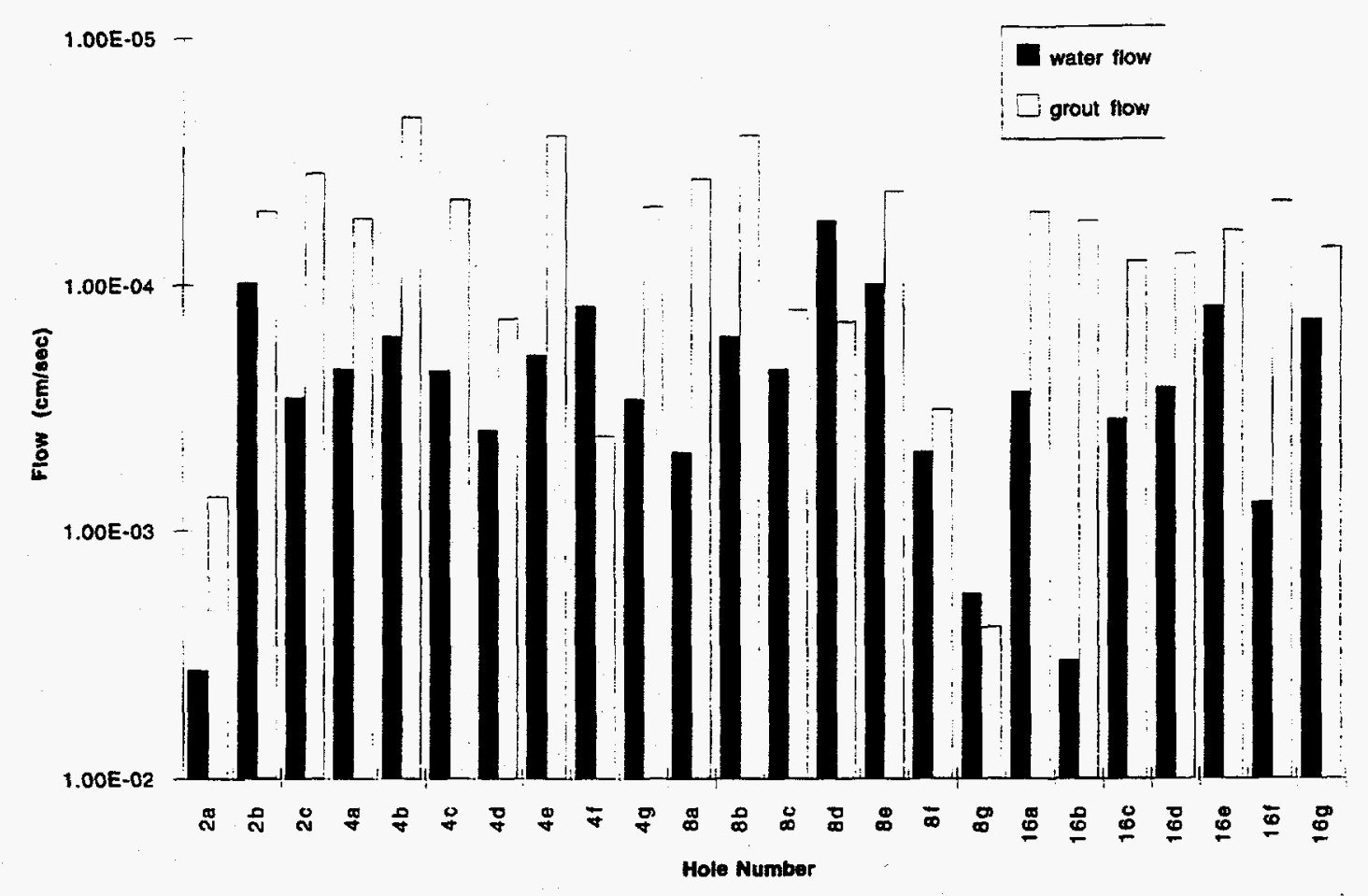

Figure 21. Comparison of average grout and water flow through basaltic rock fissures at 5.8 meters depth.

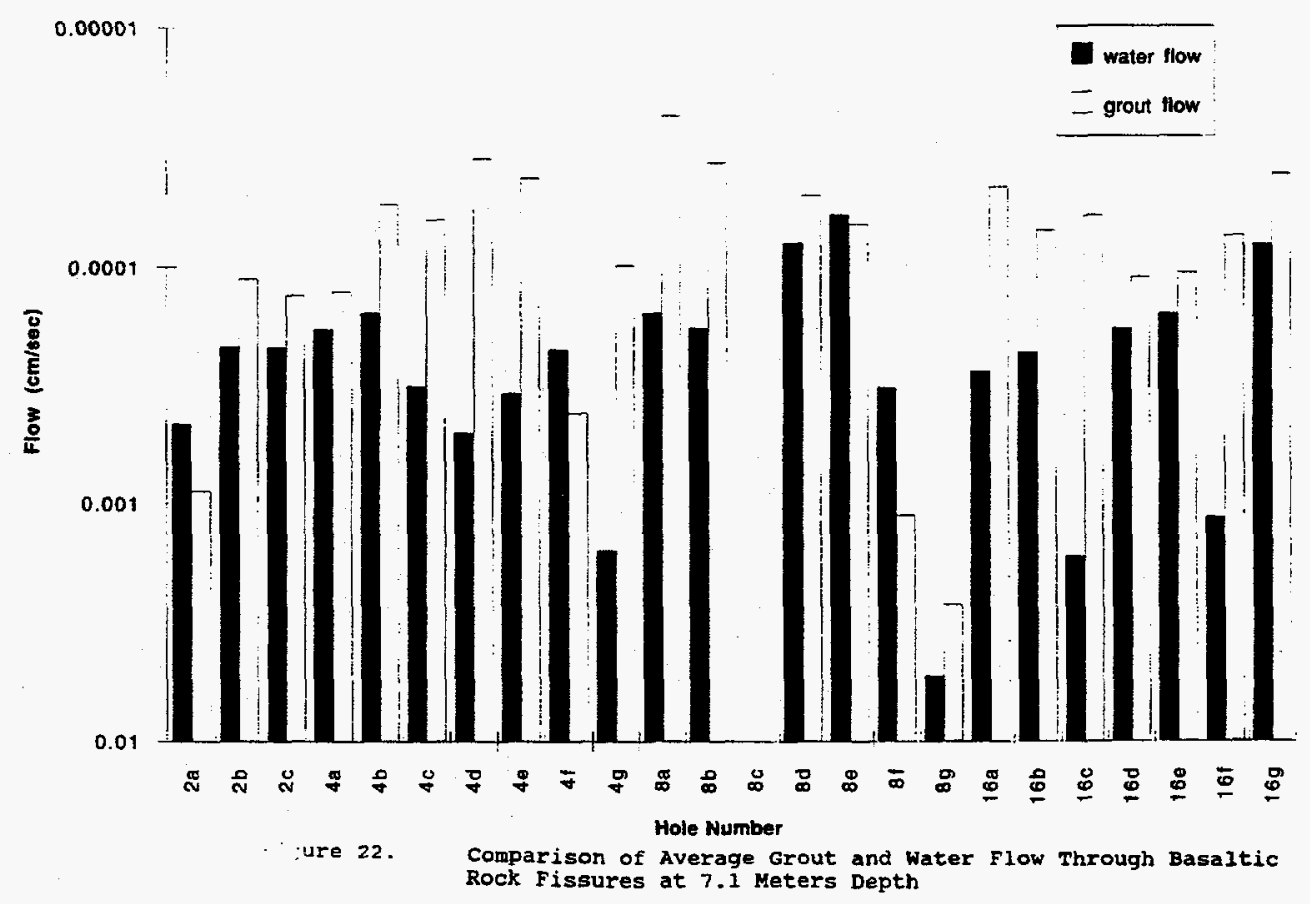

Figure 22. Comparison of average grout and water flow through basaltic rock fissures at 7.1 meters depth. 


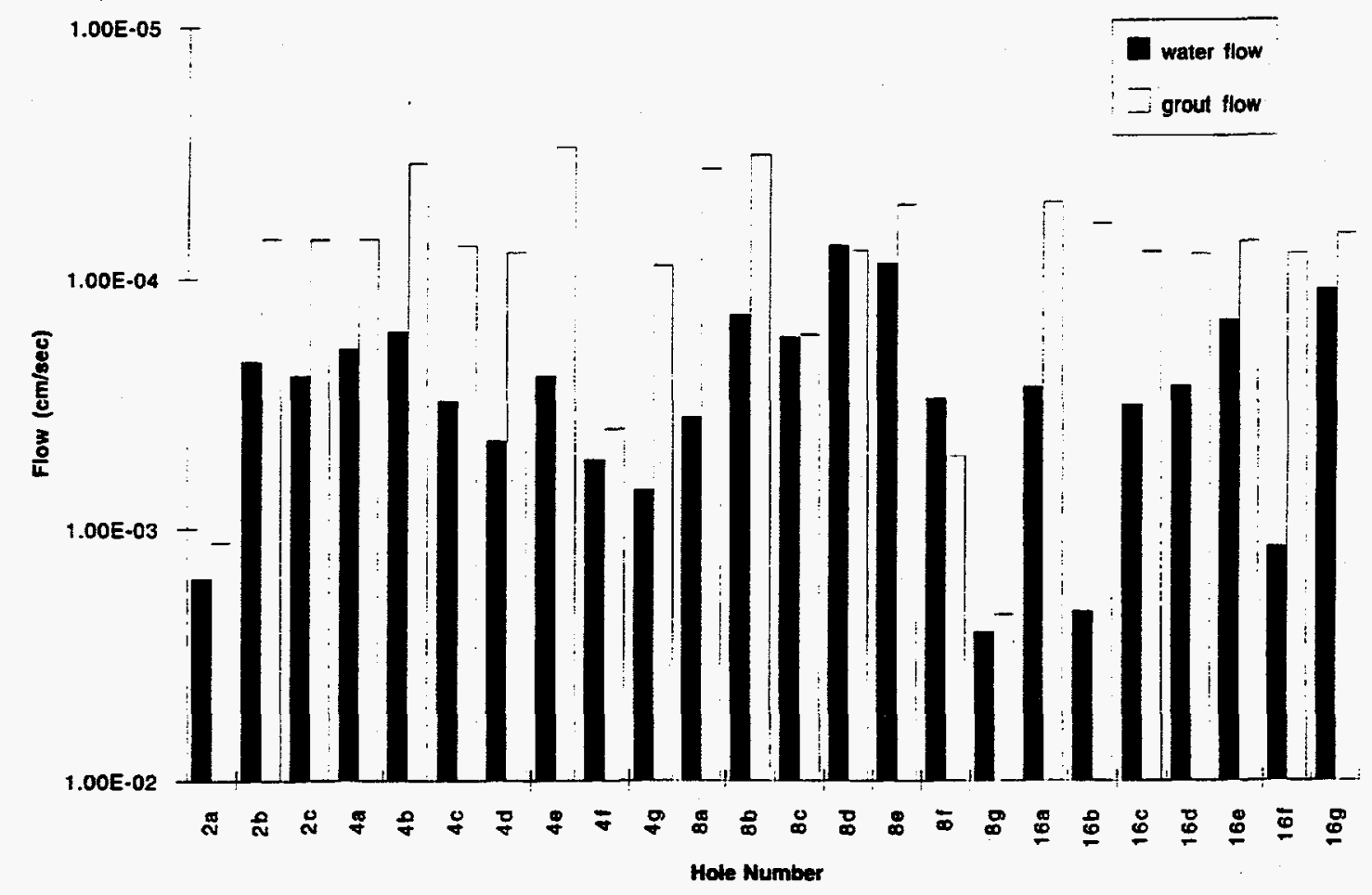

Figure 23. Average grout and water flow through basaltic rock fissures.

Table 4. Hydraulic conductivity decrease after grouting at various depths. ${ }^{a}$

\begin{tabular}{lccc}
\hline \multirow{2}{*}{$\begin{array}{c}\text { Average depth } \\
\text { meters }\end{array}$} & Pre grout & Post grout & $\begin{array}{c}\text { Conductivity } \\
\text { decrease percent }\end{array}$ \\
\cline { 2 - 4 } 4.5 & $4.8 \pm 6.3 \times 10^{-4}$ & $1.7 \pm 3.1 \times 10^{-4}$ & 280 \\
5.8 & $6.0 \pm 9.8 \times 10^{-4}$ & $3.4 \pm 7.2 \times 10^{-4}$ & 180 \\
7.1 & $5.9 \pm 11.7 \times 10^{-4}$ & $1.3 \pm 2.2 \times 10^{-4}$ & 450 \\
ALL & $5.6 \pm 9.3 \times 10^{-4}$ & $2.0 \pm 4.8 \times 10^{-4}$ & 280 \\
& & & \\
\hline \multirow{2}{*}{ See also Figure 26-33 } & & & \\
\hline
\end{tabular}


Table 5. Hydraulic conductivity decrease after grouting by sector. ${ }^{a}$

\begin{tabular}{|c|c|c|c|c|c|}
\hline \multirow[b]{2}{*}{ Sector } & \multirow{2}{*}{$\begin{array}{c}\text { Distance } \\
\text { from center } \\
\text { point } \\
\text { meters } \\
\end{array}$} & \multirow{2}{*}{$\begin{array}{c}\text { Distance } \\
\text { between pre and } \\
\text { post grout holes } \\
\text { meters }\end{array}$} & \multicolumn{2}{|c|}{ Average hydraulic conductivity } & \multirow{2}{*}{$\begin{array}{c}\text { Conductivity } \\
\text { decrease } \\
\text { percent } \\
\end{array}$} \\
\hline & & & $\begin{array}{l}\text { Pre grout } \\
\mathrm{cm} / \mathrm{sec}\end{array}$ & $\begin{array}{l}\text { Post grout } \\
\mathrm{cm} / \mathrm{sec}\end{array}$ & \\
\hline Center & 0 & 2 & $6.8 \pm 11.2 \times 10^{-4}$ & $1.2 \pm 0.6 \times 10^{-5}$ & 5700 \\
\hline \multirow[t]{4}{*}{ South } & 1 & 1 & $9.0 \pm 13.6 \times 10^{-4}$ & $1.1 \pm 1.2 \times 10^{-5}$ & 8200 \\
\hline & 3 & 1 & $8.7 \pm 13.7 \times 10^{-4}$ & $8.3 \pm 3.9 \times 10^{-6}$ & 10500 \\
\hline & 6 & 2 & $2.0 \pm 0.9 \times 10^{-4}$ & $7.4 \pm 7.8 \times 10^{-5}$ & 270 \\
\hline & 12 & 4 & $2.6 \pm 0.7 \times 10^{-4}$ & $2.8 \pm 4.3 \times 10^{-5}$ & 930 \\
\hline \multirow[t]{2}{*}{ South West } & 3 & 1 & $2.6 \pm 1.0 \times 10^{-4}$ & $1.8 \pm 0.5 \times 10^{-5}$ & 1400 \\
\hline & 6 & 2 & $2.6 \pm 2.1 \times 10^{-4}$ & $6.3 \pm 4.7 \times 10^{-5}$ & 410 \\
\hline \multirow[t]{5}{*}{ North West } & 1 & 1 & $9.0 \pm 14.3 \times 10^{-4}$ & $3.5 \pm 2.4 \times 10^{-4}$ & 260 \\
\hline & 3 & 1 & $3.0 \pm 1.3 \times 10^{-4}$ & $2.9 \pm 1.9 \times 10^{-5}$ & 1030 \\
\hline & 3 & 1 & $4.9 \pm 5.4 \times 10^{-4}$ & $1.7 \pm 1.0 \times 10^{-3}$ & -350 \\
\hline & 6 & 2 & $2.9 \pm 3.4 \times 10^{-4}$ & $6.2 \pm 7.7 \times 10^{-4}$ & -210 \\
\hline & 12 & 4 & $4.3 \pm 5.0 \times 10^{-4}$ & $7.3 \pm 2.3 \times 10^{-5}$ & 590 \\
\hline
\end{tabular}

a. See also Figure 25

from the center, average postgrouting values for each sector were less than the surrounding pregrouting values. For the 10 of 12 holes that showed decreases, the reductions ranged from a factor of 3 to 105 , and averaged $29 \pm 38$ with a median of 10 .

Figure 24 shows the grout injection volumes mapped with the postgrouting hydraulic conductivities. Both the lowest and highest postgrouting conductivity are located near high volumes of injected grout. Large volumes of grout do not guarantee major voids will be filled but the probability of some reduction is high. Figure 25 illustrates this phenomenon by mapping grout injection volumes and hydraulic conductivity reduction factors. Reduction factors were calculated by dividing the postgrouting hole hydraulic conductivity into that of the second, third, or fourth closest grout injection holes.

The two postgrouting holes that showed no improvement in hydraulic conductivity after grouting (reduction factors $-2.1,-3.5$ ) are along the northwest lateral in the region where the largest grout quantities per hole were injected in four holes (Figure 19a). This illustrates that grout injection is not effective for large rubble zones or voids. However, the highest hydraulic conductivity reductions $(105,82$, and 57$)$ are close to this general high-cement-volume area. Reduction factors outside of this area are more consistent, averaging $7.7 \pm 4.2$ with a range of $2.7-14$. An order of magnitude reduction in hydraulic conductivity seems to be achievable in most cases with 2-meter injection hole spacing, except where large voids exist.

Figures 26-33 detail hydraulic conductivity values both graphically and on maps averaged for each hole and for each of three zones at 7.1, 5.8, and 4.5 meters deep. The greatest variability centers around the area of highest grout uptake as has been discussed previously. Reduction of conductivity outside this area is much more consistent. The distance of the postgrouting hole from the closest injection holes is greater in this region. 


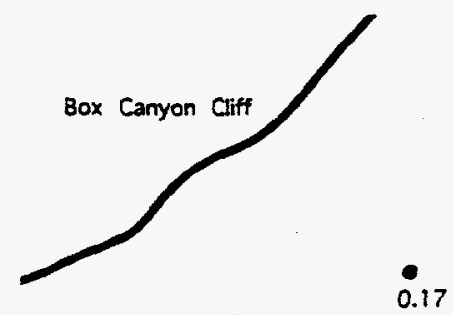

- Grouted Holes Pordand Total Grout Volume in $\mathrm{M}^{3}$

- Grouted Holes Microfine Totai s.pur Voitime in $\mathrm{m}^{3}$

a Grouted Holes Both Cements

$\star$ Post Grouted Holes Hydraulic Conductivity in 0.19 0.17

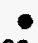
cmisec 0.08
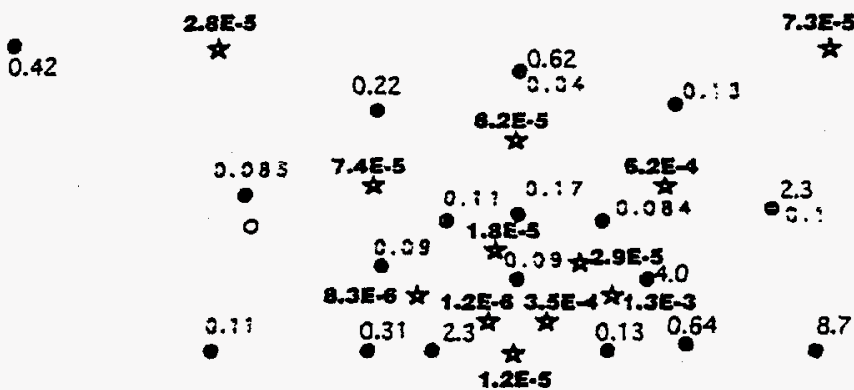

1.9

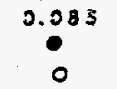

c. 15

$$
3.11
$$$$
0.31 e_{1.25 .5}^{2.3^{+3}+x^{25}} 0.130 .64
$$

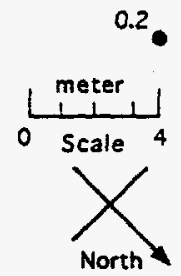

Figure 24. Map of grout volumes and post grouting average hydraulic conductivities.

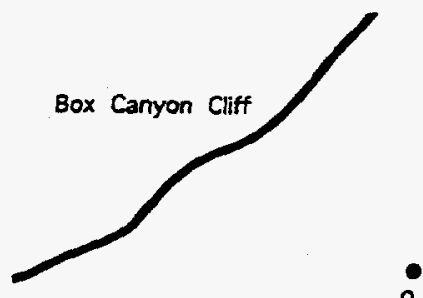

0.17
- Grouted Holes Portland Total Grout Volume in $\mathrm{M}^{3}$
- Grouted Holes Microfine
Total Grout Yokume in $\mathrm{M}^{3}$
- Grouted Holes Both Cements
* Post Grouted Holes, Redectien lactor
0.19
17
0
0.08
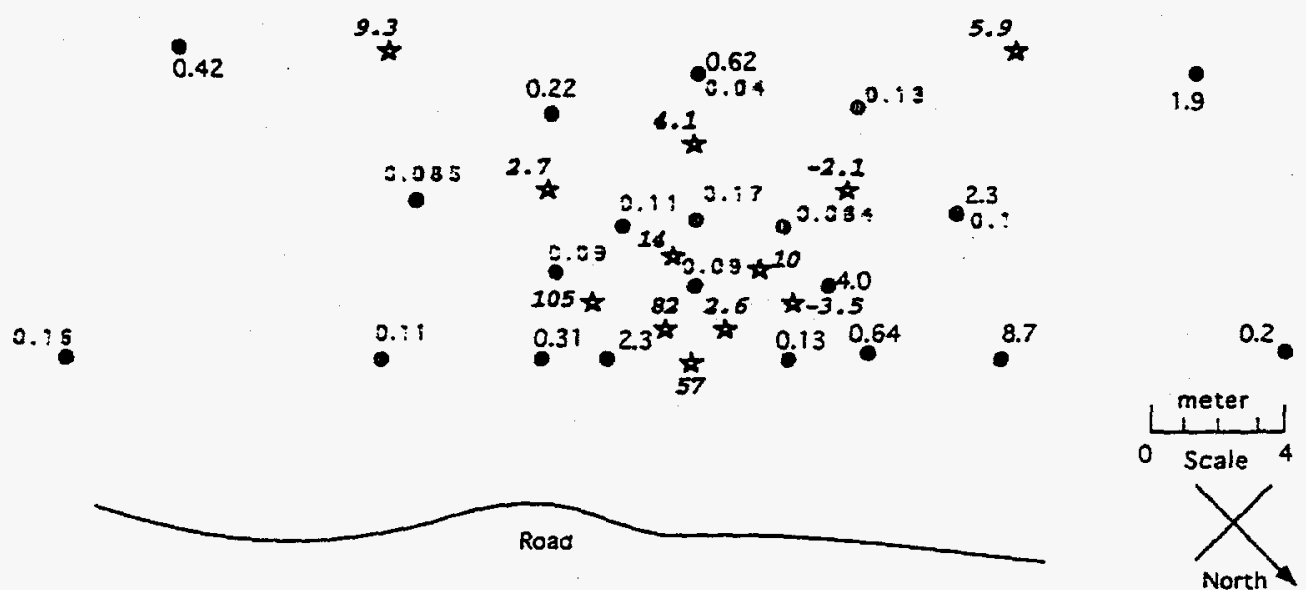

Figure 25. Map of grout volumes and hydraulic conductivities reduction factors. 


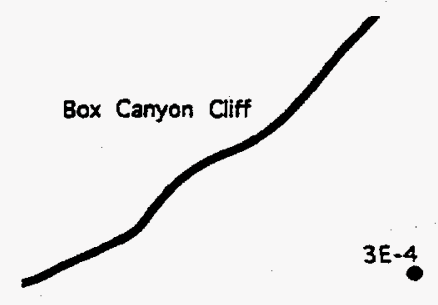

2E-3. $\quad \stackrel{3 E-5}{\square}$

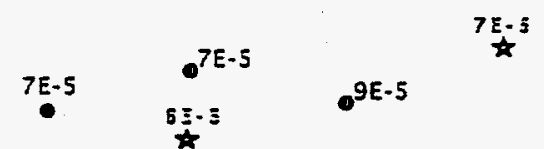

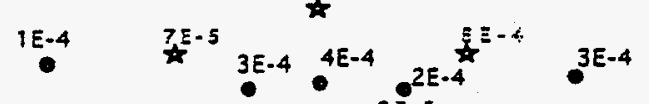

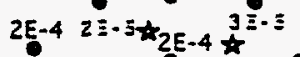

$3 \varepsilon-4$

$1 E-4$

$3 E-5 * T E-5: 3 E-4+5 E-4$

$3 E-4$

$4 E-4$

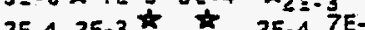

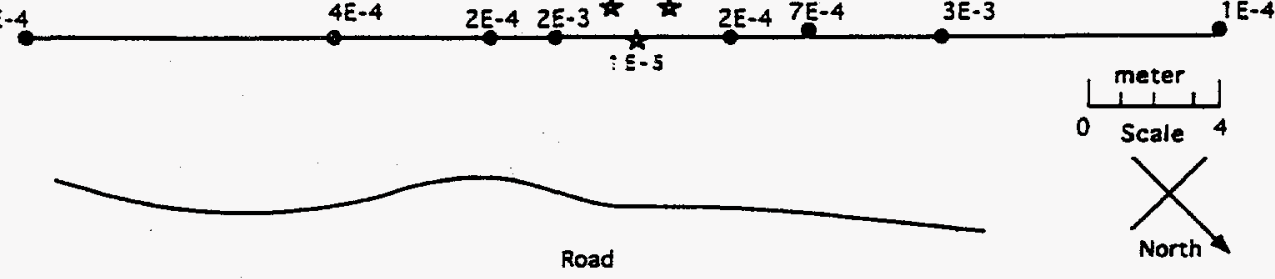

Figure 26. Map of average pre and post grout hydraulic conductivities.

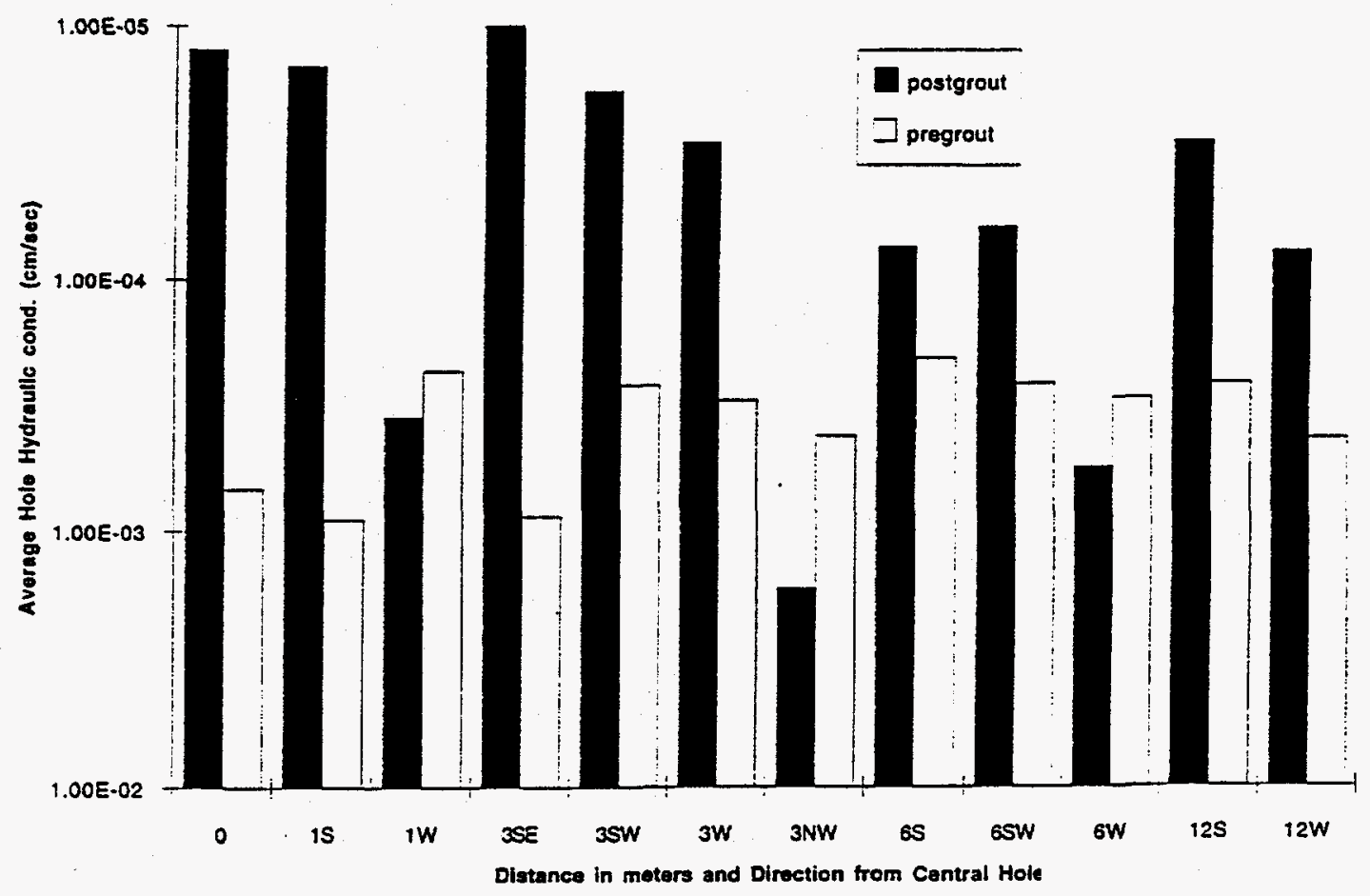

Figure 27. Pre and post grouting average hydraulic conductivity. 

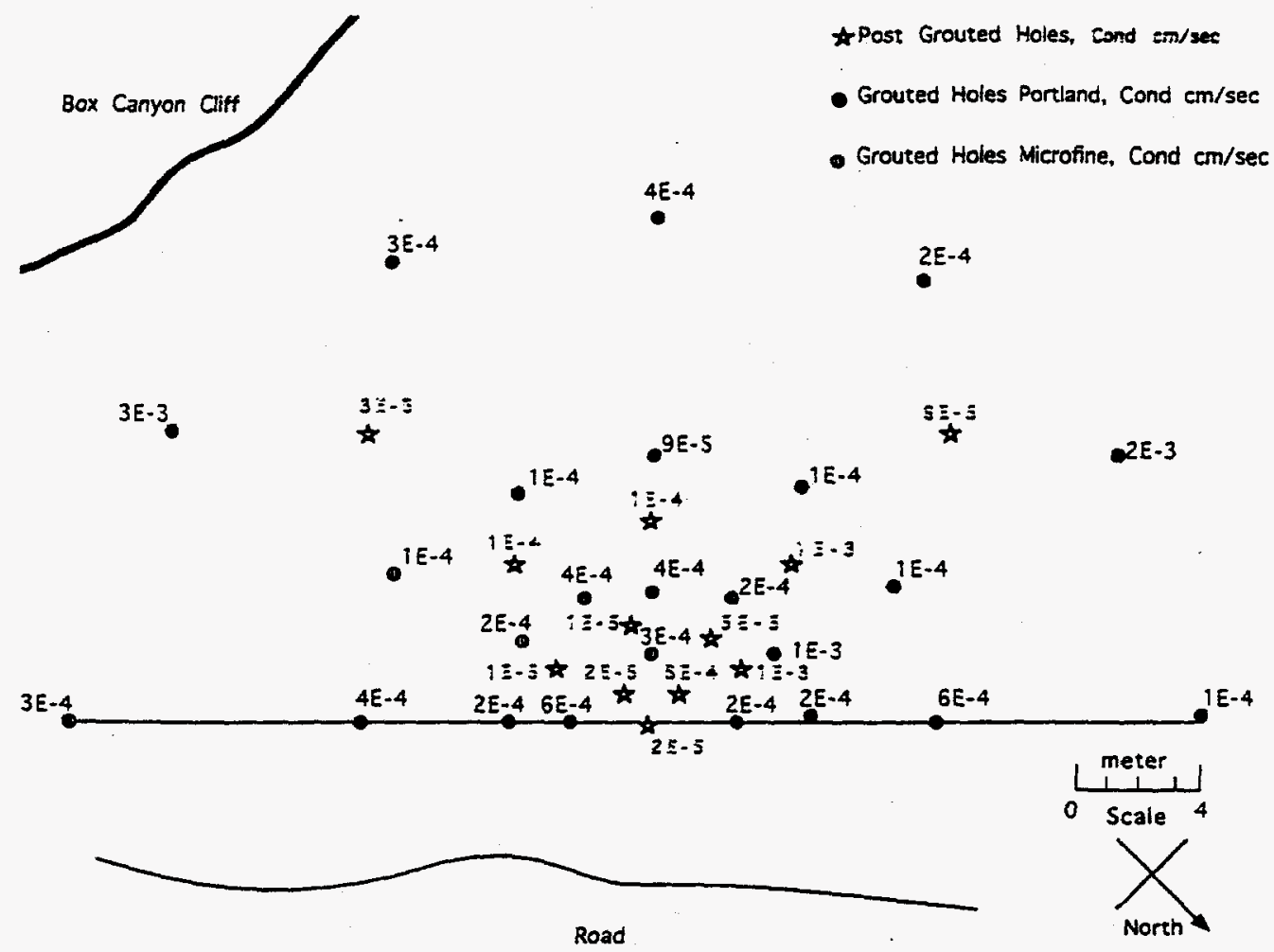

Figure 28. Comparison of pre and post grouting average hydraulic conductivity 4.5 meters deep.

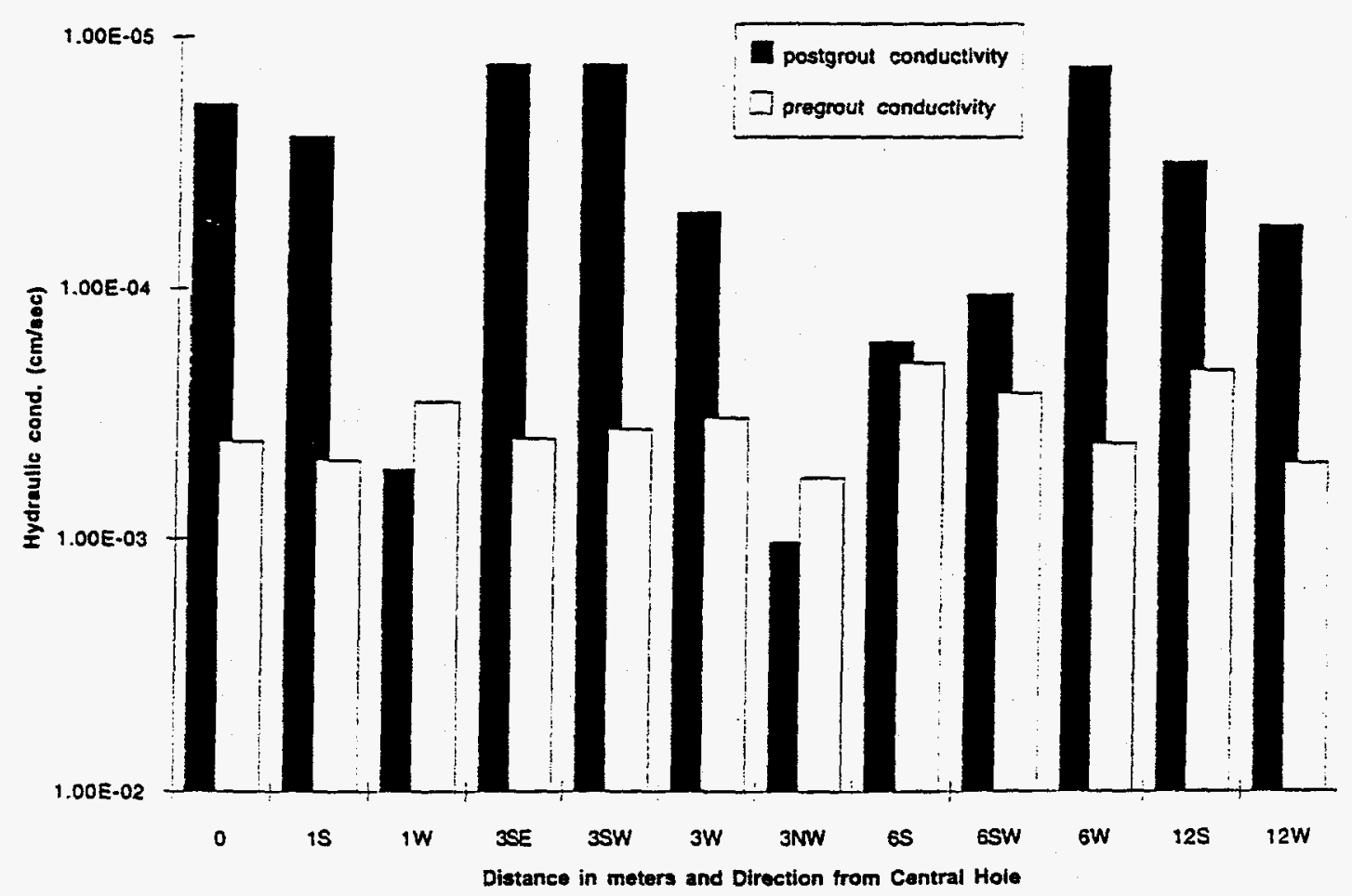

Figure 29. Map of pre and post grout hydraulic conductivities 4.5 meters deep. 

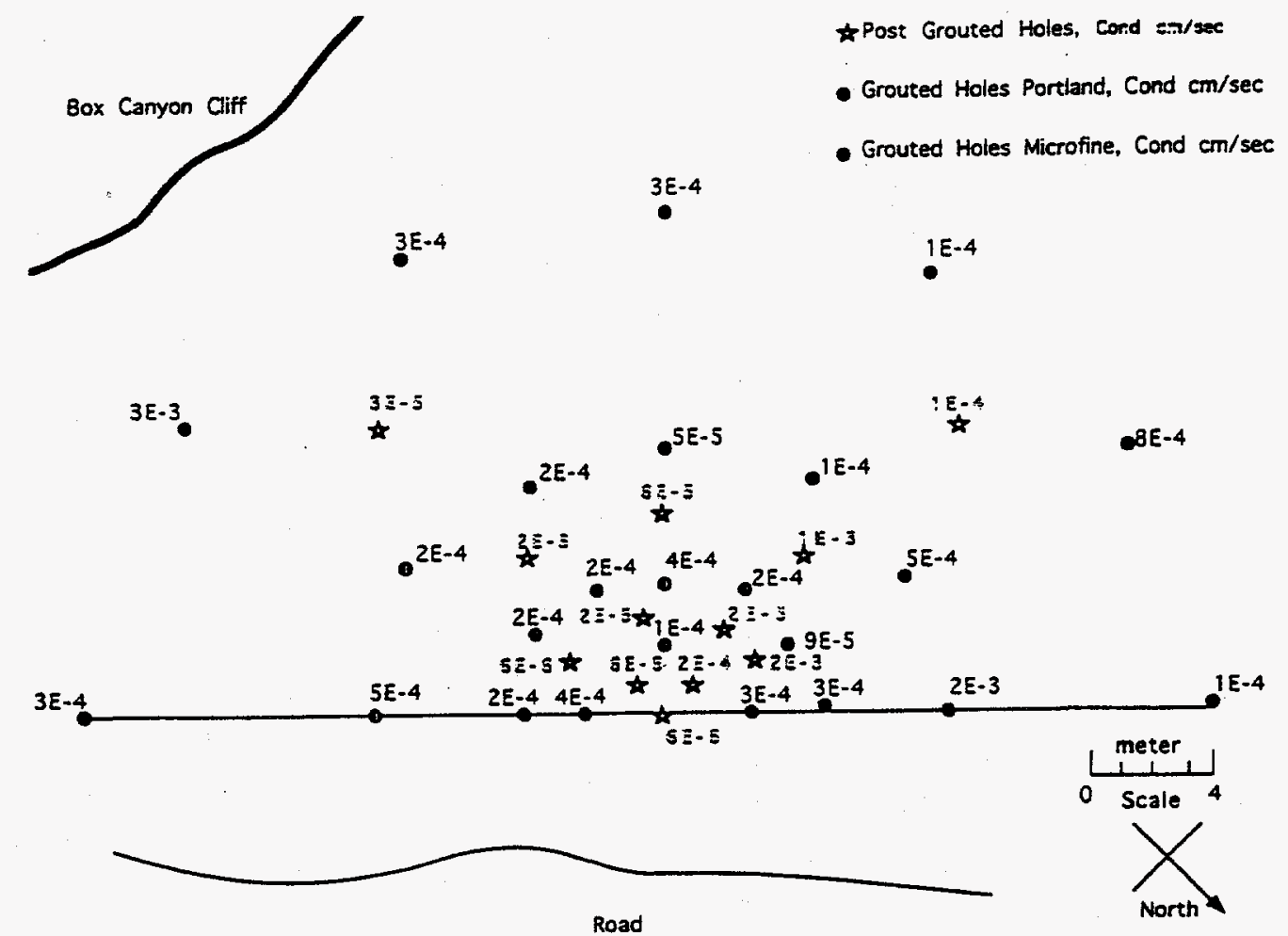

Figure 30. Map of pre and post grout hydraulic conductivities 5.8 meters deep.

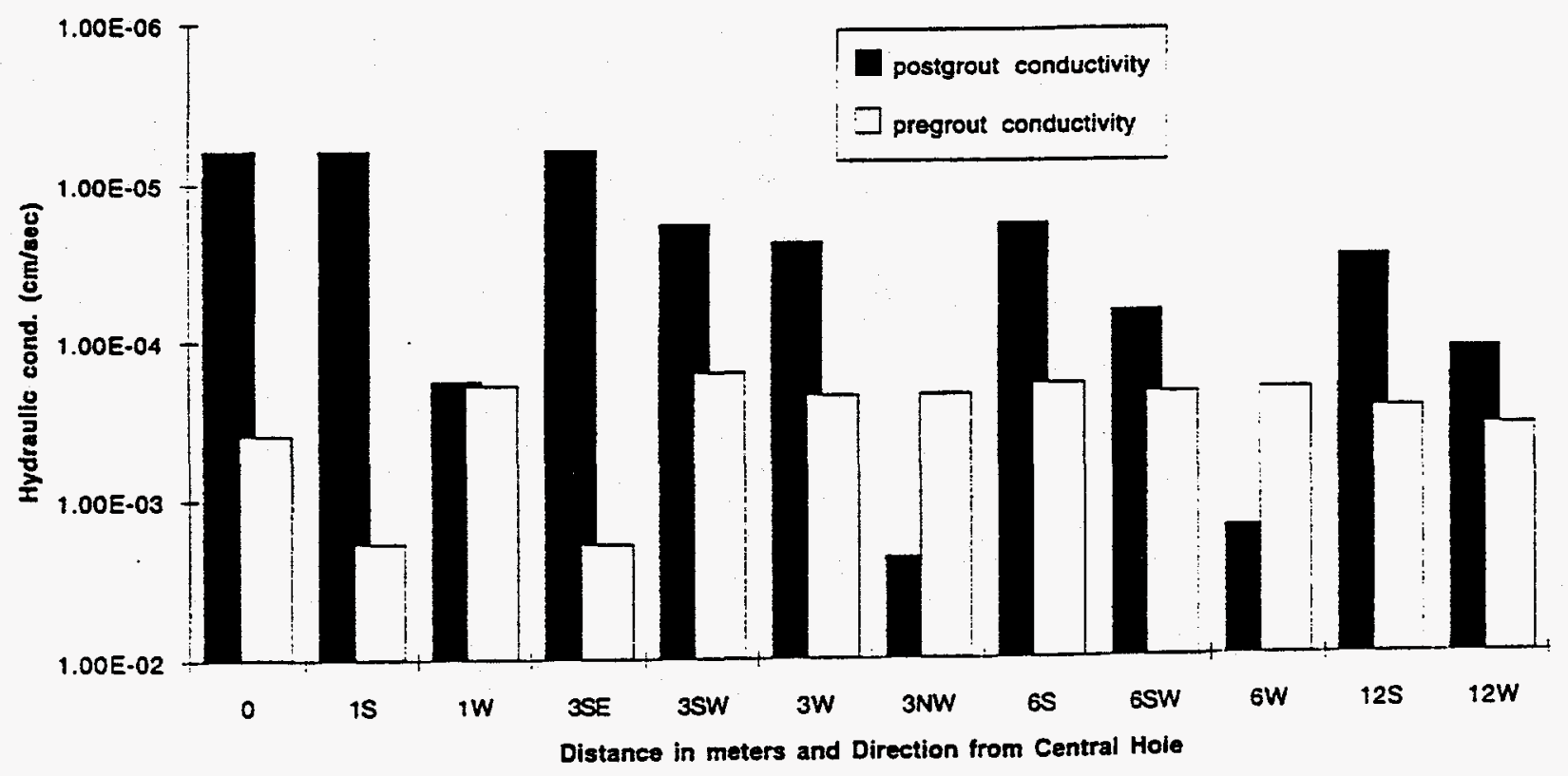

Figure 31. Comparison of pre and post grouting average hydraulic conductivity 5.8 meters deep. 


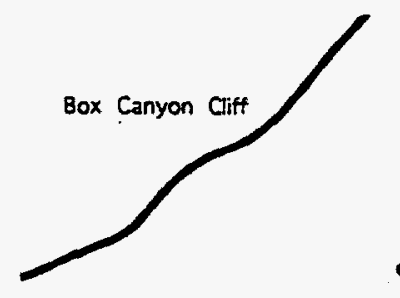

$\star$ Post Grouted Holes, Sond en/zex

- Grouted Holes Portland, Cond $\mathrm{cm} / \mathrm{sec}$

- Grouted Holes Microfine, Cond $\mathrm{cm} / \mathrm{sec}$ $2 E-4$

- $2 E-4$
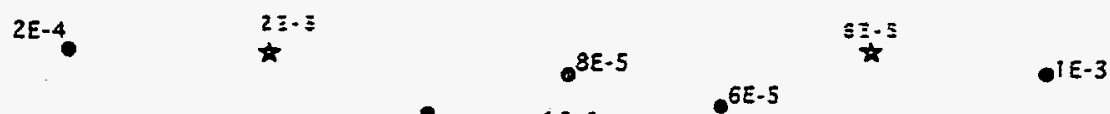

- $\star_{3 E-4}^{5-3} e^{5 E-4} e^{3 E-4} \hbar^{j E-4} e^{3 E-4}$

2E-4 $2 E-5 t_{2 E-4} t^{\mathrm{E}-3}$

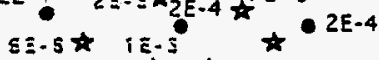

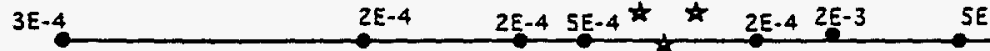

$5 E-3$ $8 E-5$
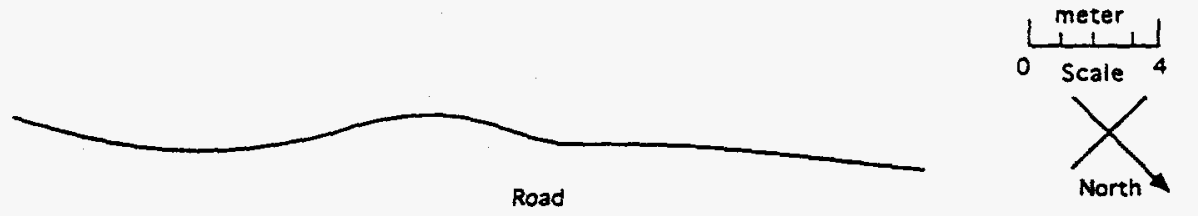

Figure 32. Map of pre and post grout hydraulic conductivities 7.1 meters deep.

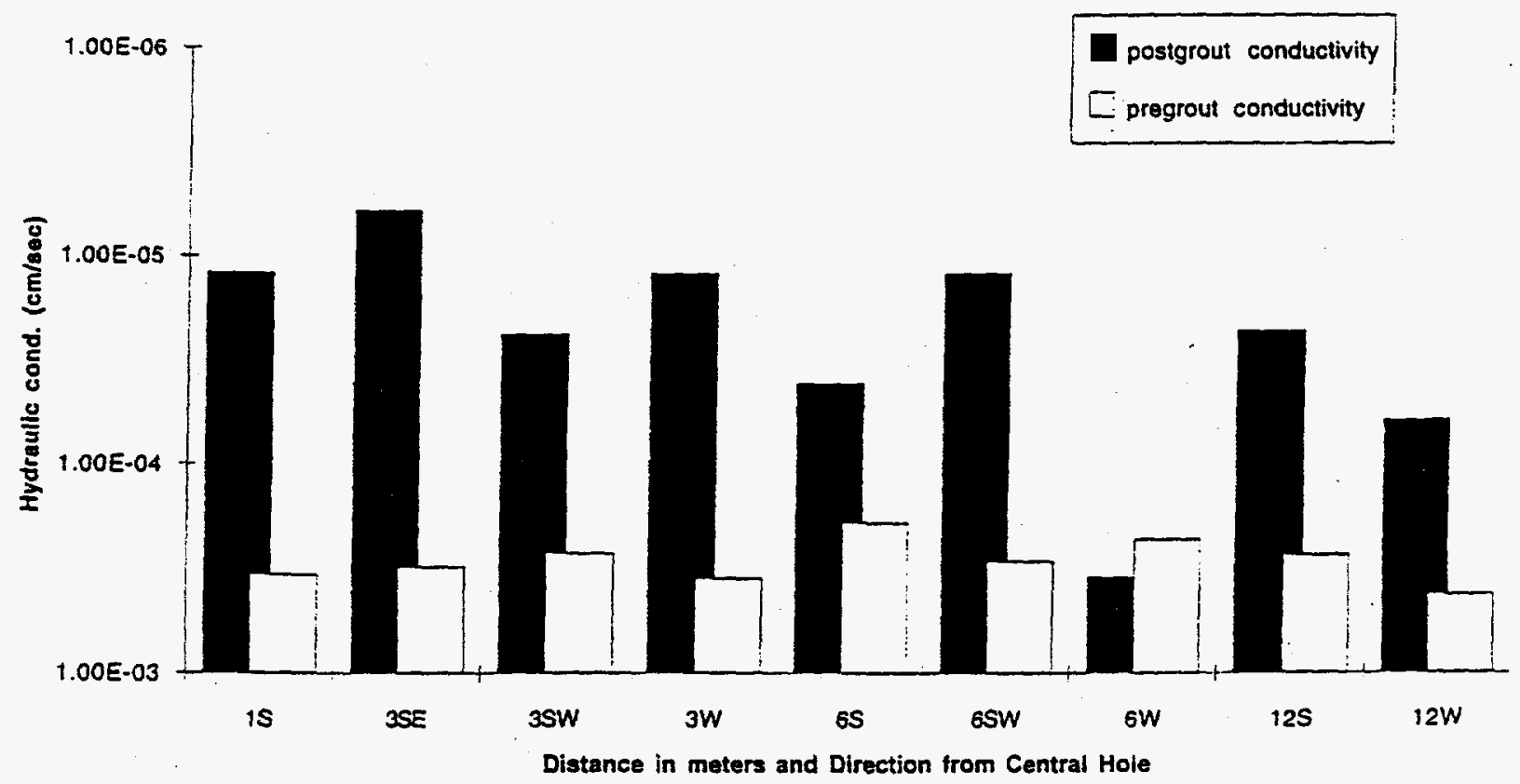

Figure 33. Comparison of pre and post grouting average hydraulic conductivity 7.1 meters deep. 
Overlapping or closer spaced grout holes might give some advantage, but the influence of a large void can overwhelm multiple high volume injections. However the close distance between the noreduction area and the maximum-reduction region indicate that over the entire site hydraulic conductivities reductions can be achieved if the connective fractures to the large void are filled.

Figures 34-37 attempt to illustrate this phenomenon. Hydraulic conductivities and percent reductions are graphed with the number and distance of grout injection points from the postgrouting hole. The results seem to indicate a downward flow of grout. It also seems that upper zones at 4.5 and 5.8 meters are unaffected by distance to grouting holes, while at the lower zone of 7.1 meters there is a much greater reduction. Conductivity is decreased even at a distance of 4 meters from the nearest grout injection point. Obviously the formation has a large role in these results. The consistency of conductivity values both before and after grouting 6 meters from the pivot and beyond seem to be ideal for this pressure grouting technique to reduce conductivity at greater distances or through less holes.

Table 6 and Figure 38 compare pre and post hydraulic conductivity values based on whether the surrounding holes were injected with Portland or Microfine cement. Nine holes were exclusively injected with Microfine cement, and 13 holes with Portland cement. Two holes had both types of cement injected; Portland cement at the lower depths (7.25 and 6 meters), and Microfine cement from 4.25 meters to the surface. Microfine cement was used in those sections of the boreholes that contain only small fractures, lacked extensive rubble zones, and had hydraulic conductivity generally below $4 \times 10^{-4} \mathrm{~cm} / \mathrm{sec}$.

Results show that Microfine cement generally achieves a higher reduction in hydraulic conductivity especially at middepths 4.1 and 5.8 meters. Microfine cement reduces conductivity of more competent basalt with a lower initial hydraulic conductivity starting point. Hydraulic conductivity values above $2 \times 10^{-3} \mathrm{~cm} / \mathrm{sec}$ cannot be reduced even with large quantities of Portland cement injected. The effect of downward creep can be seen on both grout types with the lowest values and reduction factors in the bottom of the holes beyond the 7-meter hole depth. Grouting below injection points will also be seen in core fracture analysis. Except for the 7.1-meter depth, the lowest values achieved overall were from Microfine cement grouted areas.

\subsection{Tracer Interpretation}

During boring of the postgrouting holes, samples were collected at 1.5-meter intervals as the drill descended and were analyzed for a UV sensitive tracer. The interpretation of the tracer data is problematic for two reasons: cross-contamination and natural substance sensitivity. Crosscontamination occurred as the drill contacted tracer and continued down the hole as it is bored along with the cuttings falling down the hole. There also are natural species in the calcite deposited in basalt that are sensitive to UV light. ${ }^{16}$ The samples were bottled and analyzed later in a laboratory with a UV light.

Results are tabulated as tracer present, absent, or present in trace amounts. Because of the difficulties in tracer detection, a method was devised to interpret the results. The method of quantitating these tracer results was to assign a $100 \%$ probability to those times tracer present in large amounts, $50 \%$ to those times tracer in trace amounts, and $0 \%$ to the time tracer was not found at all in a particular cutting sample. These values were then averaged by hole or by depth to generate bar graphs shown in Figures 39 and 40 . Each figure gives the relative percentage that tracer and therefore grout contacted that section of the postcoring holes. These results are then grouped by depth or by hole.

At least a trace of some UV active substance was found at every depth and in every hole but one, which was the cutting at the 4-meter depth of the hole located 3 meters from the pivot along the D Lateral southwest from the pivot labeled P5 in Figure 6. Figure 40 shows three holes that overall had less than $70 \%$ likelihood of tracer from grout present. This hole (P5) along with the next one 


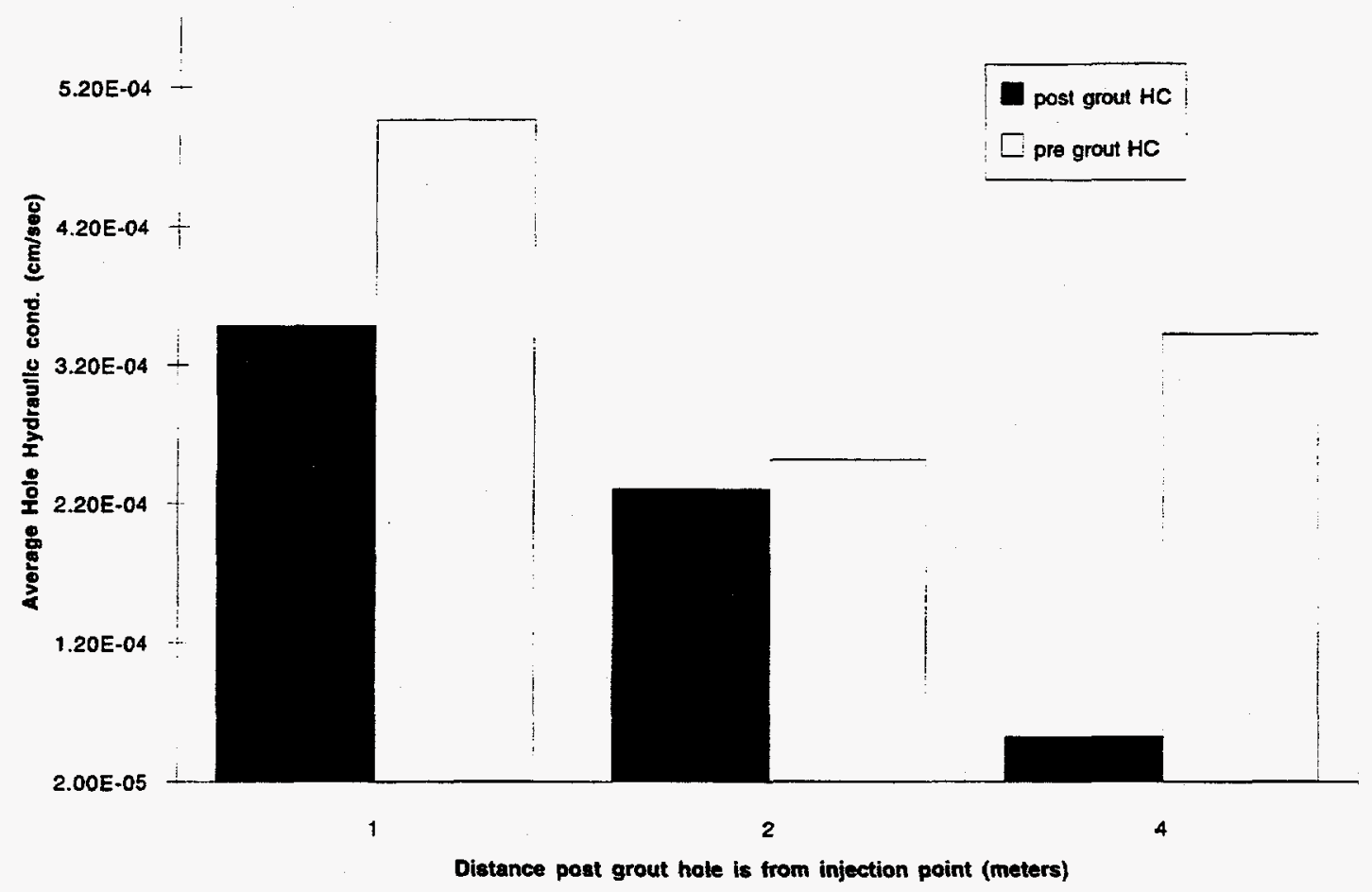

Figure 34. Comparison of average hydraulic conductivities based on mean distance from pressure grouting holes.
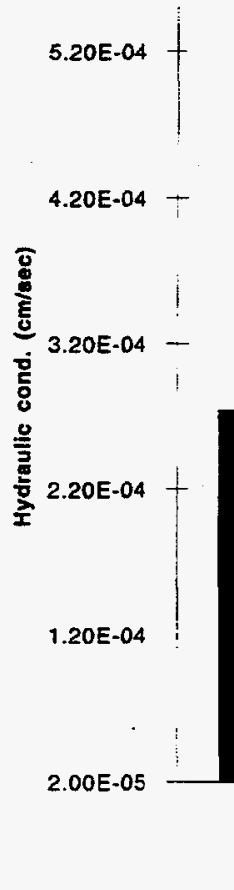

$$
\begin{aligned}
& \square \text { post grout HC } \\
& \square \text { pre grout } H C
\end{aligned}
$$




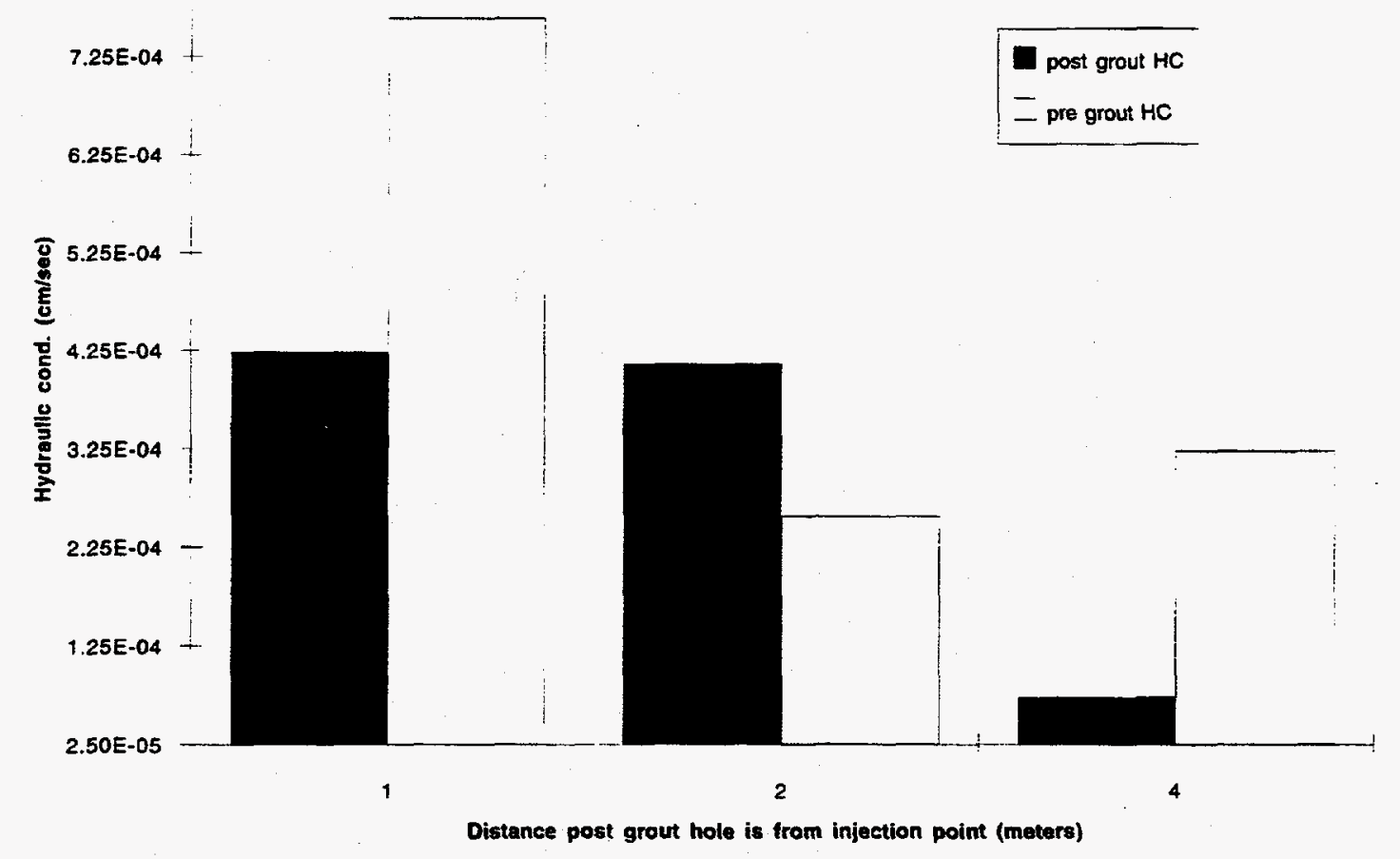

Figure 36. Comparison of hydraulic conductivities 5.8 meters deep based on mean distance from pressure grouting holes.

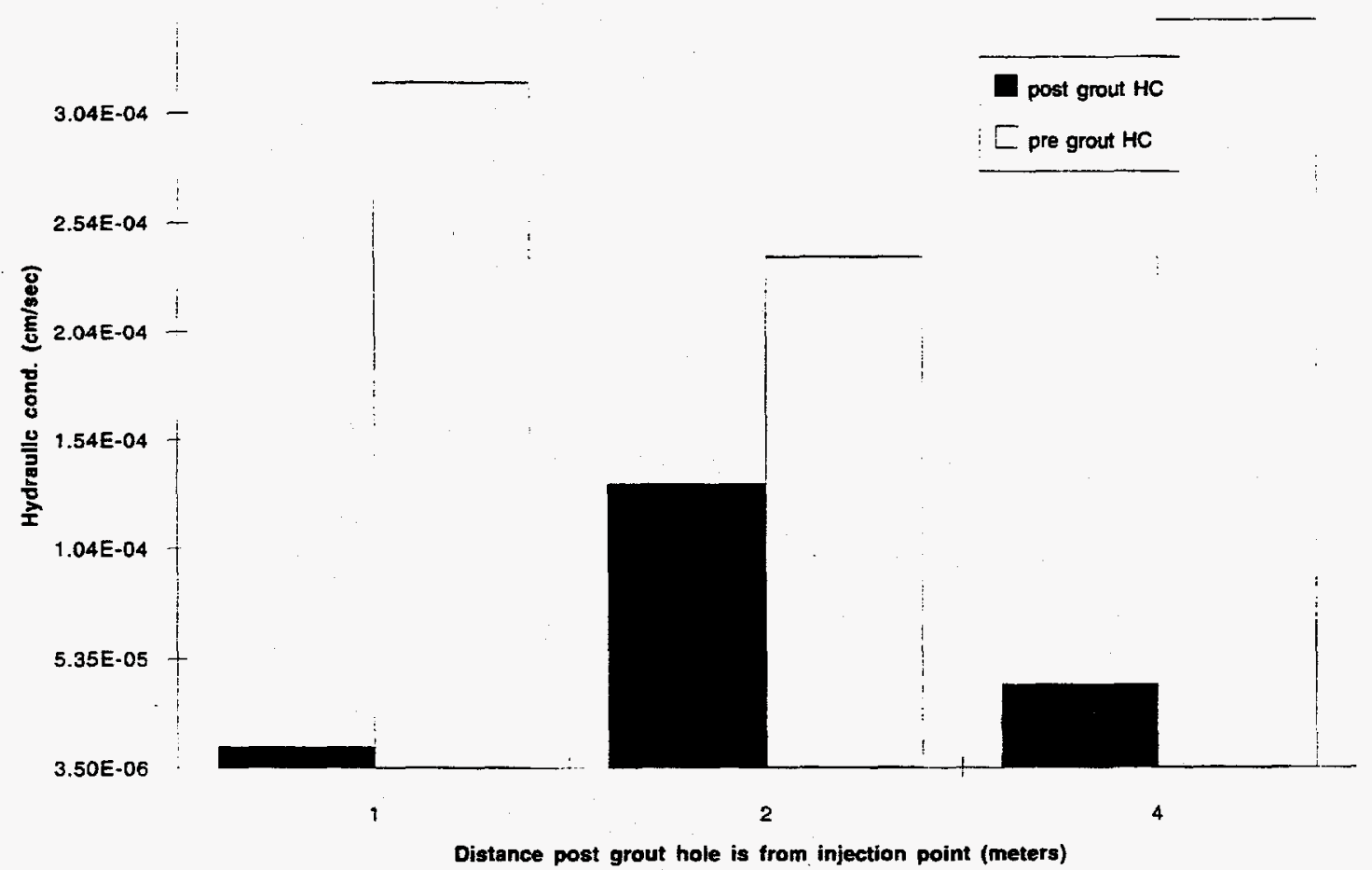

Figure 37. Comparison of hydraulic conductivities 7.1 meters deep based on mean distance from pressure grouting holes. 
Table 6. Hydraulic conductivity reduction by grout type.

\begin{tabular}{|c|c|c|c|c|c|}
\hline $\begin{array}{c}\text { Cement } \\
\text { Type }\end{array}$ & $\begin{array}{l}\text { Depth } \\
\text { meters }\end{array}$ & All & 4.5 & 5.8 & 7.1 \\
\hline & & \multicolumn{4}{|c|}{ Hydraulic Conductivity Reduction Factors } \\
\hline Portland & & 1.3 & 1.8 & 1.3 & 10.5 \\
\hline Microfine & & 2.2 & 2.6 & 1.6 & 3.7 \\
\hline \multicolumn{6}{|c|}{ Hydraulic Conductivity, $\mathrm{cm} / \mathrm{sec}$} \\
\hline Portland & pre & $5.3 \times 10^{-4}$ & $4.2 \times 10^{-4}$ & $6.3 \times 10^{-4}$ & $3.1 \times 10^{-4}$ \\
\hline Portland & post & $3.6 \times 10^{-4}$ & $2.3 \times 10^{-4}$ & $4.9 \times 10^{-4}$ & $3.0 \times 10^{-5}$ \\
\hline Microfine & pre & $3.5 \times 10^{-4}$ & $3.3 \times 10^{-4}$ & $4.4 \times 10^{-4}$ & $2.8 \times 10^{-4}$ \\
\hline Microfine & post & $1.6 \times 10^{-4}$ & $1.3 \times 10^{-4}$ & $2.7 \times 10^{-4}$ & $7.5 \times 10^{-5}$ \\
\hline
\end{tabular}

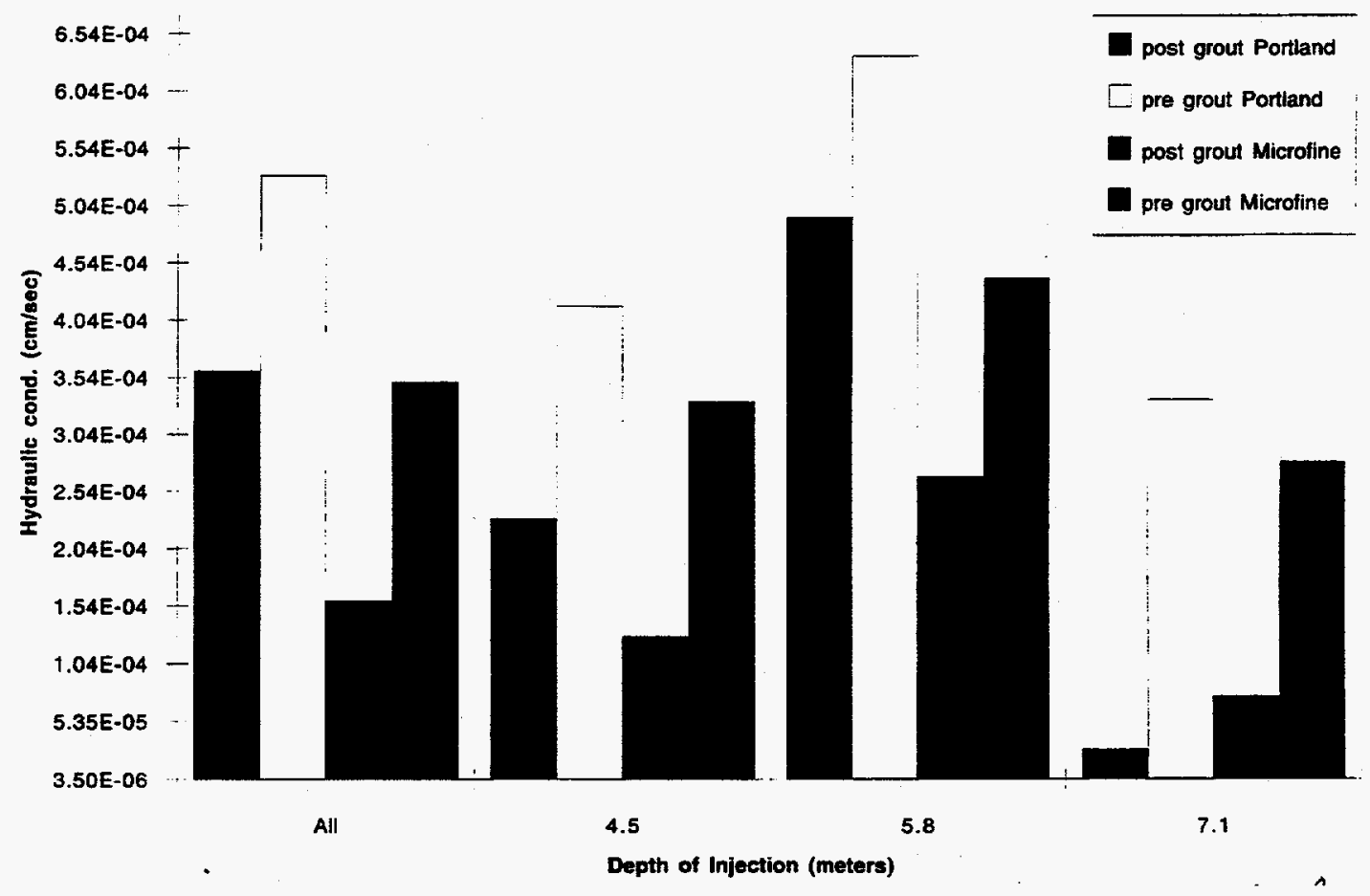

Figure 38. Grout selection effect on hydraulic conductivity. 


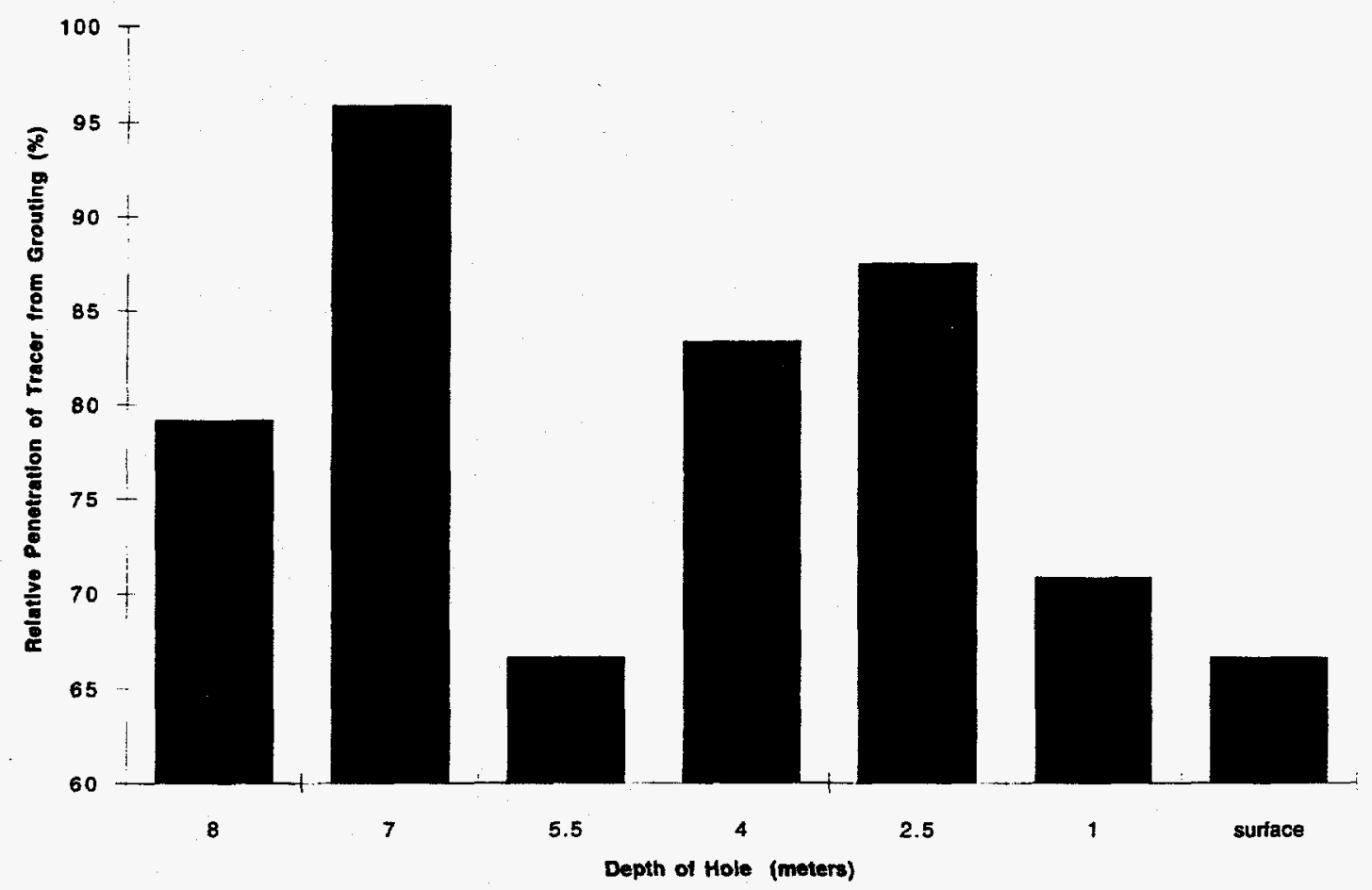

Figure 39. Borehole chip tracer presence by depth.

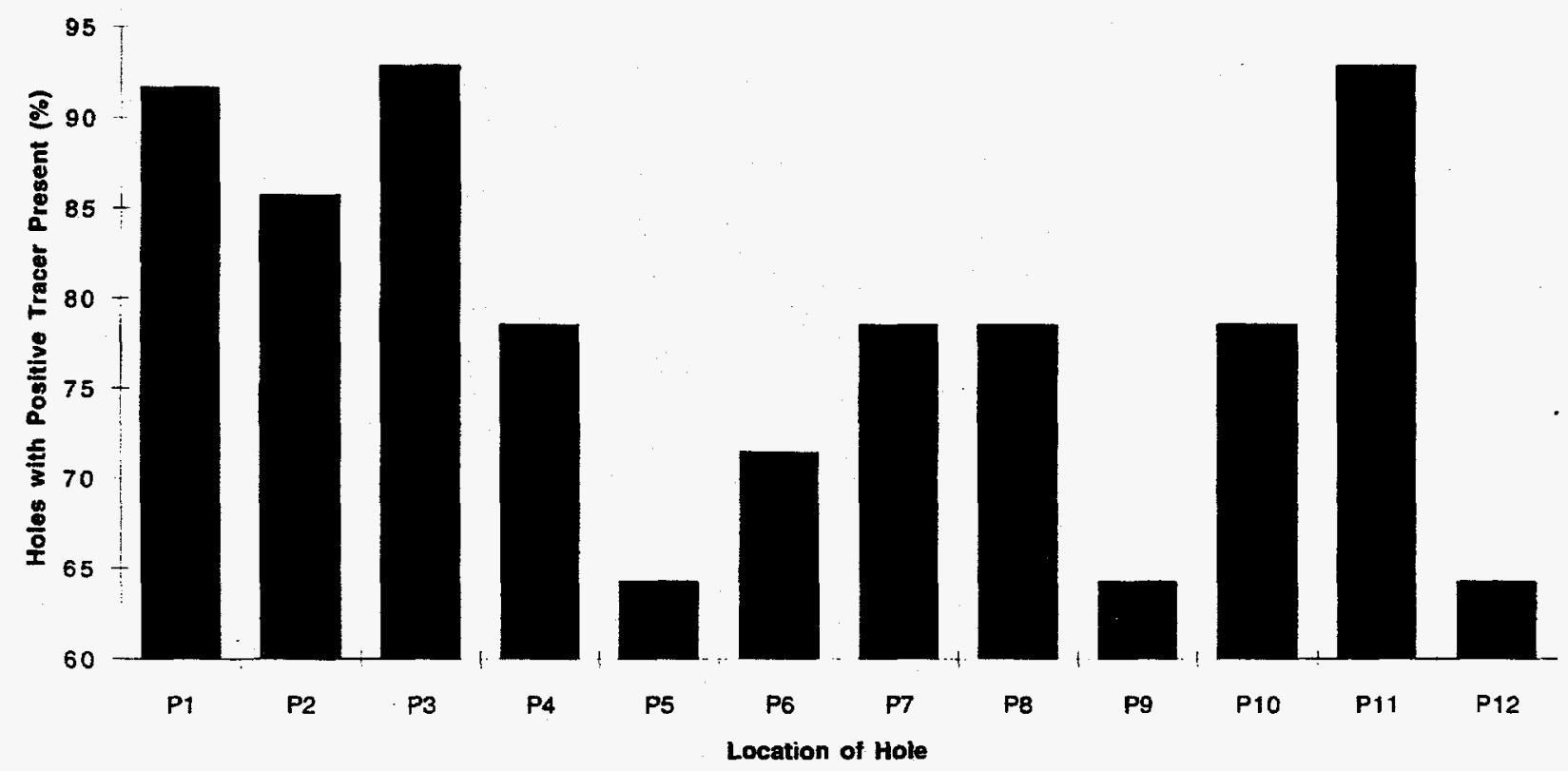

Figure 40. Borehole chip tracer presence by hole. 
along this lateral [6 meters out (P9)], and one hole 12 meters out west of the pivot (P12) had the lowest probability of tracer being genuine and grout having penetrated that region. The area immediately around these holes did not generally show significant grout in fractures from subsurface cores (discussed in the next section). However, hydraulic conductivity reduction factors of 14 , 4.1, and 5.9 were achieved for these holes.

The general direction northwest of the pivot toward one of these holes (P12) along the F Lateral is the region with highest grout takes and in two instances, no conductivity reductions in postgrout holes were noted. This region seems to correspond to a large void or rubble zone between two lava flows at the 5-meter depth. Figure 39 reveals a lower percentage of grout tracer likely at this depth. This percentage is similar to that of tracer at the surface. Surface results should be the most reliable and least likely to be crosscontaminated. The surface also would likely be the area of lowest grout penetration. Lack of tracer at the 5-meter depth might also confirm that it is not high grout volume injected that directly brings a decrease in conductivity, but the filling of specific conduit voids. Large conduits for water transmission might require more than large quantities of grout such as some method of plugging the void if consistent hydraulic conductivity reduction is to be achieved for a large area of basalt.

\subsection{Downhole Radar, Surface Permeability, and Cross-Hole Subsurface Postgrouting Core Data}

Borehole radar surveys were carried out in the fractured vadose zone basalt of the Box Canyon Site as shown in Figure 5. A well from past studies, (H1) was used during grouting borehole drilling. Two of the newly drilled grouting boreholes [H2 (16a), H3 (16b)] were also surveyed. These same holes were used to evaluate radar frequency electromagnetics in the characterization of the fractured basalt and to evaluate its capability to track the downward flow or linkage in the vadose zone fractures.

Signals over 20 meters distance were interpretable. Well-to-well tomograms indicated an additional lava flow finger and were also used to follow infiltration through the boundaries of two major lava flows. Successive tomograms indicated the increasing sized area in the water infiltration zone. The borehole radar was capable of detecting water leaking from a nearby surface source in the fractured basalt zone.

Other hydraulic conductivity measurements corroborate the flows measured here. Results from a surface infiltration tests were obtained near a lava flow boundary ${ }^{3} 2$ meters southeast of Hole 16 A. A 2-meter pool was set up above and 3 meters southeast of this boundary. Flows determined over a 3-hour period gave a conductivity of $0.27 \mathrm{gpm} / \mathrm{ft}^{2} / \mathrm{ft}$-head water, which is approximately $5 \times 10^{-3} \mathrm{~cm} / \mathrm{sec}$ based on the surface area of basalt covered by the pool. The water plume movement was followed by radar and moved to the juncture of two major lava flows. The two highest hydraulic conductivities found in boreholes in this lava flow were about the same within in measurement uncertainty $\left(2 \mathrm{~A}, 3.8 \times 10^{-3}\right.$, and $8 \mathrm{G}, 5.3 \times 10^{-3} \mathrm{~cm} / \mathrm{sec}$ ). The conductivity of Hole $2 \mathrm{~A}$ was measured at 6 meters and Hole $8 \mathrm{G}$ was measured at 7.1 meters below the surface. This is apparently the same large rubble zone encountered between lava flows, which runs directionally in a straight line 14 and 24 meters north-northwest (parallel to the road) of the infiltration test. This test is just outside the area defined by boreholes of the monolithic confinement test. The map (Figures 5 and $5 a$ ) shows the location of the test and a sketch of the lava flows. The P11 testhole in this area seemed to have its hydraulic conductivity reduced by the grouting 4 meters away in holes $16 \mathrm{~b}, 16 \mathrm{c}, 8 \mathrm{~b}$, and $8 \mathrm{c}$.

Figures 6 and 41 show the locations of the seven coreholes that were water drilled at an angle, (C 1-7) and the one vertical hole, air drilled corehole $\mathrm{C} 11$. The traverse horizontal distance is approximated on the map. These cores were taken a year after the grouting, radar mapping, and 


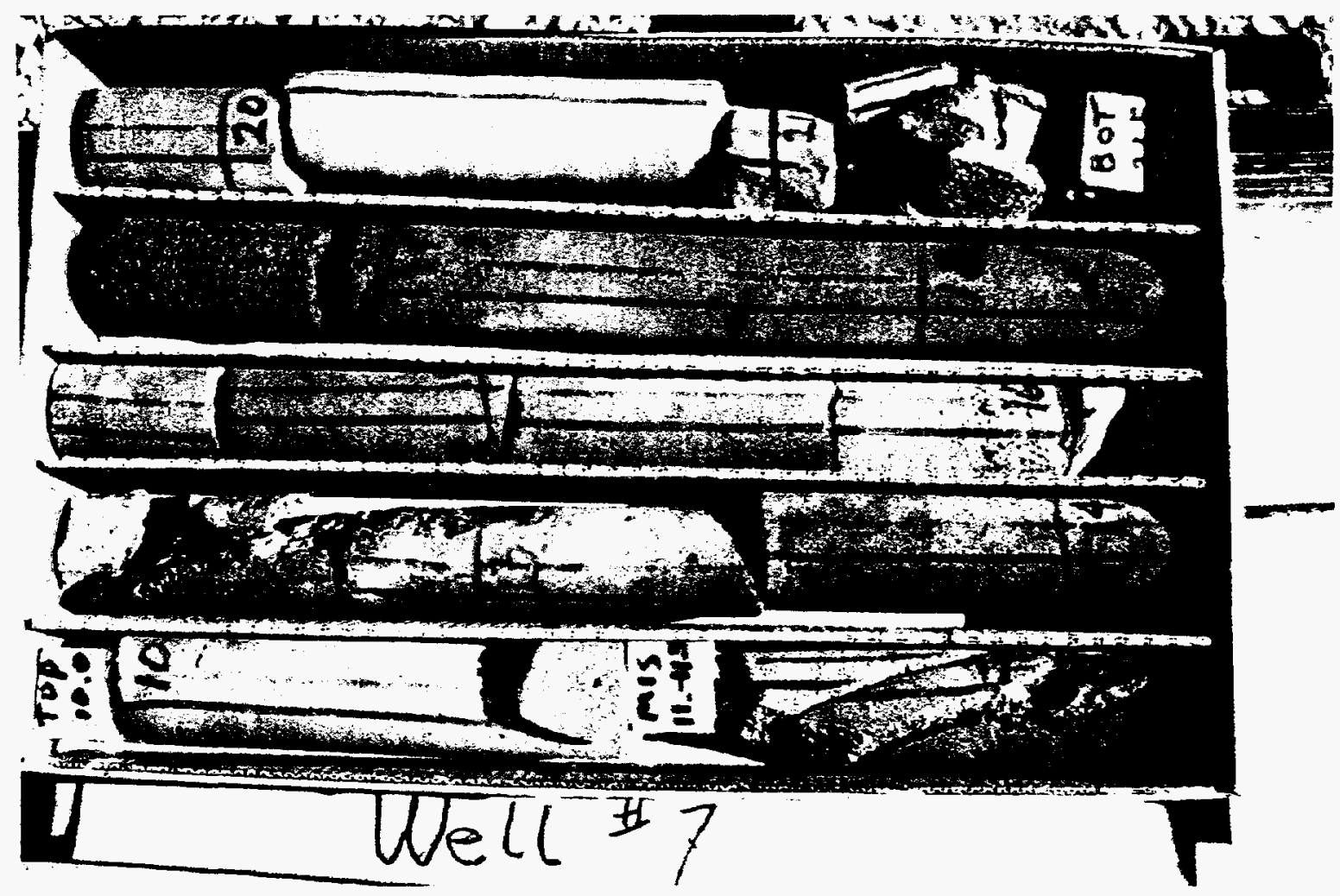

Figure 41. Core C-7 at 4-7 meter depth showing near vertical fractures.

surface infiltration test. Holes $\mathrm{C} 1$ and $\mathrm{C} 2$ angling south are within 2 meters of four grout injection points. Holes $\mathrm{C} 3$ and $\mathrm{C} 4$ angling southwest, hole C5 angling northwest, and hole C6 angling southeast, and hole $\mathrm{C} 11$ straight down are within 3 meters of two grout injection holes. Hole C7 starts 1 meter from one injection hole.

Figures $41-42$ show the $\mathrm{C} 7$ core, taken near but angling away from injection hole $16 \mathrm{a}$. Three to 8 meters of this core is shown. Diagonal rough type fractures seen in the figure are actual fractures in the basalt whereas short smooth perpendicular ones are usually caused by the drilling process. The former fractures were used in the analysis of fractures/foot of core and percent fracture filled with cement to quantitate grout penetration. Close-up photographs (Figures 43-46) of portions of core C-7 highlight fractures of interest. Figure 44 shows a fracture filled partially with Portland cement and sediment. Figures 45 and 46 show what appears to be Microfine cement fracture filling; the bluer, gray material is found along with sediment, Portland cement (gray), and cal- cite (white material). The use of water and air in the drilling did seem to remove and weaken some of the cement in the fractures. This phenomenon was observed as a portion of core C-3 was removed and the cement crumbled away from the fracture it had filled.

Photographs of the orientated air drilled Core C-11 from the 4 meter to 8.4-meter depth are shown in Figures 47 and 48 . Generally, the basalt is competent with some vesicular pockets at the end of the core for 7 to 8.7 meters. The red and blue lines mark the orientation line. Close-up photographs (Figures 49-51) show the filling of some of the finer fractures found in generally competent basalt. The directional aspect of the core helps envision the entrance side of the grout and why some fractures were partially filled. Figure 51 illustrates grout penetrating a narrow fracture pushing sediment ahead.

Fracture data were compiled at the different depths from a visual inspection of the cores as has been described previously. The fracture density was calculated by counting the total number of 


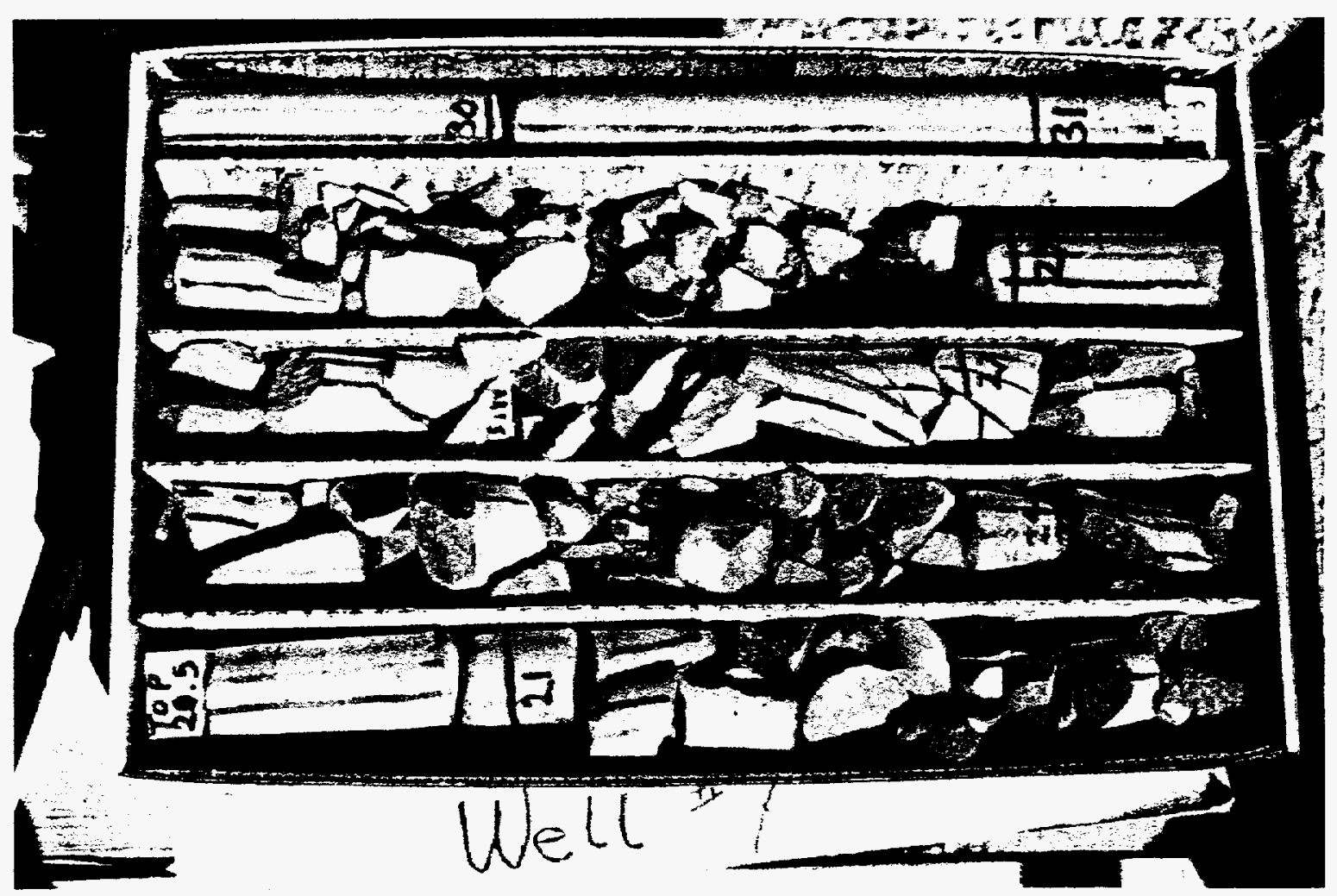

Figure 42. Core $\mathrm{C}-7$ at the $7-10$ meter depth showing rubblized zone.

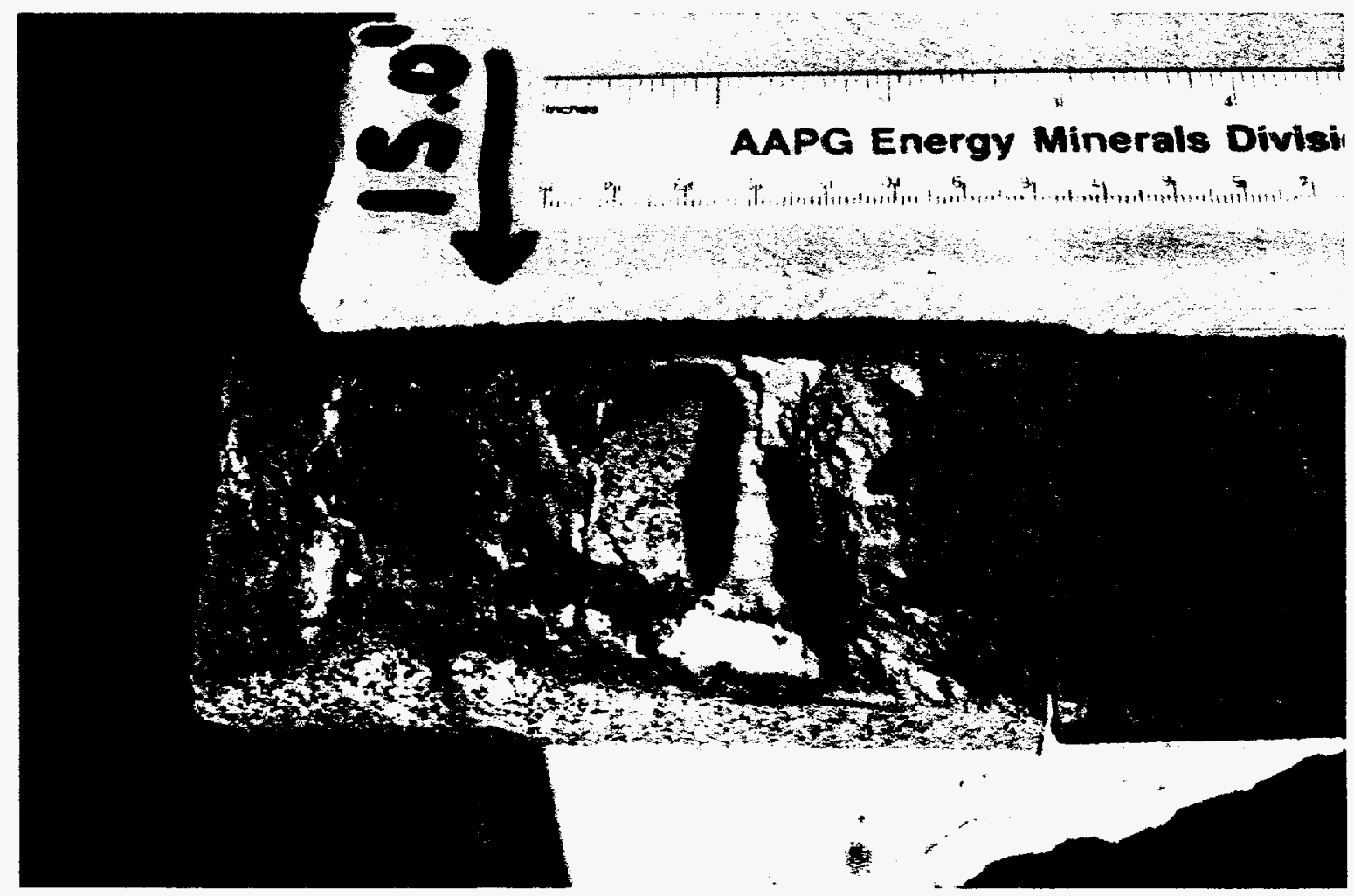

Figure 43. Close up core fragment showing portland grout penetration. 


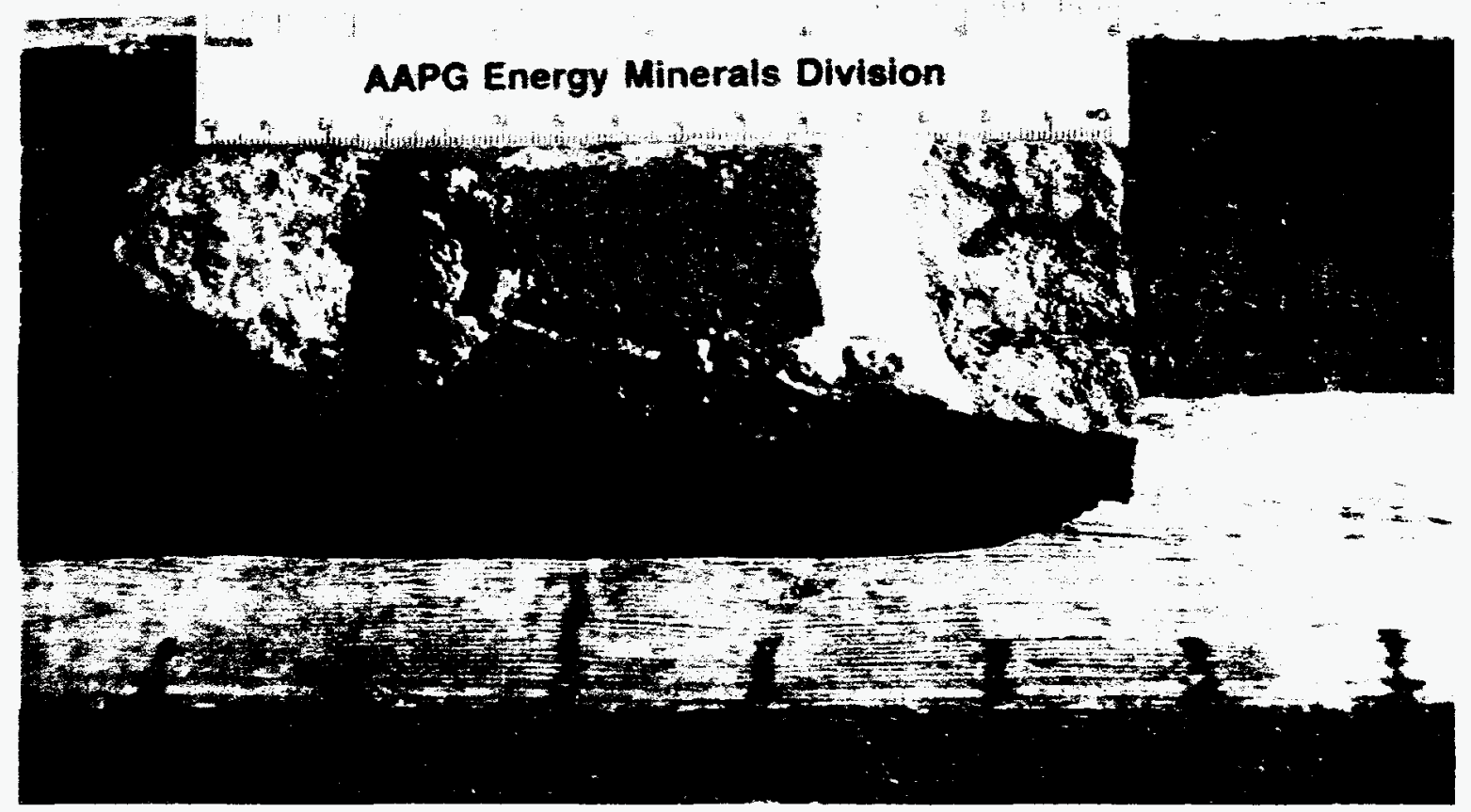

Figure 44. Close up core fragment showing microfine grout penetration.

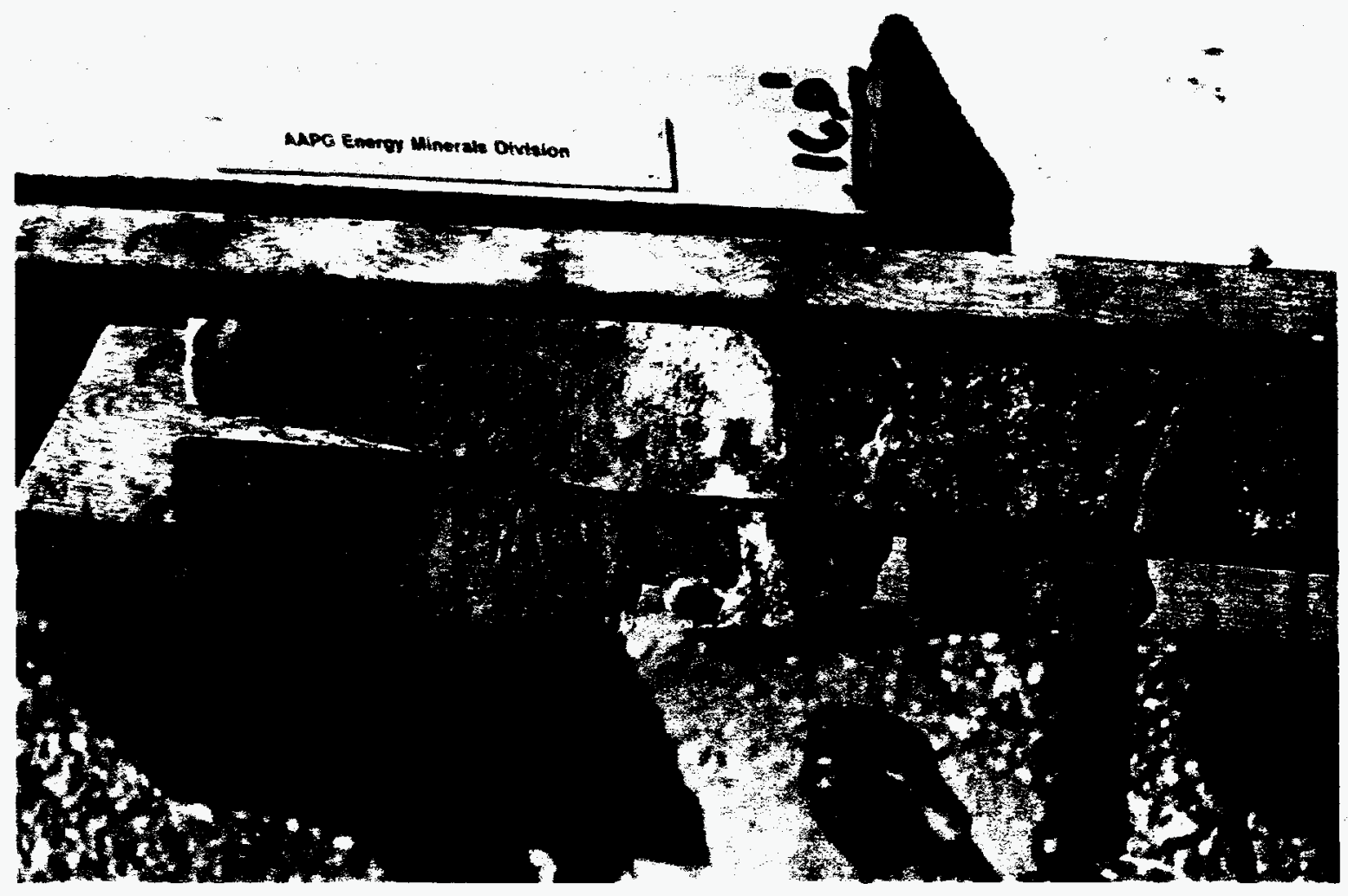

Figure 45. Close up core fragment showing grout and sediment 


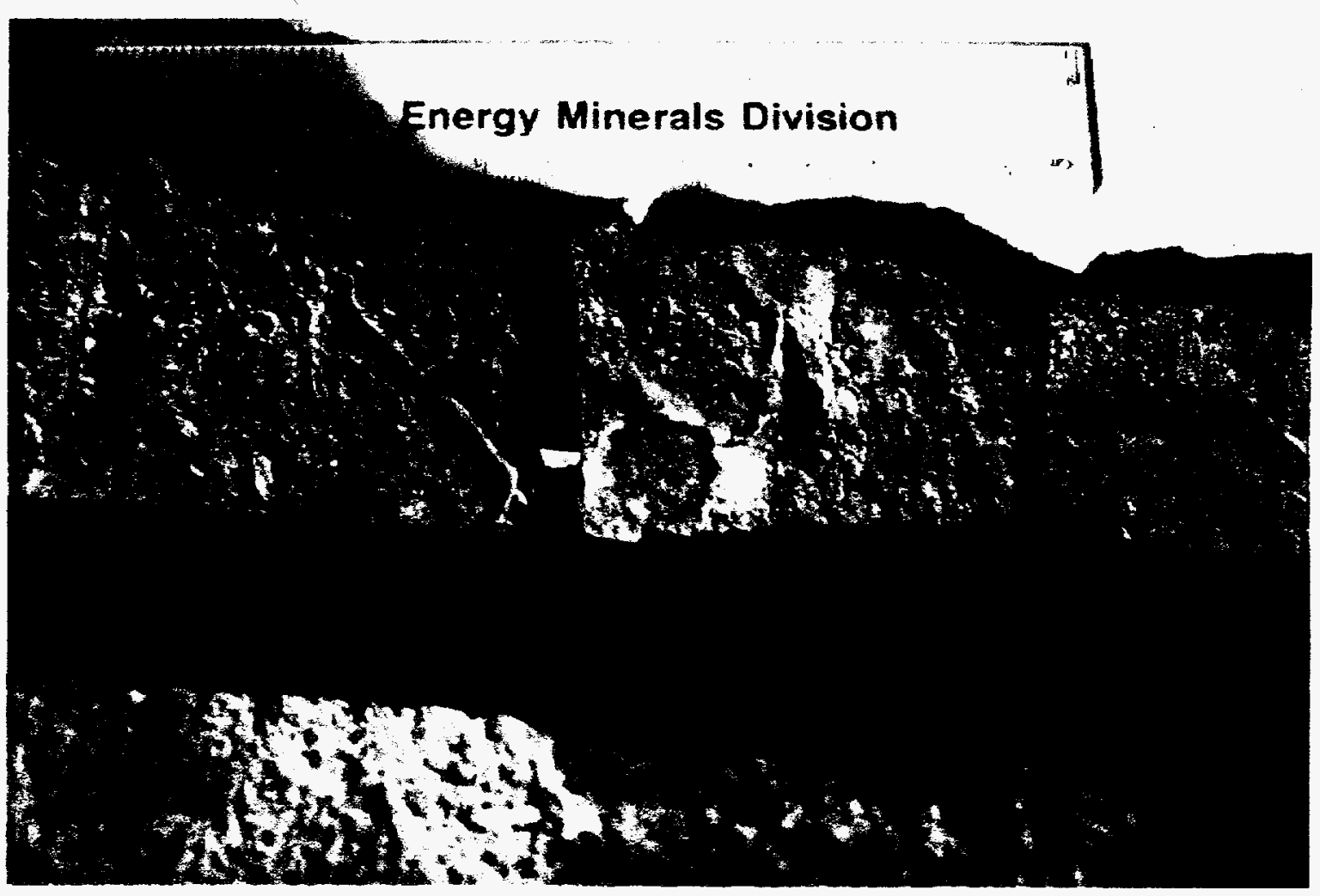

Figure 46. Close up core fragment showing partial grout filling.

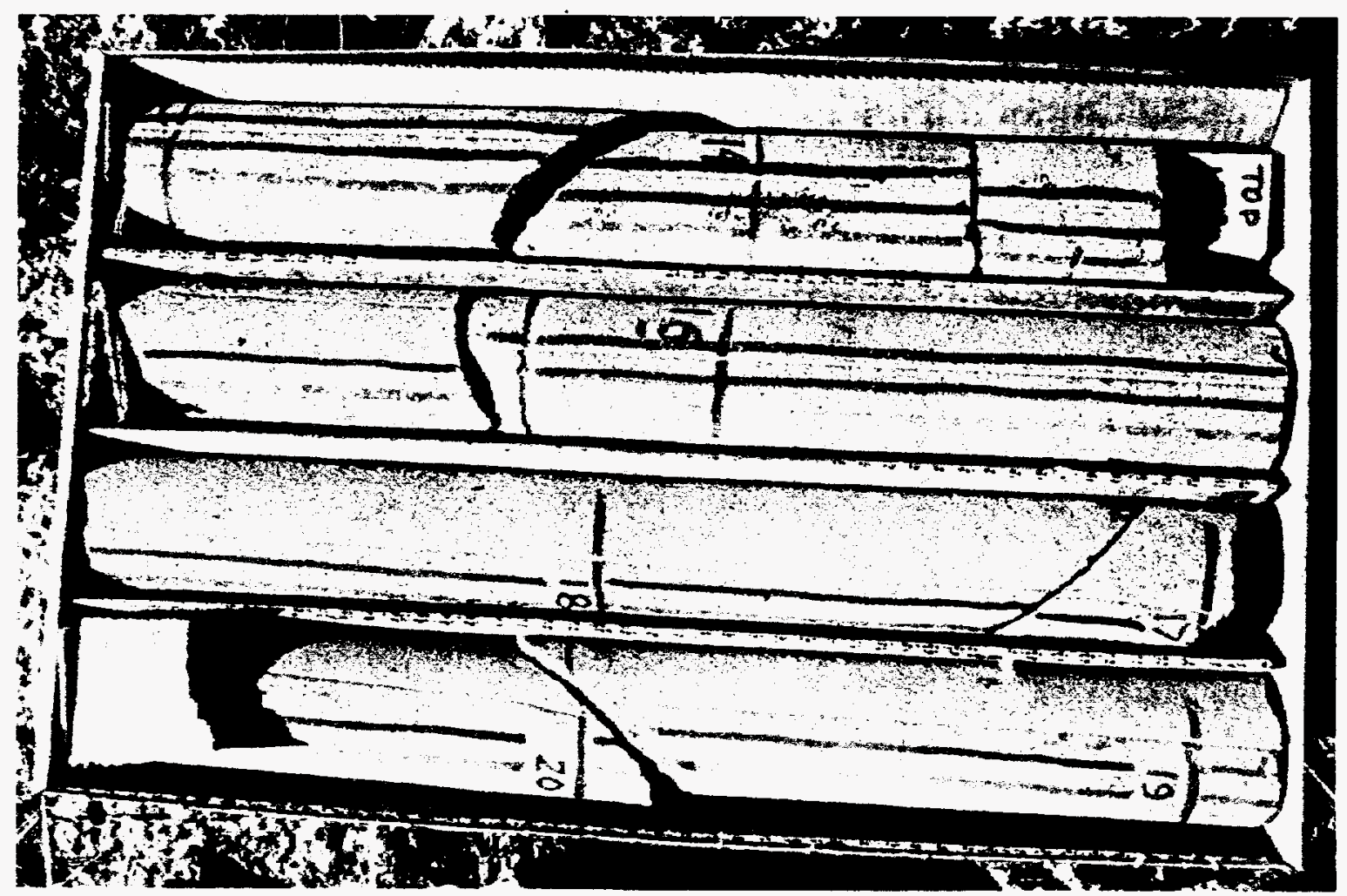

Figure 47. Competent Basalt core C-11 4-7 meter depth. 


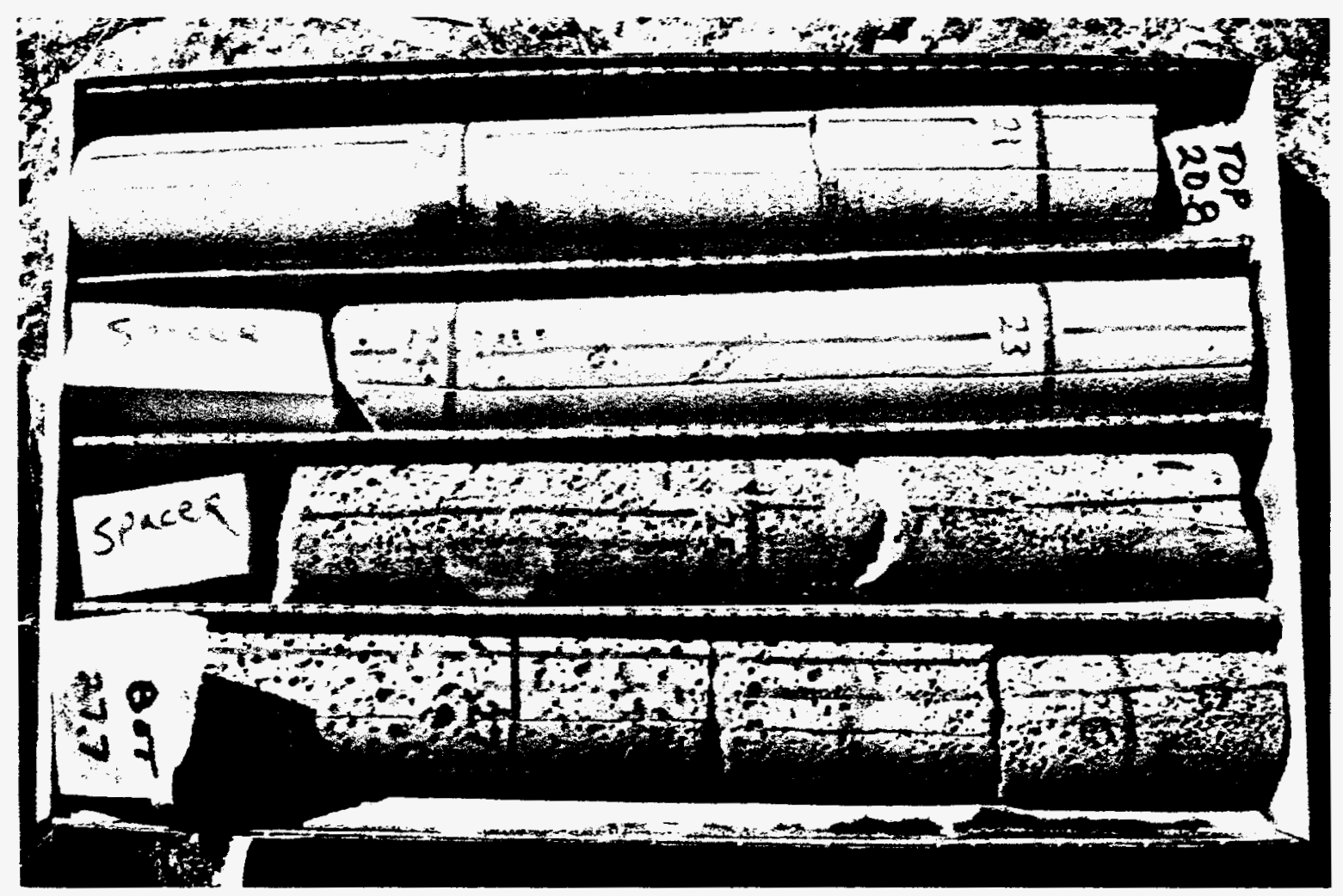

Figure 48. Competent Basalt core C-11 7-9 meter depth.

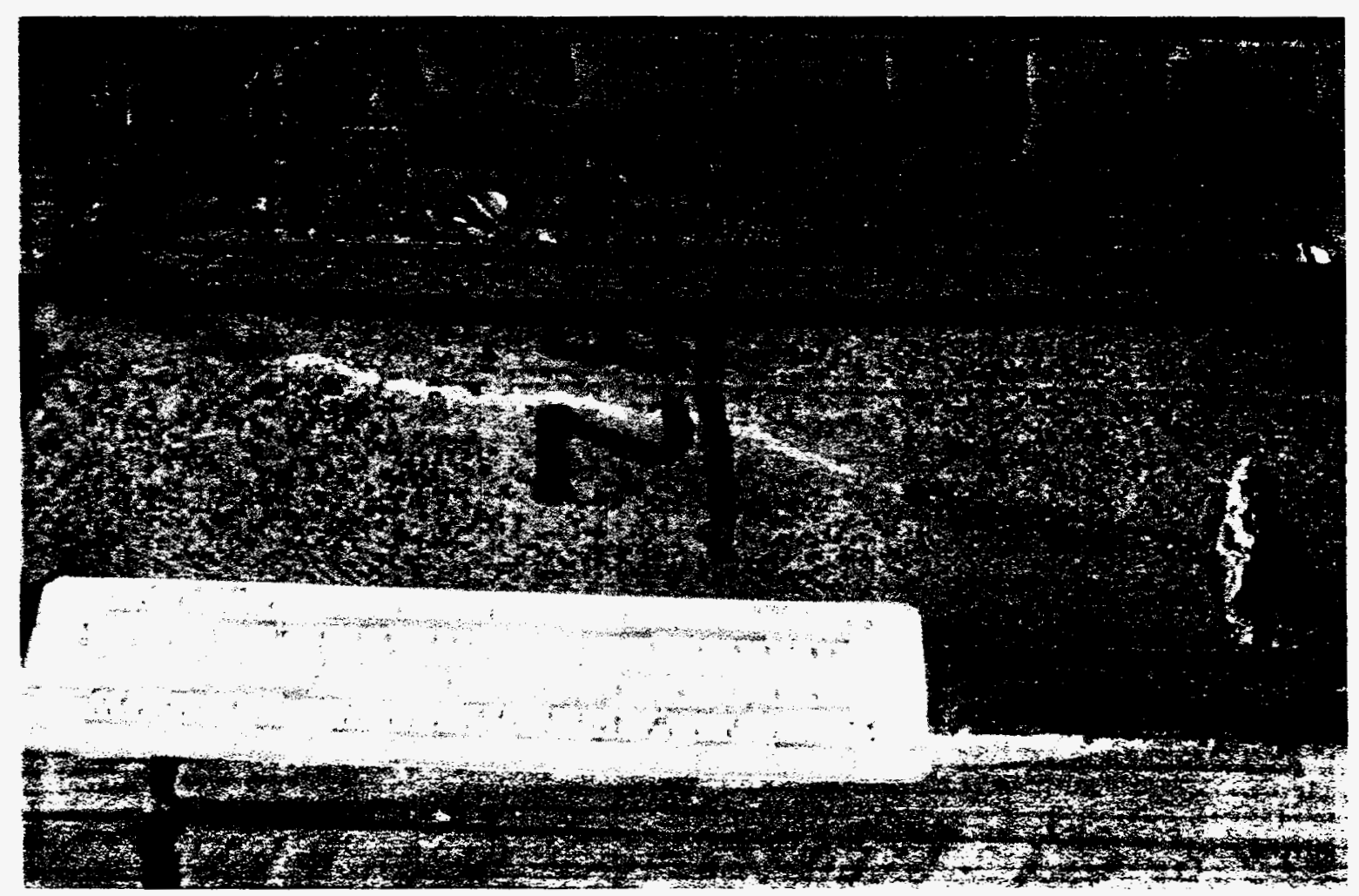

Figure 49. Close up core fragment showing partial small fracture grout penetration. 


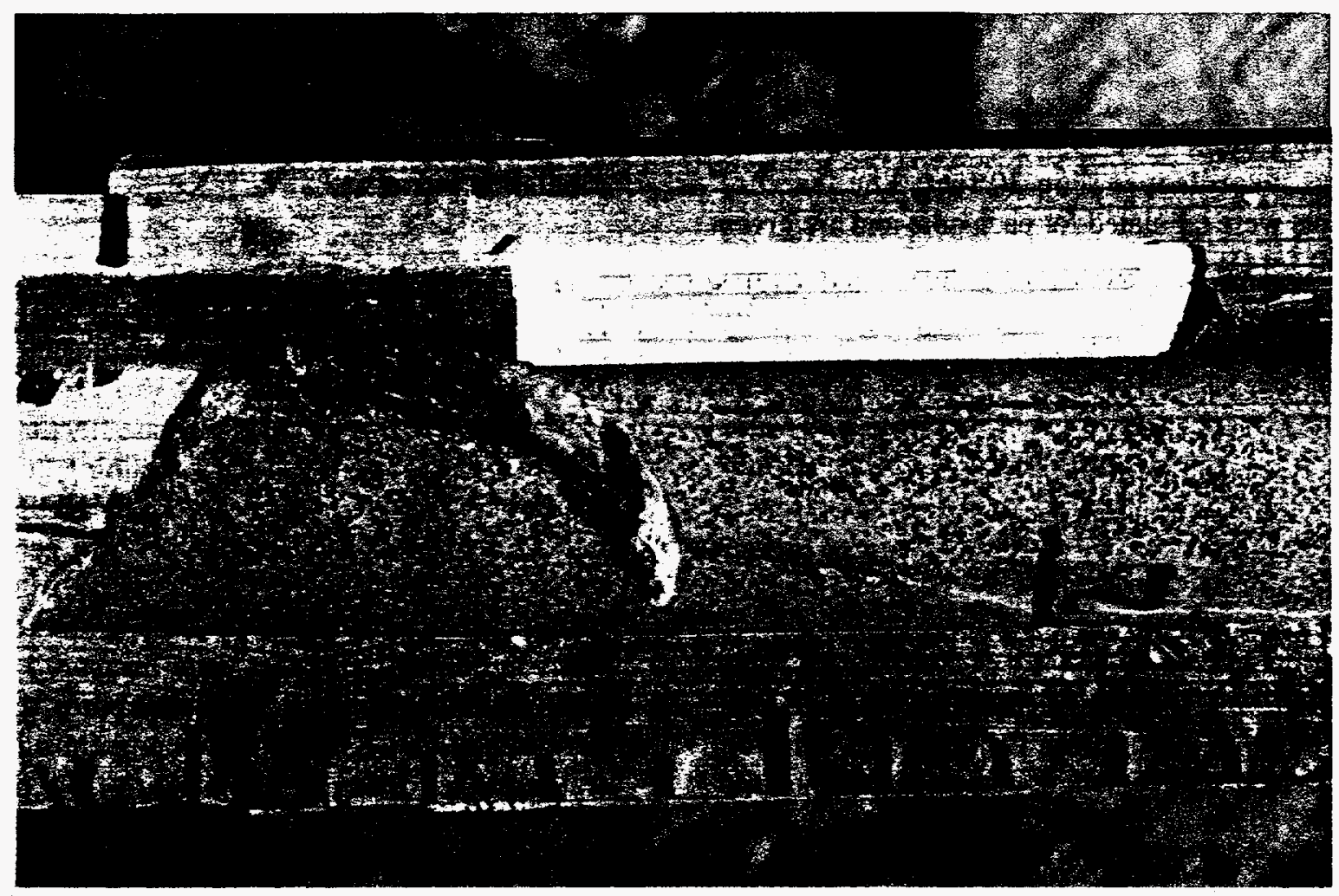

Figure 50. Close up core fragment showing partial large fracture grout penetration.

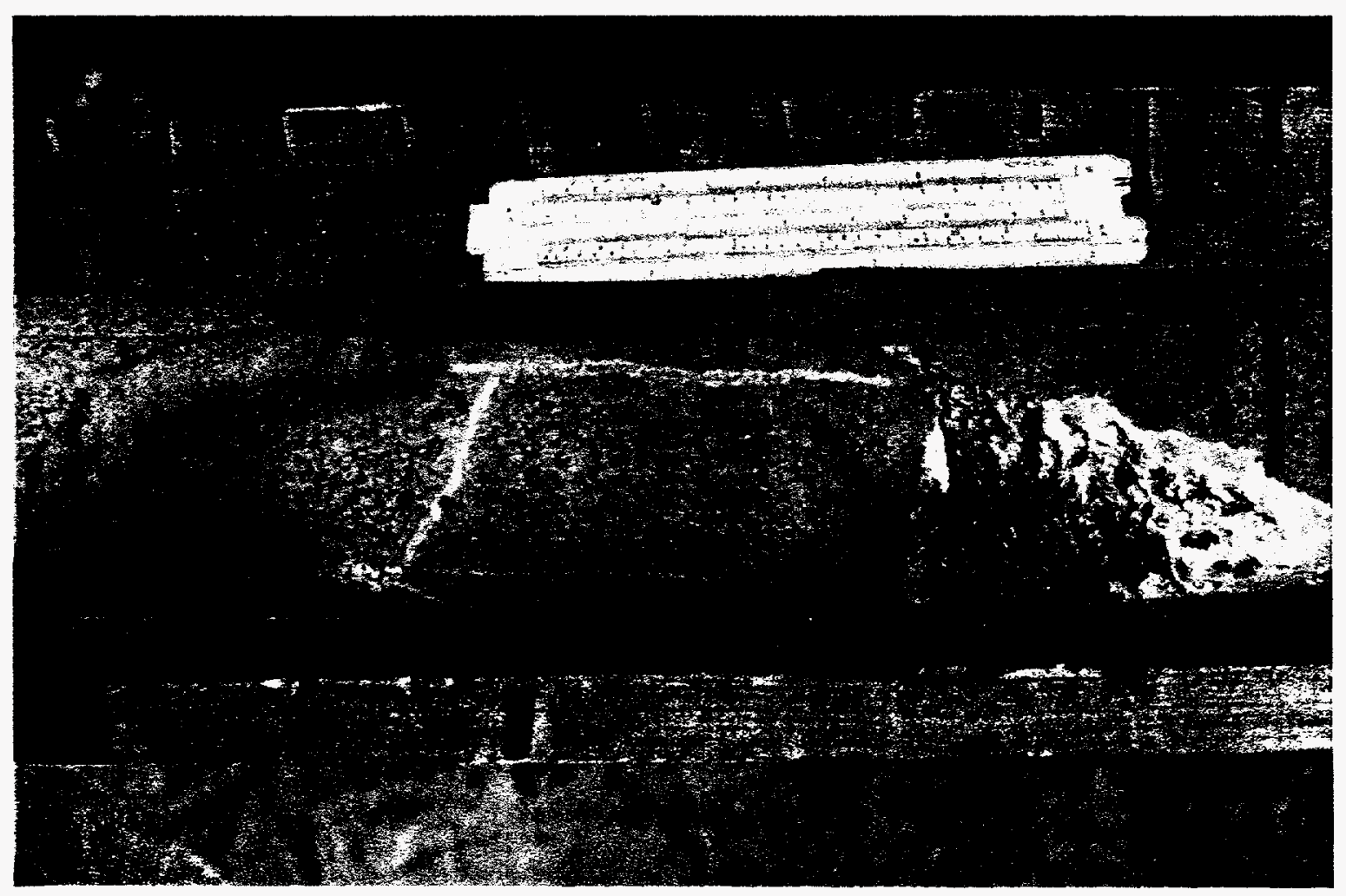

Figure 51. Close up core fragment showing microfine grout penetration. 
natural fractures of any size every 10 feet. Large spaces and rubble zones were not included, though these areas were encountered and are marked in the core samples with spacers. Two cores went deeper than 30 feet. The fracture counts were tabulated for each core and are given in 10-foot intervals.

The fracture density at $0-10$ feet was highly variable $0.6 \pm 0.4$ fractures/foot of core. Fracture density from 10-20 feet was lower and more consistent from hole to hole $(0.4 \pm 0.1)$. The density from 20-30 feet was the lowest for any section $(0.3 \pm 0.1$ fractures/foot). The two samples beyond the 30-foot depth had the highest fracture ratio $1.7 \pm 0.4$ fractures/foot.

The filling of these fractures by the grout was tabulated by noting from the cores and core log any evidence of cement or cement staining on the natural fractures in the cores. Figure 52 shows the fracture core fill count. This count is prone to some uncertainty as the coring method especially with the water drill tends to disrupt and wash out fracture material in general and cement in particular. Thus, any evidence of grout (gray for Portland cement; blue-gray for Microfine cement) or grout staining was noted as a fracture fill in the tabulation.

The fracture fill near the surface, 0 to 10 feet deep, showed the lowest percentage of cement or cement stains in the fractures $(4.3 \%)$. Each interval further down showed an increase fracture fill. The percentage of fractures containing cement 10-20 feet and 20-30 feet was much higher; 23 and $25 \%$, respectively. The fracture fill percentage beyond 30 feet was much closer to what would be expected based on some of the reductions in conductivity that were measured after grouting. Though only based on two cores, the fill percentage was $53 \%$. This phenomenon illustrates the tendency of the grout to flow down beyond the point of injection. The fracture fill also might be improved when there is a higher density of fractures since this depth had the highest fracture density.

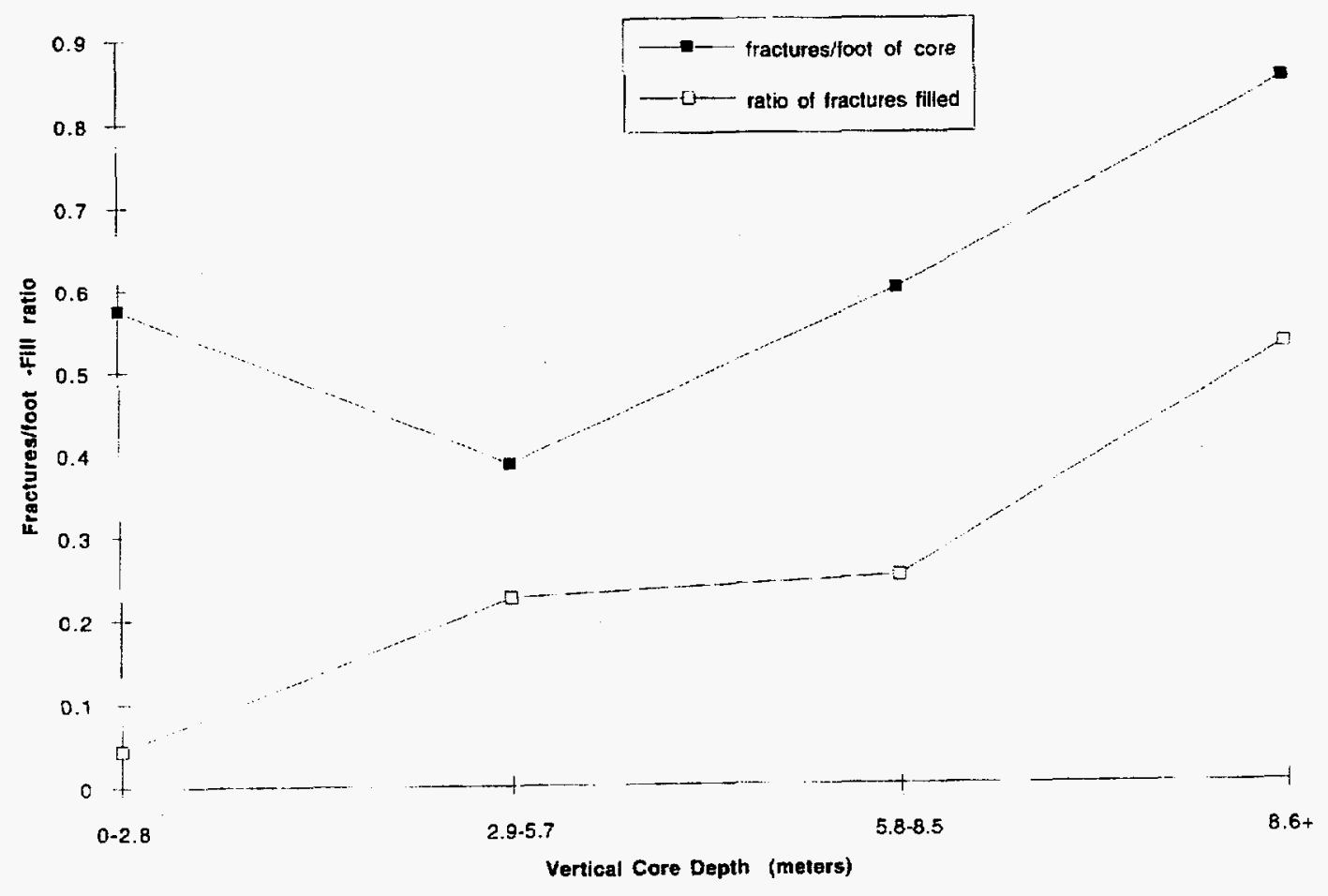

Figure 52. Fracture frequency by depth. 
Figure 53 places the fracture fill ratio on a map with the grout injection holes. Figure 54 gives the range of fracture fill at each depth. There did not seem to be a correlation between the number of surrounding injection holes, their proximity to the core, and the percentage of fractures filled. Holes C-4, C-5, C-6, C-7, and C-11 showed more evidence of cement in fractures despite being farther away from injection holes. Holes $\mathrm{C}-1$ and $\mathrm{C}-2$ were closest to the most injection holes and though conductivities in that area seem to be reduced, little evidence of cement in the fractures was noted. Hole C-1 was the only core taken with no evidence of cement in any of the fractures.

Figure 55 shows the fracture fill and the nearest hole conductivity reduction factor. From the coring-fracture-fill-counts that have been discussed, only $20 \%$ of all fractures were filled, so the effective average diameter in monolithic confinement is about 2 meters. Figure 56 indicates that the grout volume is not necessarily related to percentage of fractures grouted. As Figure 9 indi- cates, significant hydraulic conductivity reduction in competent basalts can extend to 4 meters from the injection hole. Again it must be emphasized that this does not include the large lava tubes, which can render large quantities of grout ineffective in reducing conductivity. Figure 57 compares the three instances of grout penetration in the basalt fracture fill, conductivity reduction, percentage fractures filled, and presence of tracer. There is some correlation especially on Cores C-11 and C-5.

The actual extent that the fractures in the basalt might be filled with grout in a large subsurface, basalt pressure grouting activity can be roughly estimated from these data and some 3-D modeling that was done at the Box Canyon Site and throughout the basalt of the Snake River Plain underlying RWMC. ${ }^{6}$ Based on this study the bulk density of basalt is about 2.8 and the mean specific gravity is 3.5 . With the lower density sediment and calcite also in the basalt about $20 \%$ of

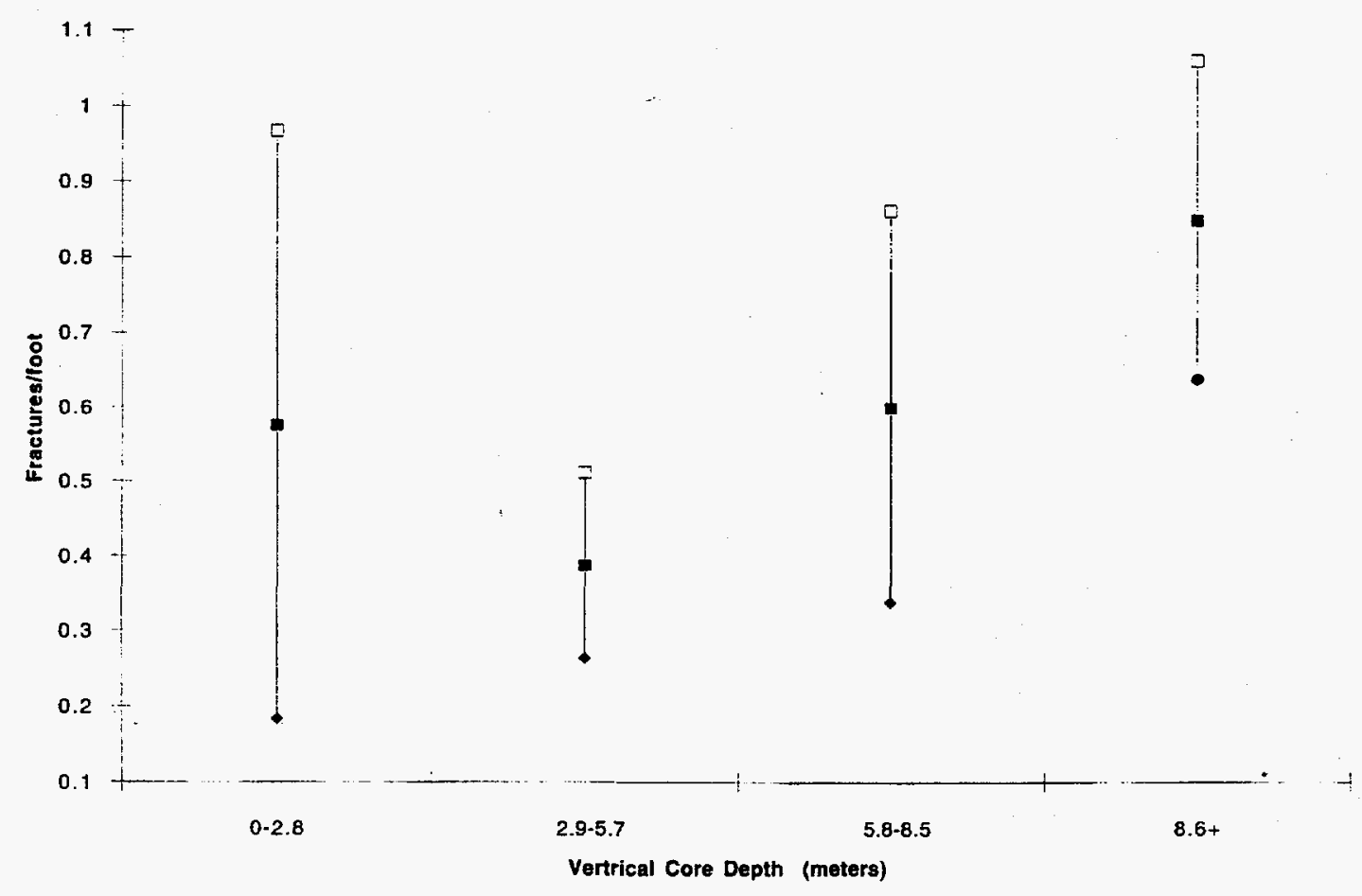

Figure 53. Fracture frequency range at various depths. 


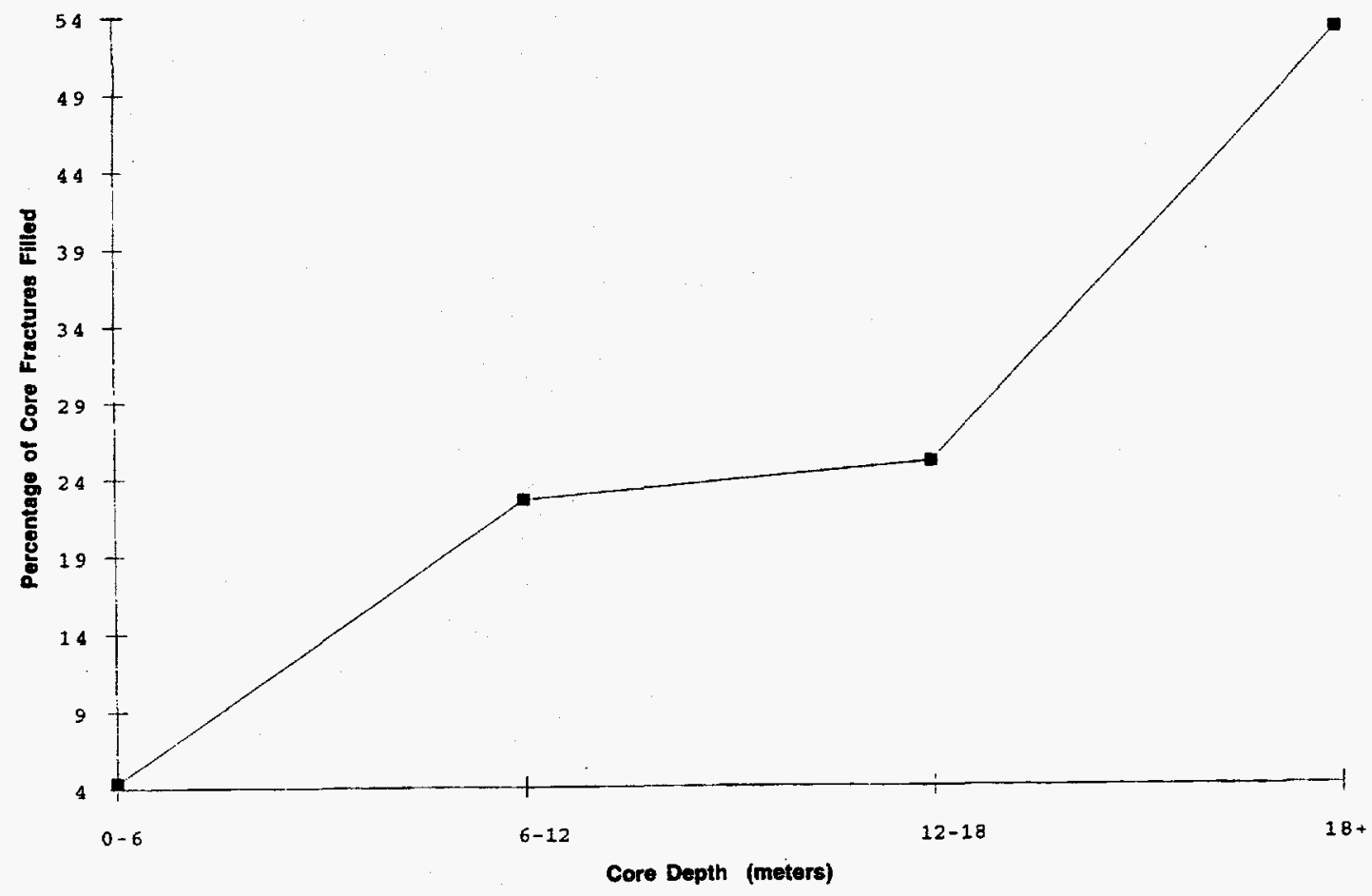

Figure 54. Fracture fill percentage by depth.

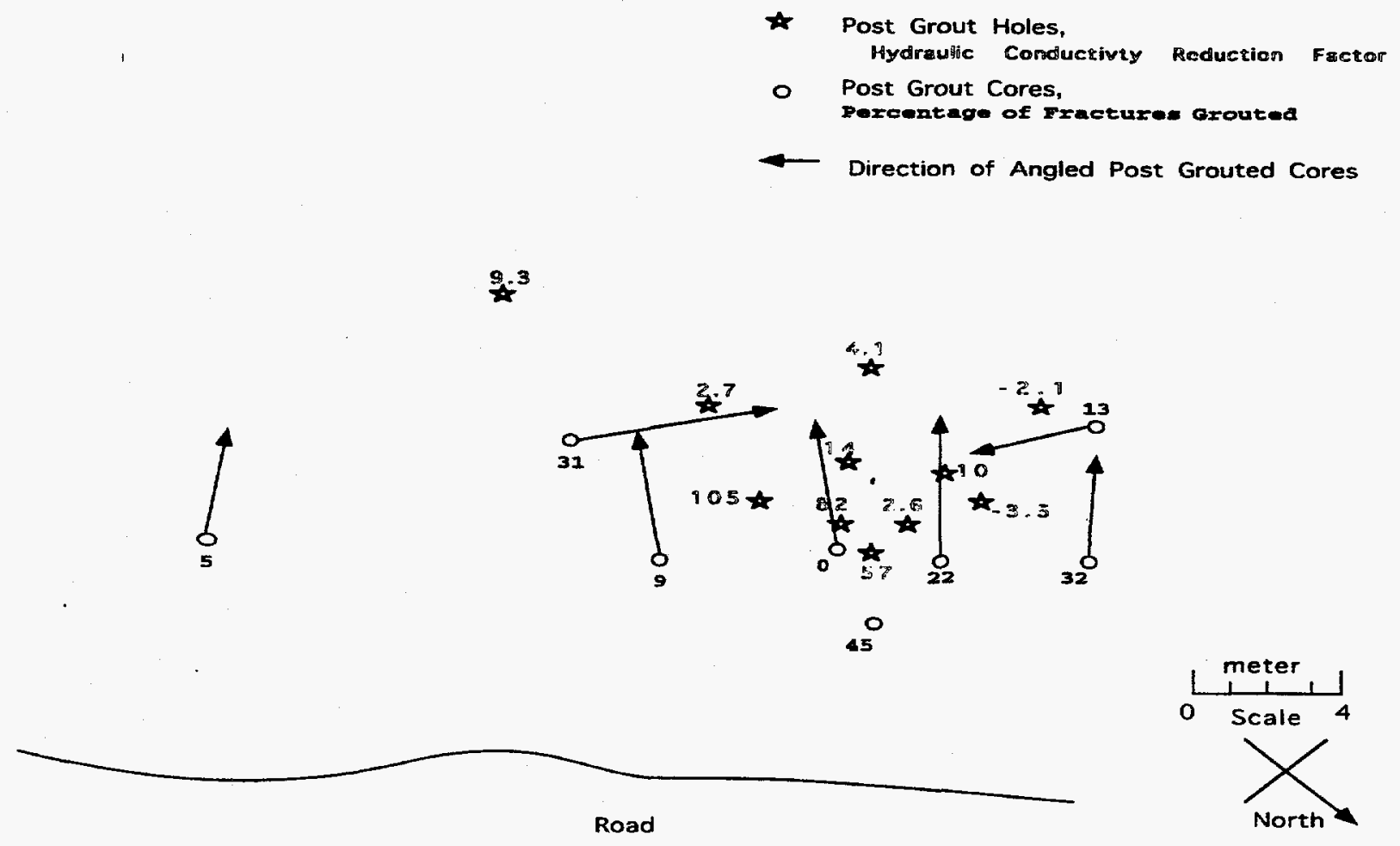

Figure 55. Companions of fracture fill percentage and hydraulic conductivity reduction by hole location. 
- Portland Grouted Holes, Volume $M^{3}$

- Microfine Grouted Holes, Volume $\mathrm{M}^{3}$

- Post Grout Cores, Percentage of Fractured Grouted

Direction of Angled Post Grouted Cores

0.42

$0.16 \cdot d$

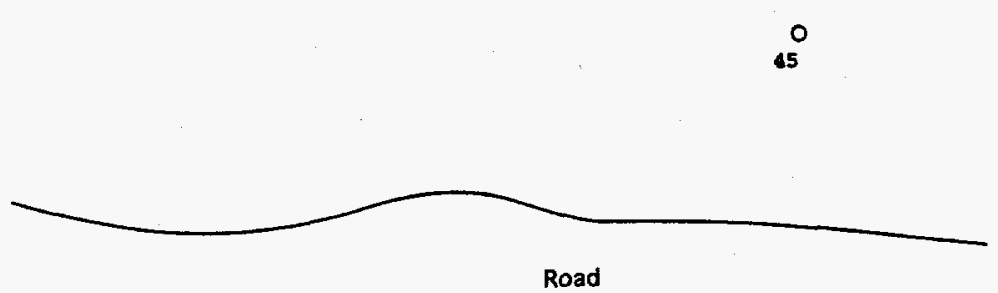

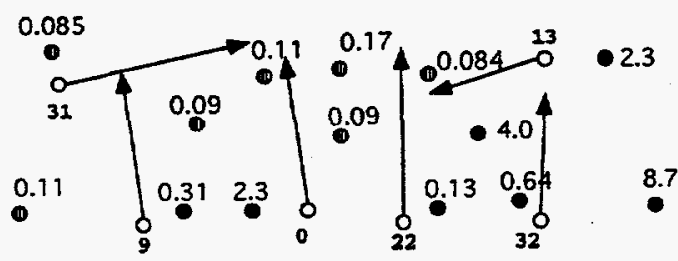

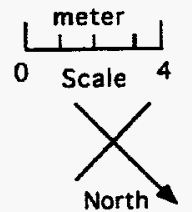

Figure 56. Map of average grout volumes injected and percentage of core fractures filled.

- Portland Grouted Holes, Volume $\mathrm{M}^{3}$

- Microfine Grouted Holes, Volume $M^{3}$

- Post Grout Cores, Pereentage of Fractures Grouted

- Direction of Angled Post Grouted Cores 0.42

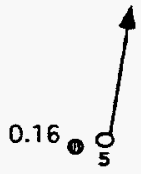

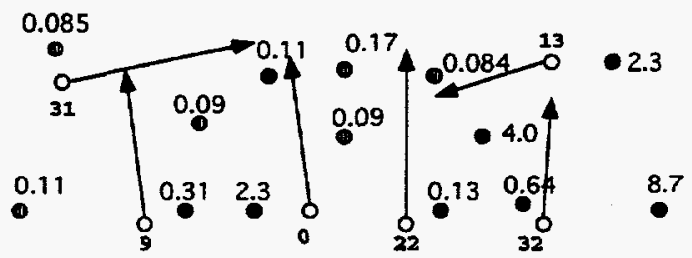

4
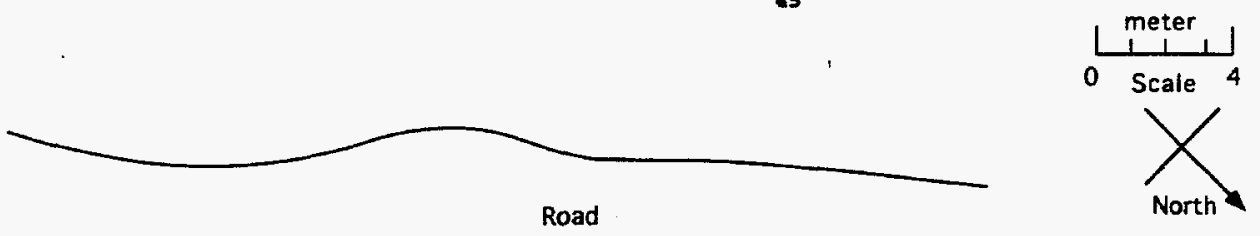

Figure 57. Map of average hydraulic conductivity reductions and percentage of core fractures filled. 
basalt at least is void space. ${ }^{7}$ Actual fractures assumed to be accessible to water or grout other than vesicular holes and crystalline inclusions is about $25 \%$ of the void space or $5 \%$ of the basalt ${ }^{8}$ The average grout "take" for 8.4-meter holes was $0.31 \mathrm{~m}^{3}$. A perfect fill then would fill fractures in $6.2 \mathrm{~m}^{3}$ of basalt. If the injection extends equally in all directions from the hole, then the effective radius for complete fill of all fractures is about 0.5 meters from the injection point. If the percentage of fractures filled is $50 \%$, as it was at depths below 8.5 meters, this radius extends to 0.7 meters. If the percentage is only $4 \%$, as it was in the first 3 meters at the surface, the effective radius extends to 2.5 meters. This does not include large voids and rubble zones.

These estimates correlate with the hydraulic conductivity reductions, cement found in fractures and tracer tests, which indicate the presence of grout and the apparent beneficial effects of reduced hydraulic conductivity up to 4 meters from an injection hole. 


\section{CONCLUSIONS}

Monolithic confinement was successfully tested by the INEL and at a test area near the INEL. Pressure grouting of particulate cements into fractured bedrock basalt flows similar to those underlying the waste at INEL was demonstrated. Hydraulic conductivity of the basalt in most cases was reduced, up to three orders of magnitude in one case, though only $20 \%$ of the visible fractures were filled. The overall hydraulic conductivity of the site was decreased by a factor of 3 averaging $6 \pm 9 \times 10^{-4} \mathrm{~cm} / \mathrm{sec}$ before grouting to $2 \pm 5 \times 10^{-4} \mathrm{~cm} / \mathrm{sec}$ after grouting for all locations all depths. The reduction of permeability was generally greater but more variable in the deeper zones. Localized large voids such as lava tubes result in no conductivity decrease unless filled or plugged in some manner.

Grout penetrated up to 4 meters from the drill application hole. A UV sensitive tracer injected with the grout was present in all holes, which provided some indication of grout penetration throughout the test area. This technique should be effective on any fractured rock system where contaminant spread is a problem and water penetration though the rock needs to be reduced. Pressure grouting of rock can be combined with grouting of the overlying waste if cement injection continues as the bit is raised through the waste.

\subsection{Recommendations}

The in situ pressure grouting process is a low impact, cost-effective strategy for buried waste confinement compared to more intrusive remediation techniques. The technology forms a horizontal subsurface barrier that retards further migration of buried waste contaminants. The waste is minimally disturbed, thus reducing the risk of surface contamination release. Further migration of contaminants that might be present within the fractures of the underlying basalt and the transport of hazardous leachate from waste components above the basalt to underlying aquifers are diminished without digging up the waste or disturbing the site.

Pressure grouting of basalt fissures can decrease the permeability of the basalt to form a horizontal barrier. Leachate movement from the buried waste residing above fractured rock should decrease existing contamination in the rock fixed in place. The successful development and application of this technique would produce a permanent in situ subsurface barrier and be far less expensive and much safer than any of the ex situ waste treatment systems for remediating buried waste. The technique is both effective in reducing permeability and implementable, having been proven on a formation similar to one actually underlying waste. 
. 


\section{REFERENCES}

1 Alexander R. G., Monolithic Confinement of RWMC Contaminated Geologic Media, TTP No. RL421212, Office of Technology Development Buried Waste Integration Demonstration, August 1993.

2 Knutson C. F. and T. R. Wood, Innovative Geophysical Characterization for Evaluation of Fractures and Liquid Transport in Fractured Rock, Interim LDRD Report, p. 25, August 1994.

3 Knutson C. F. et. al, 3D RWMC Vadose Zone Modeling;Basalt Characterization Results, EGGERD-10246, pp 200, May 1992.

4 Knutson C. F. et. al., Characterization of Low-Permeability Media Using Outcrop Measurements, SPE 26487, \#729 p 1-11, 68th Annual Technical Conference and Exhibition of the Society of Petroleum Engineers, Houston, Texas, October 1993.

5 Khaleel R., Scale Dependence of Continuum Models for Fractured Basalts Water Resources Research, V 25 (8), pp 1847-1855, August 1989.

6 D. A. Arrenholz and J. L. Knight, A Brief Analysis and Description of Transuranic Wastes in the Subsurface Disposal Area of the Radioactive Waste Management Complex at INEL, EGG-WTD-9438, Rev. 1, August 1991.

7 Moreno L and Neretneiks I, Flow and Nuclide Transport in Fractured Media, Journal of Contaminant Hydrology, 13, pp. 49-71, 1993.

8 Handbook on In Situ Treatment of Hazardous Waste in Contaminated Soils EPA/540/2/90/001; Risk Reduction Engineering Laboratory, Office of Research and Development U.S. Environmental Protection Agency, Cincinnati, Ohio 45268, 1990.

9 M. L. Allan et. al., In Situ Containment and Stabilization of Buried Waste Annual Report, prepared for MWLID TTP No. CH3211-01, BNL_48252, DE93 008563, pp.1-70 November 1992.

10 T.J. McLaughlin et. al., Subsurface Barrier Technologies as Potential Interim Actions for DOE Underground Storage Tanks, Westinghouse Hanford Co., Richland WA., Spectrum 92, Nuclear and Hazardous Waste Management, pp. 1200-1205, August 1992.

11 Phillips, S. J.,et. al, Development, Testing and Demonstration of Geotechnical Equipment and Cement Based Void-Fill Encapsulant Materials for Isolation of Radioactive and Hazardous Waste Disposal Structure, Proceedings of the Fourth International Conference on Fly Ash, Silica Fume, Slag And Natural Pozzolans in Concrete, Istanbul Turkey, 1992.

12 Loomis G. and Low J., In Situ Grouting for Improved Confinement of Buried Transuranic Waste at the Idaho National Laboratory Engineering, Proceedings of Spectrum 88, Pasco, Wash. pp. 496-498, September 1988.

13 G.G.Loomis, D.N.Thompson, Innovative Grout/Retrieval Demonstration Final Report, INLE-94/001, January 1995.

14 May, J.H., Larson, R.J., Malone, P.G., Boa, Jr.,J.A., Grouting Techniques in Bottom Sealing of Hazardous Waste Sites, EPA/600/2-86/020, Hazardous Waste Engineering Research Laboratory, Office of Research and Development, U.S. Environmental Protection Agency, Cincinnati, Ohio 45268, 1986. 
15 Nonveiller E., Grouting Theory and Practice, Developments in Geotechnical Engineering, 57 , Elsevier, pp. 248, 1989.

16 Bechberger P.F., Franklin Fluorescents, Vol 6, pp 6-9, 1974. 


\section{Appendix A}

Interim Report 


\section{Interim Report - LDRD - Innovative Geophysical Characterization for Evaluation of Fractures and Liquid Transport in Fractured Rock}

by

C. F. Knutson and T. R. Wood 


\title{
Interim Report - LDRD - Innovative Geophysical Characterization for Evaluation of Fractures and Liquid Transport in Fractured Rock
}

\author{
ABSTRACT
}

Borehole radar surveys were carried out in the fractured vadose zone basalts at Box Canyon and at the Infiltration Test Area south of the RWMC. Interpretable signals were obtained in the well to well mode at well separations of $20 \mathrm{~m}$ but not at $50 \mathrm{~m}$. Therefore, the viable well to well transmission distance in the Snake River Plains basalts appears to be between 20 and $50 \mathrm{~m}$. Well to well tomograms at Box Canyon indicated the occurrence of an additional flow finger that would not have been noted based on other available information. Thus, the technique provides enhanced characterization capabilities in the fractured basalt. Tomograms were also obtained with well to cliff face and well to surface configurations.

Repeat well to well tomograms were obtained from the $\mathrm{H} 1-\mathrm{H} 2$ wells during water infiltration from a $2 \mathrm{~m}$ diameter pool located between the two wells. Successive tomograms depicted an increasing sized area of extreme signal attenuation in the water infiltration zone. Thus, the borehole radar is capable of detecting water leaking from a near surface source in the fractured basalt vadose zone.

Reflection radar tomograms were successfully run in a well at the ITA site. These tomograms provided fractured basalt flow characterization through the upper part of the vadose zone. Four tomograms were obtained in the well. These tomograms represented formation conditions along azmuths of $\sim 220,310,70$, and 160 degrees from the wellbore and extended about $6 \mathrm{~m} \pm 2 \mathrm{~m}$ out into the formation. This provides a powerful characterization technique.

The wellbore radar technique in the fractured basalts of the Eastern Snake River Plains appears to provide a new and very significant subsurface logging technique up to maximum transmission distances in the order of between $2050 \mathrm{~m}$.

\section{INTRODUCTION}

The first objective of this LDRD is to evaluate the application of radar frequency electromagnetics in the characterization and monitoring of the fractured basalt in the vadose zone at the INEL (and elsewhere, where subsurface conditions are similar). The secondary objective is to evaluate the capability of the radar to track the downward liquid flow in the vadose zone fractures. This technique would be useful in evaluating liquid leakage under burial pits, trenches, infiltration pools, percolation pools, and leaking storage tanks. The principle medium under investigation in both phases is the fractured vadose zone basalt.

The main research site is on the northern margin of Box Canyon, about 6 miles southeast of the town of Arco, Idaho. A contemporaneous monolithic confinement test, MCT, at the Box Canyon site provided several $30 \mathrm{ft}$ deep uncased wells which were used, in conjunction with an existing $51 \mathrm{ft}$ deep USGS well, in the cross hole testing. The secondary test site was at the Infiltration Test Area, ITA, about one mile south of the RWMC. Two uncased $100+\mathrm{ft}$ well, that were scheduled to be used in the ITA tests, were made available for cross hole and reflection radar testing.

Raytheon Nevada supplied the radar equipment and operators. Personnel from the buried waste integrated demonstration (BWID) group, Raytheon Nevada, and EGG geoscience supplied technical expertise and assistance. The initial Raytheon involvement, for the initial phase of this test, was limited to a two week 
window from May 2 to the 13th. During this period, cross hole testing was carried out at both sites and in hole radar reflection tests were carried out at the ITA.

\section{SUMMARY OF PRELIMINARY RESULTS}

\section{Field Design and Development}

A reconnaissance survey of the Box Canyon site was made and a generalized map of the surface and outcrop geology was constructed. The sketch map of the site is presented as Figure 1. The generalized geology from the survey and the video log from the USGS well (H1) indicated that (a) two vertically stacked flows with a rubbly flow interface were present at the $\mathrm{H} 1$ - cliff face area (surface Flows A and buried Flow F) and (b) the MCT wells would be drilled into a separate surface flow (Flow B) with an high angle flow contact of unknown character between Flow A and Flow B. Based on the surface and outcrop studies, the B flow appears to overly the F flow with an unknown type of contact between them. The B-F flow contact or interface was expected at a depth of from $25-30 \mathrm{ft}$ below the surface in the MCT area.

The ITA location is a major research site at which approximately 60 wells have been drilled, see Figure 2 . The wells used for the radar tests, B05011 and B03N11, were drilled to the B-C Interbed at about $175 \mathrm{ft}$ below the surface and had not been grouted. The wells had been cored or logged and information on the flow contact and element locations was available for comparison with the radar logs.

\section{Preliminary Borehole Radar Evaluation}

\section{Introduction}

The borehole radar system used by Raytheon is an automatic one/two component unit manufactured by ABEM. The system has two computer controlled draw works and a software program that automatically positions the sending and receiving sondes in two boreholes and records and processes the data stream. In these tests, the tools were moved in $1 / 4 \mathrm{~m}$ steps. In a typical run, the sender and receiver were placed $1 / 4 \mathrm{~m}$ below the bottom of the casing). The sender transmitted a preset number of $30 \mathrm{Mhz}$ radar pulses $(\sim 300)$ and the receiver captured each signal, averaged them and stored the averaged signal. After the averaged signal had been stored, the receiver was lowered $1 / 4 \mathrm{~m}$ and the process was repeated until the receiver reached the bottom of the well. At this point the sender was lowered $1 / 4 \mathrm{~m}$, the sender was raised to its starting position and the cycle was repeated. The averaged signal (wave train) was displayed on the monitor while being stored on the computer's hard disk. A tomogram graphic was also displayed on the monitor during the lowering of the sonde showing the locations of the sender and receiver. The tomogram for a limited number of parameters (time for arrival of first maximum or minimum or attenuation for first maximum) was also calculated and displayed and stored at the end of each series of top to bottom nuns by the sender. The draw works and control system are shown in Figure 3A and a sonde with battery pack being placed in a hole is displayed as Figure 3B. An arrow on Figure 3B indicates the location of the second hole being used in the cross hole test.

The system utilizing a single sonde operates consists of a sender and receiver and a double battery pack for power. The sonde orientation of the reference direction for the sonde is set with a magnetic locator, see Figure $4 \mathrm{~A}$ and the system records the average of four sets of reflected signals taken at ninety degree azimuths at each depth station. The azimuth of the reference signal set is also measured and recorded at each depth station. Figure 4B shows the single sonde system being lowered into the hole.

The sondes are powered by a battery pack approximately $5 \mathrm{ft}$ long located below the sender or receiver section when used in the two sonde mode. Thus, the depth of effective data retrieval is from about a meter 
below the casing to about $2 \mathrm{~m}$ above the bottom of the boreholes (or any obstruction that prevents the sonde from reaching the bottom of the borehole). Dual battery packs are fitted below the sender receiver section when a single sonde system is used. This places the maximum record depth at about $4 \mathrm{~m}$ above the bottom of the hole.

The signals are transmitted over a fiber optic cable. Thus, more care must be taken to prevent cable damage then with a coaxial or multiple wire system.

\section{Borehole to Borehole Survey Results}

The initial Box Canyon test was run between well $\mathrm{Hl}$ and the cliff face (dashed line on Figure 1). The receiving sonde was run in the well and the sending sonde was run vertically up and down the cliff face, see Figure 5. Figure 5A shows the electronics van and draw works with the cables going to the $\mathrm{H} 1$ well and the cliff face. Figure 5B is a view from across the canyon showing the sending sonde about halfway down the face. Figure 6 is a copy of the Well H1 to cliff face tomogram. This figure shows the flow interface dipping down away from the cliff face. An area of open fracturing is also indicated near the upper edge of the cliff face (upper left corner of the tomogram).

A number of additional well to well surveys were carried out from the $\mathrm{H} 1$ well to the $\mathrm{H} 2$-to-H5 locations, see Figure 1. Several of the MCT wells (H2, H4, and H5) had ledges or doglegs that stopped the sondes downward travel in the interval 10-20 ft below the surface. Thus, only very limited sections were surveyed in these wells. These limited surveys did allow an evaluation of signal quality at various well to well distances. Good signals were obtained at all distances surveyed up to a maximum of $20 \mathrm{~m}(\mathrm{H} 1-\mathrm{H} 5)$. A tomogram of the $\mathrm{H} 1-\mathrm{H} 2$ section is presented as Figure 6. An interpretation of this tomogram is presented as Figure 7. This sketch indicated an additional flow, probably coming in from the north, appearing between Flows $B$ and $F$. If this is a correct interpretation, it represents information not known from the cliff face and surface outcrop examinations. The $\mathrm{H} 1-\mathrm{H} 2$ cross section was used in a later infiltration test.

\section{Mini-Infiltration Test Results}

Successive cross hole radar tomograms were recorded between the $\mathrm{H} 1$ and $\mathrm{H} 2$ wells while water was infiltrating into the fracture system from a $2 \mathrm{~m}$ diameter pool located between the wells. Figure $8 \mathrm{~A}$ shows the pit being constructed and Figure $8 \mathrm{~B}$ shows the pit after construction. The pit was made from a $\sim 2 \mathrm{~m}$ diameter wading pool with the bottom removed. This pool was placed on a piece of tarp with a hole in its center located on a fractured basalt outcrop between the $\mathrm{H} 1$ and $\mathrm{H} 2$ wells. Figure 9 is a cross sectional sketch of the pit. The tarp served two purposes - (1) the sand pressing down on the tarp caused the tarp to act as a seal and prevented the water from flowing out on the ground away from the pool, and (2) the tarp was held up in the air during the berm building operation and prevented any of the sand and associated fines from going into the pool. Any fine sedimentary material in the pit would tend to be suspended by the water and then carried down into and plug the fractures. Figure $10 \mathrm{~A}$ is a view of the fractured basalt surface of the pit. Figure 10B is a view of the pit being filled from a water truck.

When the water truck arrived, a preinfiltration tomography run was started. The pit was then filled with water to within a few inches of the top, and the water inflow was stopped. After the water surface had dropped about half a foot, the water was turned on again and the pool refilled to its original "full" level. The time for each pool fill was recorded. This procedure was continued until the water truck had to return to the INEL. Prior to the truck's departure a 37.5 gal container was filled with water and as soon as the pit reached the half-foot-low level the water was continuously siphoned into pit through a garden hose until the container was drained. The calculated water influx rate for this test is presented in the following table: 


\begin{tabular}{ccccc}
\hline Time & $\begin{array}{c}\text { Input } \\
(\mathrm{gal})\end{array}$ & $\begin{array}{c}\text { Rate } \\
(\mathrm{gpm})\end{array}$ & $\begin{array}{c}\text { Cum. Input } \\
(\mathrm{gal})\end{array}$ & $\begin{array}{c}\text { Ave. Rate } \\
(\mathrm{gpm})\end{array}$ \\
\hline $14: 00$ & 0 & 0 & 0 & 0 \\
$14: 12$ & 88 & 7.282759 & 88 & 7.283 \\
$14: 30$ & 88 & 4.855172 & 176 & 6.473563 \\
$14: 42$ & 88 & 7.282759 & 264 & 5.502529 \\
$15: 02$ & 88 & 4.369655 & 352 & 4.924532 \\
$15: 30$ & 88 & 3.121182 & 440 & 4.439015 \\
$15: 45$ & 88 & 5.826207 & 528 & 4.696053 \\
$16: 02$ & 88 & 5.140771 & 616 & 4.696053 \\
$16: 30$ & 88 & 3.121182 & 704 & 3.695594 \\
$17: 15$ & 128 & 2.824828 & 832 & 2.97295 \\
\hline
\end{tabular}

The initial higher infiltration rate was probably the result of water going into storage in the vesicular basalt and in the berm material. As the near surface storage was filled, the infiltration rate probably approached the transport capacity of the fractures. The fracture frequency decreases toward the center of the flow, so the water transport capacity probably also decreases. If we assume the average rate for the upper fracture system is reached during the second hour of infiltration, the capacity of these upper fractures in the basalt is about $0.27 \mathrm{gpm} / \mathrm{ft}^{2}$ surface area $/ \mathrm{ft}$ of head. The low rate for the last period of infiltration was caused by the declining head as the pool drained.

Three tomograms were obtained during the infiltration test. These tomographic cross sections through the infiltration area (see sketch presented as Figure 12) displayed an progressively larger anomaly or area of high attenuation. The high attenuation would be the expected result of introducing the high dielectric coefficient water into the fractures under the mini infiltration pit.

\section{Infiltration Test Area, ITA, Results}

Two tests were carried out at the ITA located about one mile south of the RWMC. The first was a well to well tomography attempt in two wells (B05O11 and B03N11) located approximately $50 \mathrm{~m}$ apart. Interpretable signals were not retrieved from this attempt either because of distance or completion technique. Since we were able to send and receive good signals from the B05011 well during the single sonde test, we conclude that the maximum transmission distance for the ABEM $30 \mathrm{mHz}$ radar system is between 20 and $50 \mathrm{~m}$ in the fractured Snake River Plains basalt.

The single sonde system has an azmuthly aimed transmitter and receiver. A designated number of signals (300 for this test) are sent at one depth and at the prime orientation. The resulting wave forms are averaged and the average form, depth, and prime azimuth are recorded. The transmitter and receiver are then rotated 90 degrees and the process repeated. After the four right angle data sets acquired and recorded the sonde moves up the specified increment (1/4 $\mathrm{m}$ in this test) and the next data set is developed. When the data acquisition for the well is completed (because of the length of the battery pack the maximum logged interva? is from about one meter below the bottom of the casing down to about four meters above the maximur. sonde depth. The data is presented in four Z-R tomograms. The observed average radius range for the signals in the B05O11 well was six meters, with a approximately plus or minus two meter variation.

The single sonde radar system provides characterization capabilities further out into the formation than the other available INEL logs. The radar system also provides the ability to evaluate the character of the basalt 
in four different directions. The radar provides a real advantage over the other logging systems since the other systems only provide an average of the properties without any directional information.

The possible utilization of radar logging systems to provide enhanced formation characterization information useable in 2 and 3D subsurface modeling was part of the paper presented at the AAPG convention in June of this year (Thus, this LDRD can be credited with one presentation - Knutson, C. F., 1994, " Using Reservoir Geology Characterization Techniques in Waste Management Modeling", AAPG Annual Convention, Denver, Colorado, June 12-15, 1994, pp 189. ). The presentation provided some interesting feedback and conveyed the general impression that the INEL is doing some leading edge work in the formation characterization and application area.

\section{Summary and Conclusions}

Radar signals and tomograms at Box Canyon were obtained from well to well spacing of up to $20 \mathrm{~m}$. Interpretable signals and tomograms were also obtained with one sonde in a wellbore and one sonde dropped down the cliff face (the cliff face sonde responded like a second vertical wellbore). Additionally, a configuration of one sonde in a wellbore and the other sonde being pulled away from the well along the surface of the ground produced an interpretable tomogram that characterized a triangular subsurface area (This is a technique analogous to seismic profiling). This latter configuration could be useful in evaluating buried waste in a noninvasive mode from wells drilled adjacent to the area of interest.

Well to well radar signals were not received at separations of $50 \mathrm{~m}$ at the ITA site south of the RWMC. Both the Box Canyon and ITA tests were in fractured basalt. Based on these tests, the maximum effective well to well separation for radar surveys in the Eastern Snake River Plains basalt appears to be between 20 and $50 \mathrm{~m}$.

An infiltration test was carried out at the Box Canyon site with the $6 \mathrm{~m}$ diameter infiltration pool located between the $\mathrm{H} 1$ and $\mathrm{H} 2$ wells. Three well to well tomograms were obtained during and shortly after the time in which this test was carried out. The fractured basalt accepted water at a rate of about $0.27 \mathrm{gpm} / \mathrm{square}$ foot of surface area/foot of head. The tomograms obtained during the course of this test showed an increasing sized anomaly produced by the downward migrating water plume. This indicates that the borehole radar technique is capable of detecting water leaking through the vadose zone. 


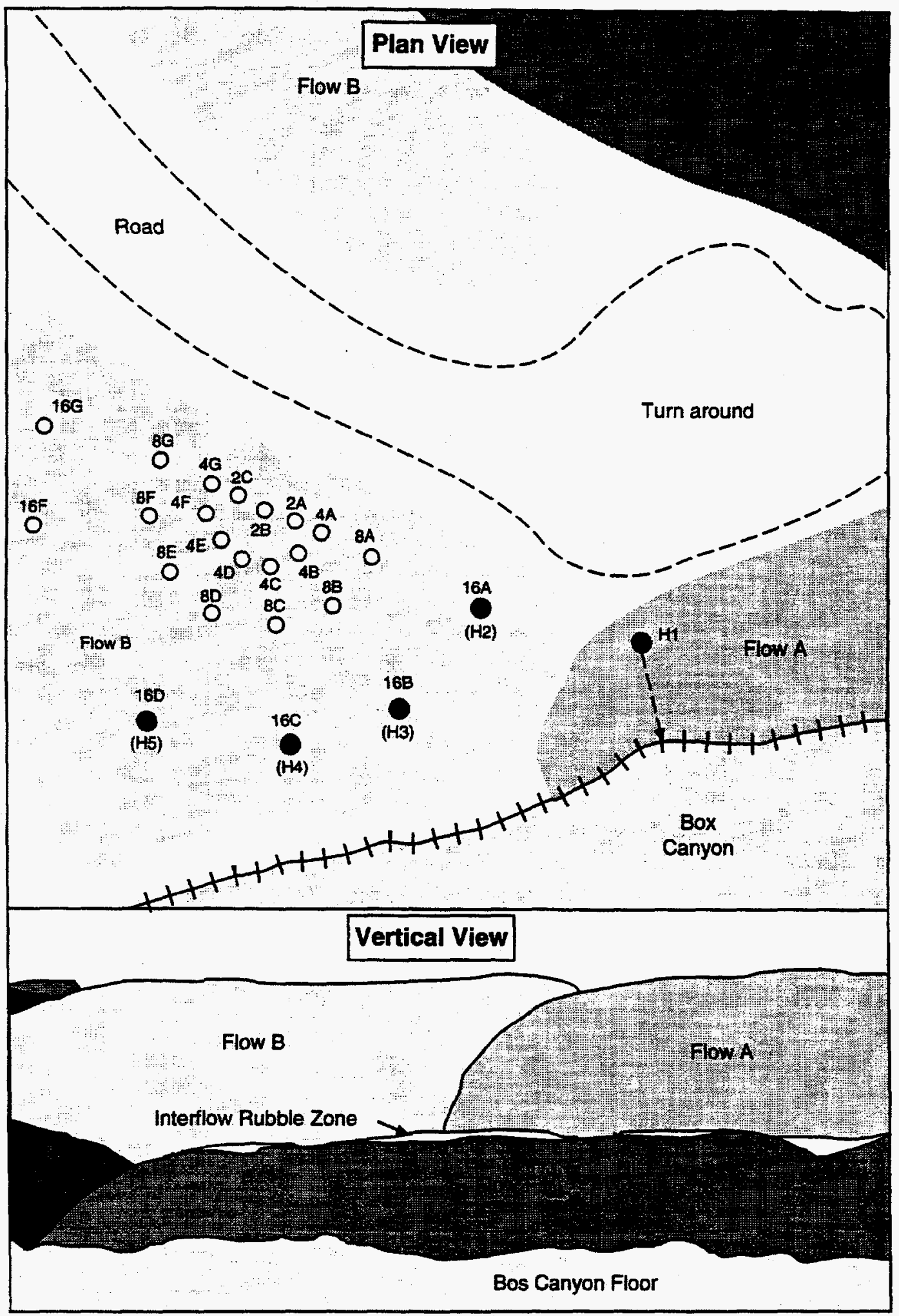

M94 0394

Figure 1. Geological sketch of the Box Canyon site. A plan view showing surface flows and well locations as well as a vertical view of flow geometry at the cliff face are presented. 


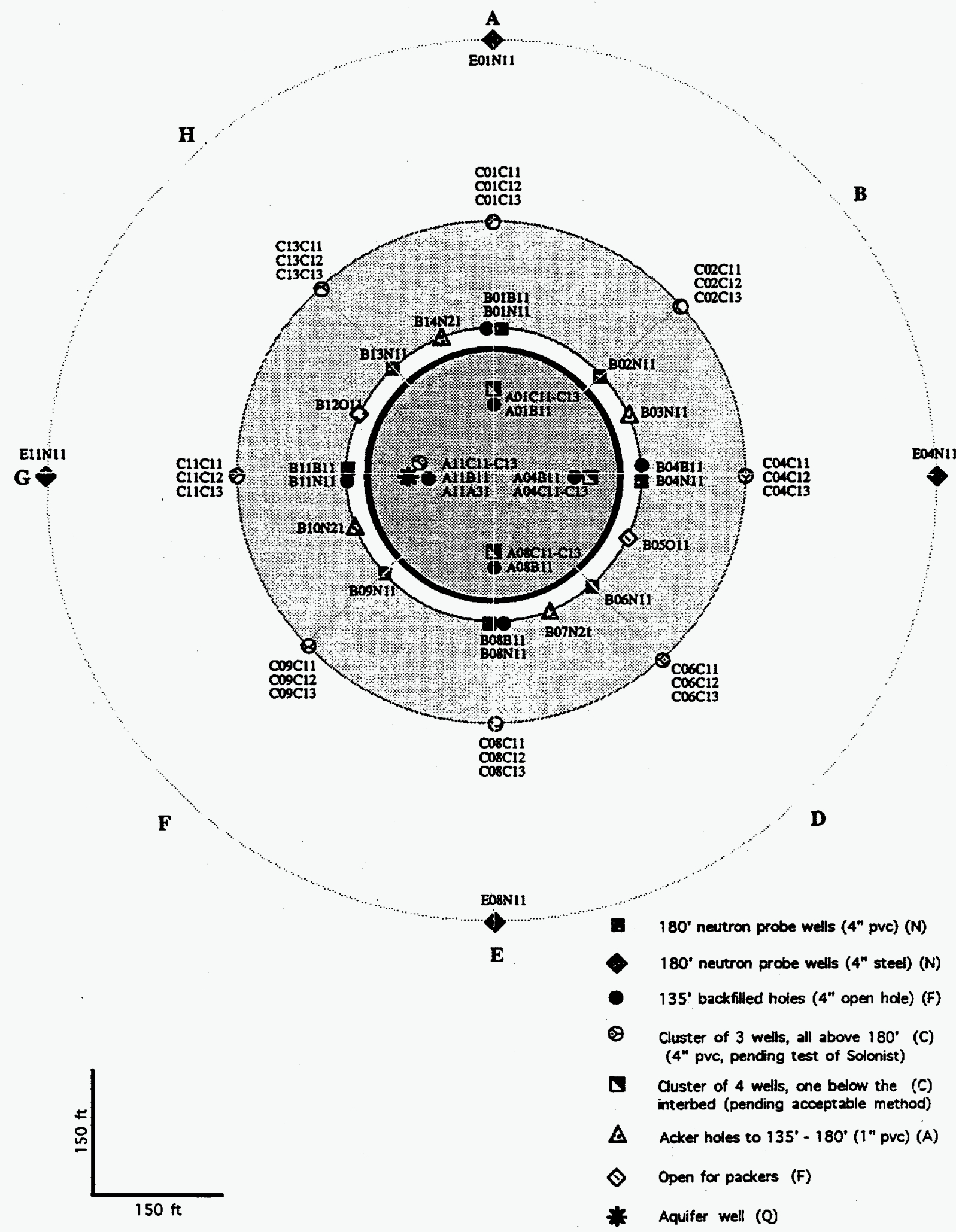

Figure 2. Well locations at the infiltration test area about one mile south of the RWMC. The B05O11 and B03N11 wells were used in the radar tests. 

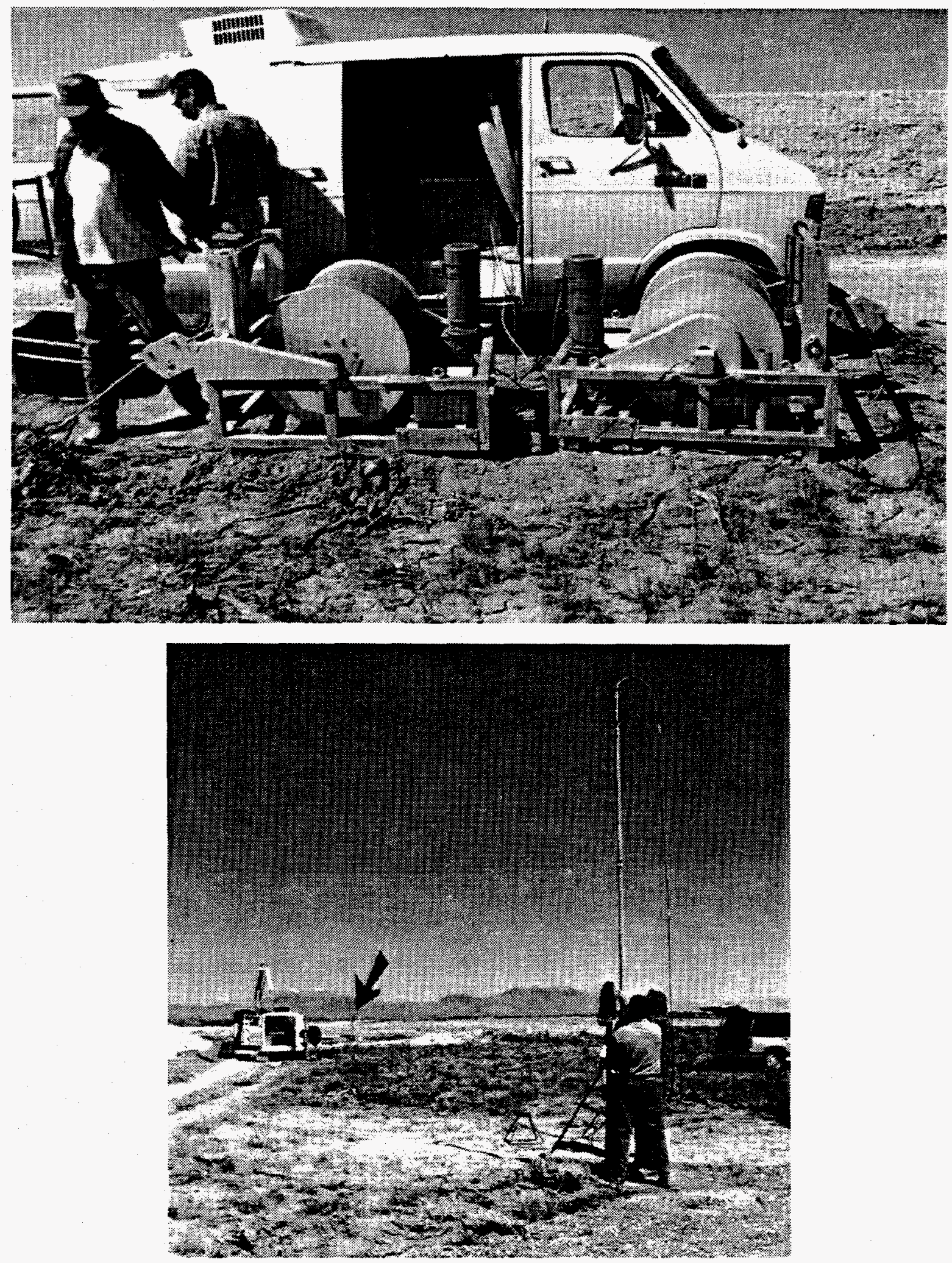

Figure 3. The upper picture (3A) shows the two draw works and the control system connected to the electronics van. The lower picture (3B) shows the sending sonde and battery pack being lowered into the hole. The arrow to the right and beyond the van (3B) indicates the location of the second well. 

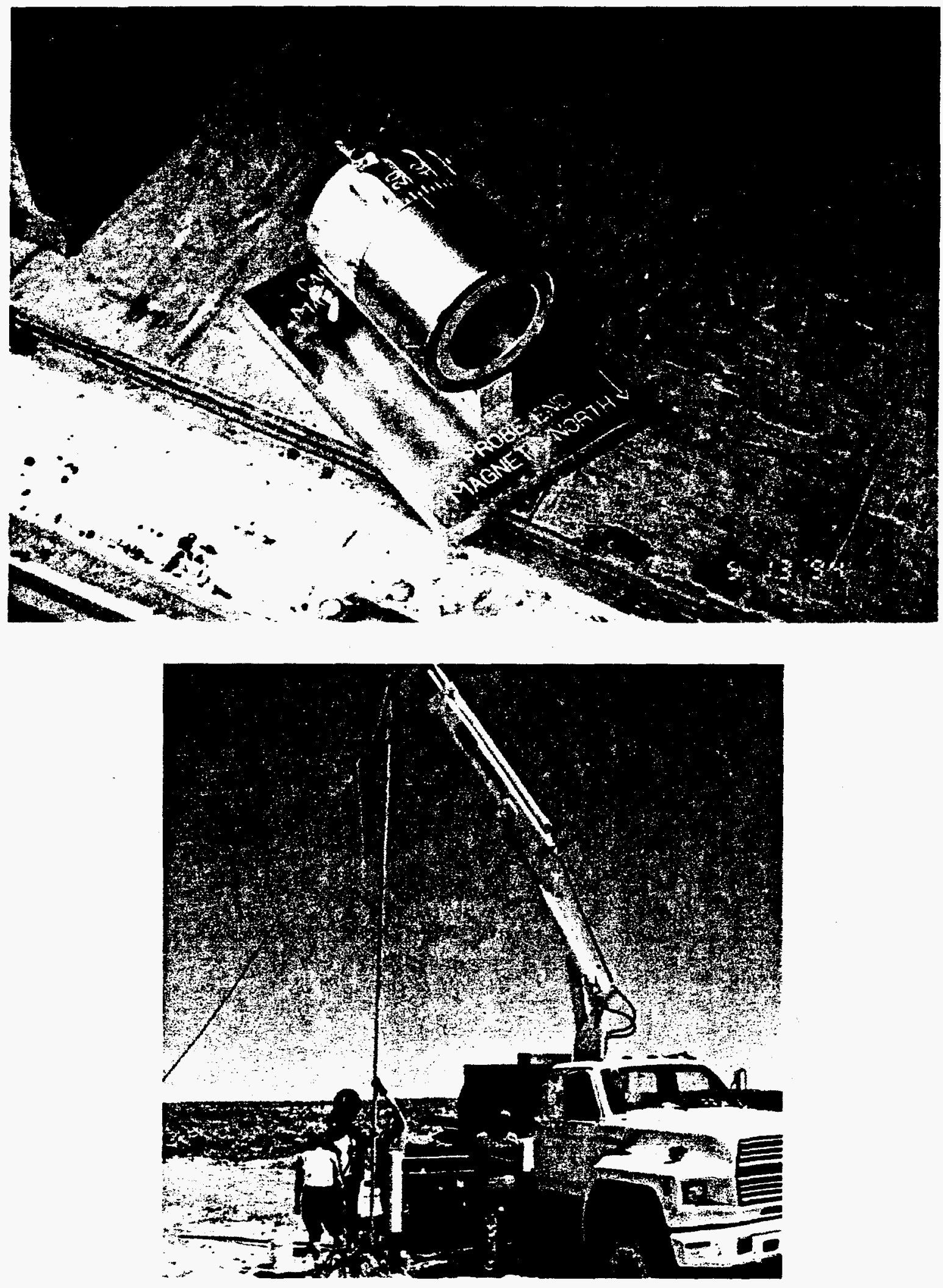

Figure 4. Upper picture (4A) shows azimuth orientation mandrel for single system sonde. Lower picture (4B) shows the single sonde system being run in hole. 

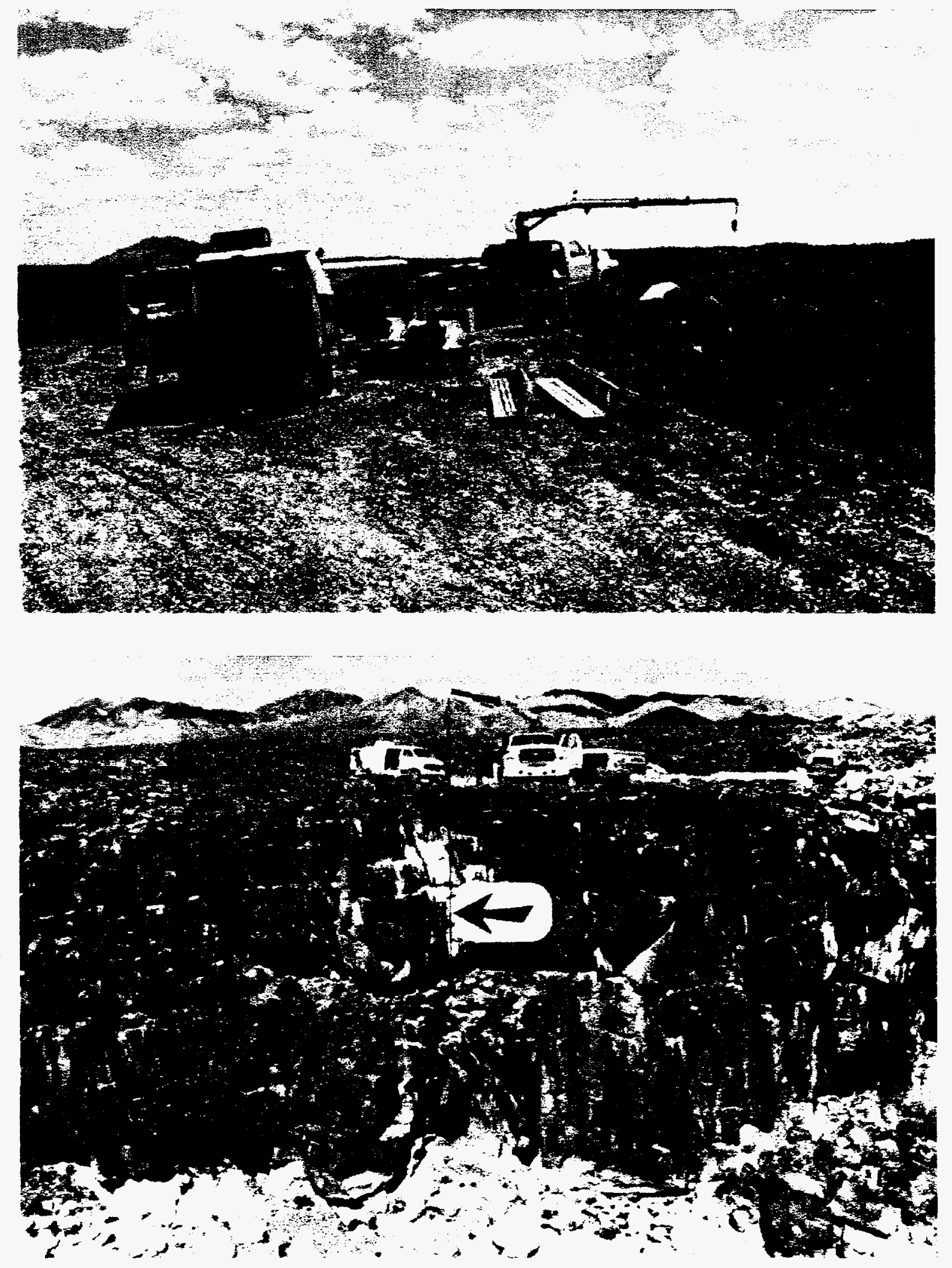

Figure 5. Upper view (5A) shows electronics van and logging setup during logging of Well H1 to cliff tomogram. Lower view (5B) shows logging sonde in middle of run. 


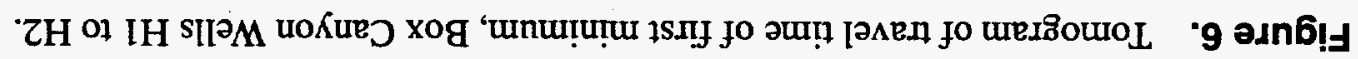

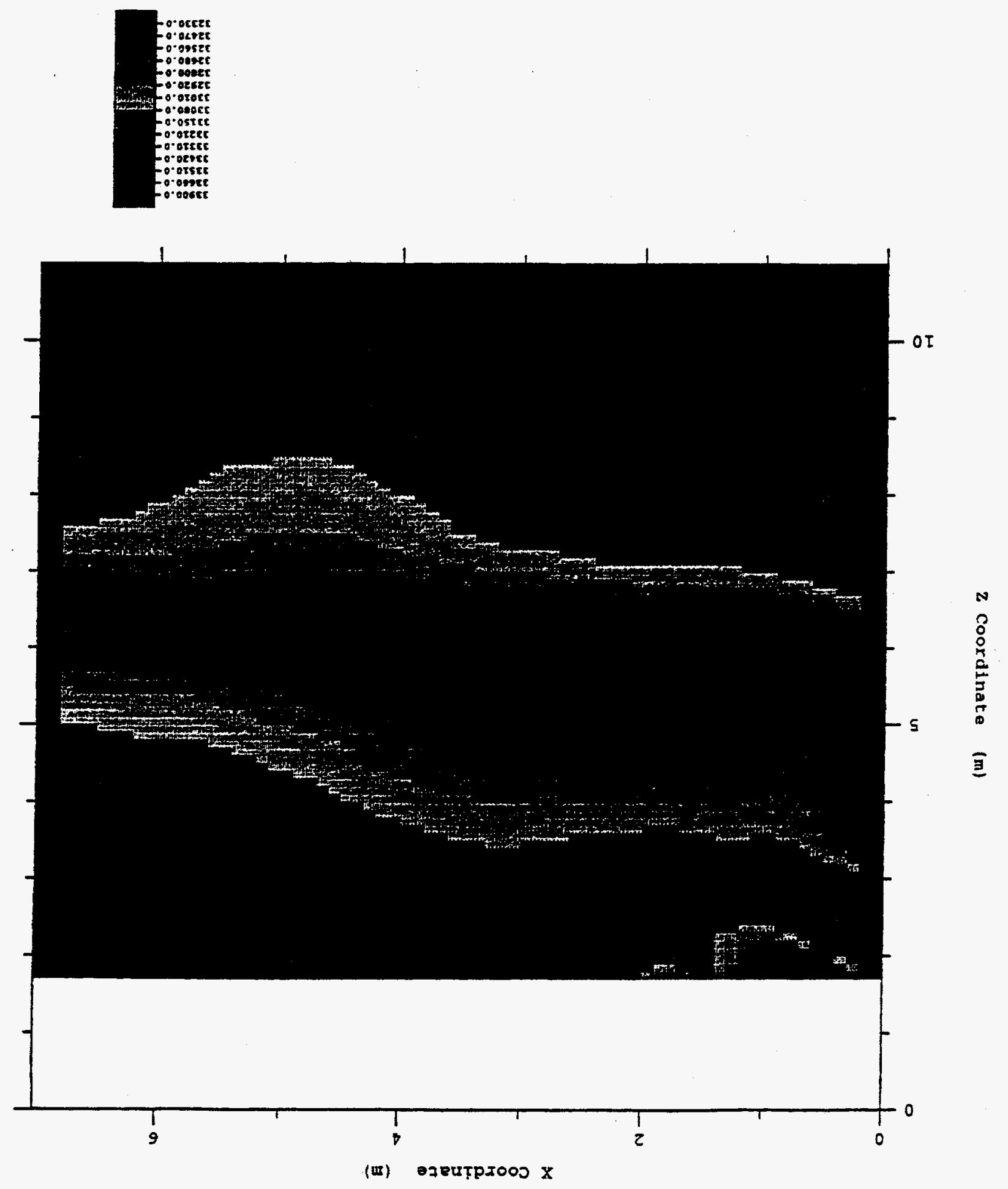




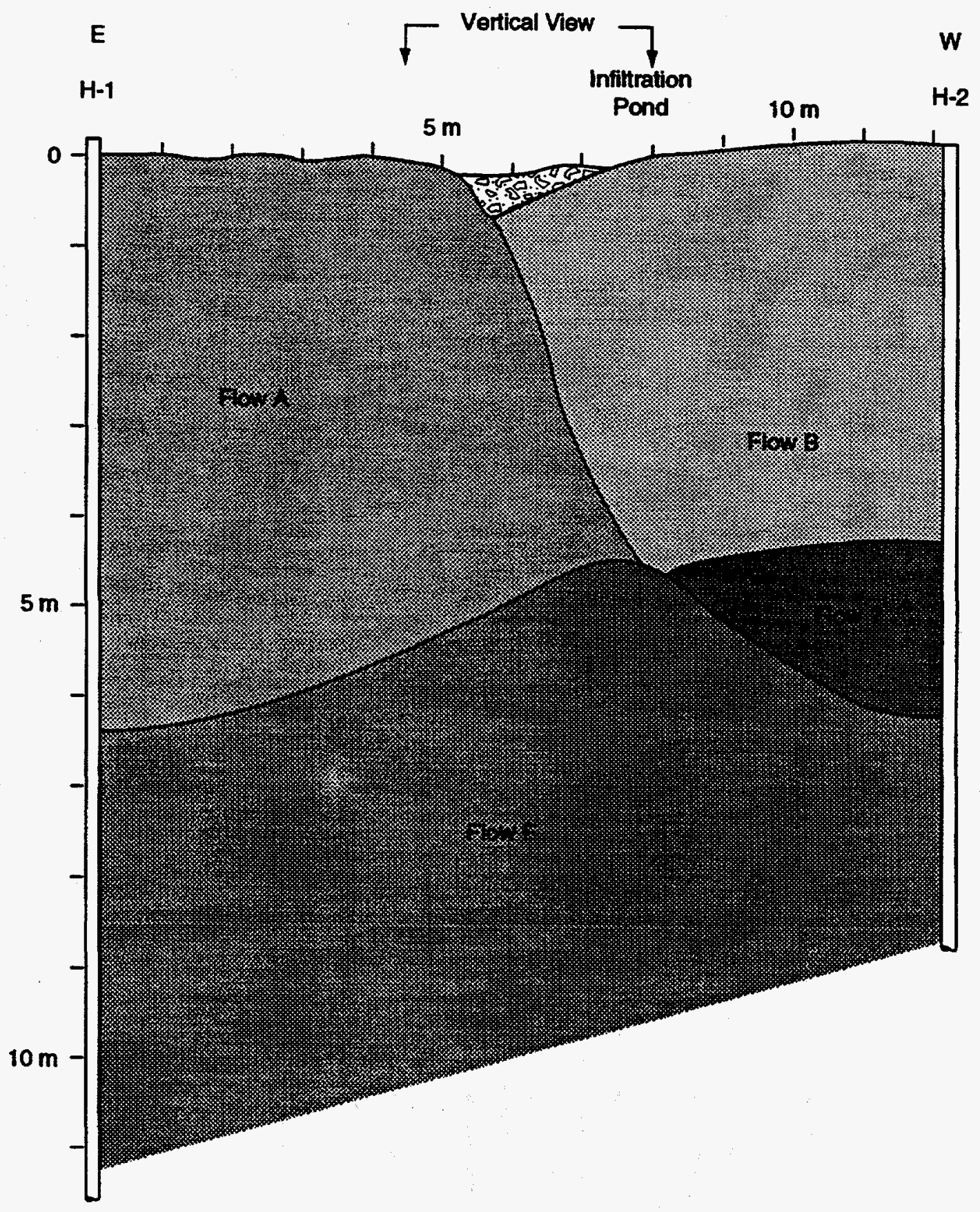

M94 0395

Figure 7. Sketch of cross sections from wells $\mathrm{H} 1$ to $\mathrm{H} 2$ showing basalt flows $\mathrm{A}, \mathrm{B}$ 

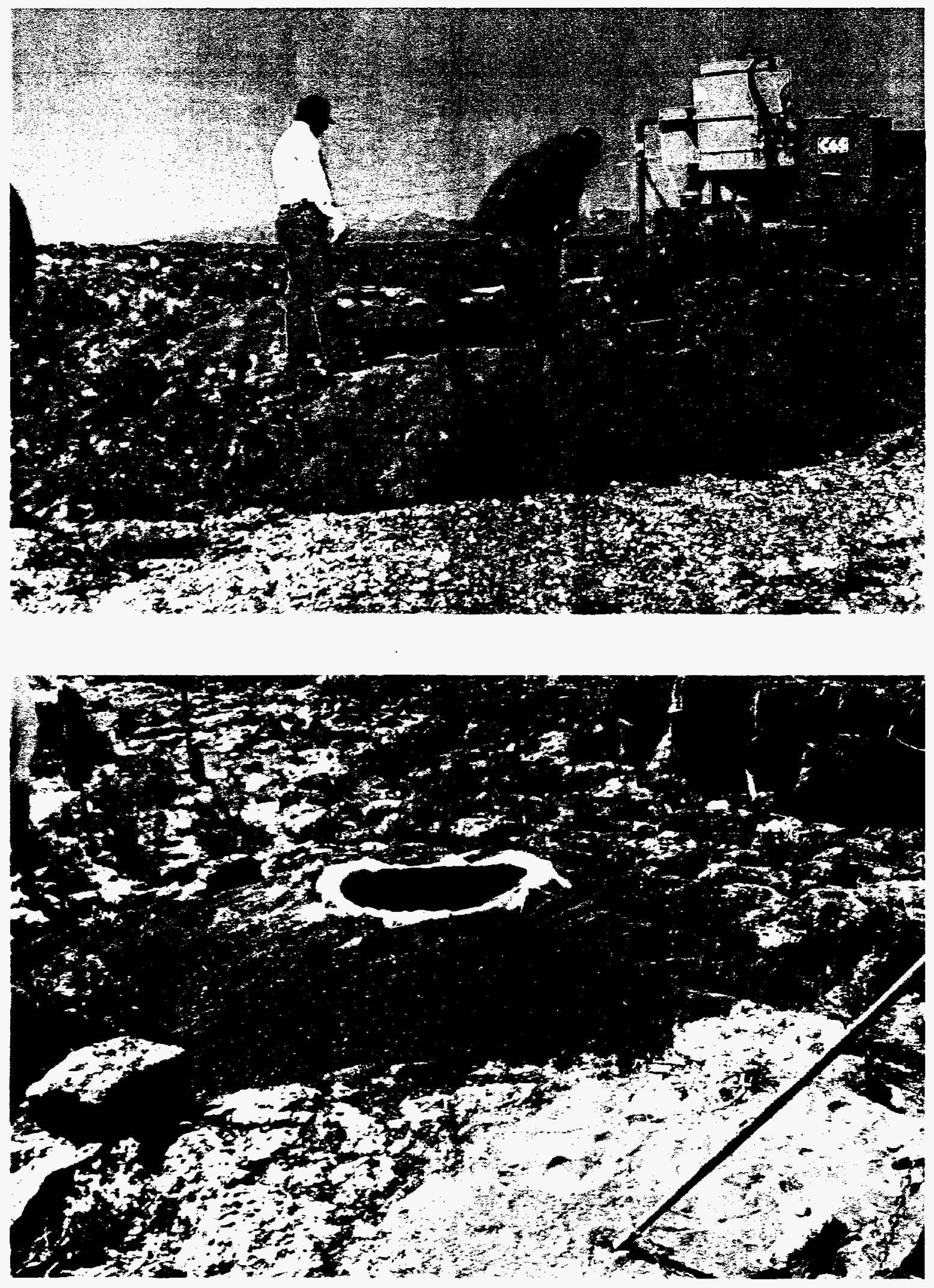

Figure 8. Upper view (8A) shows construction of infiltration pool. Lower view (8B) shows completed infiltration pool. 


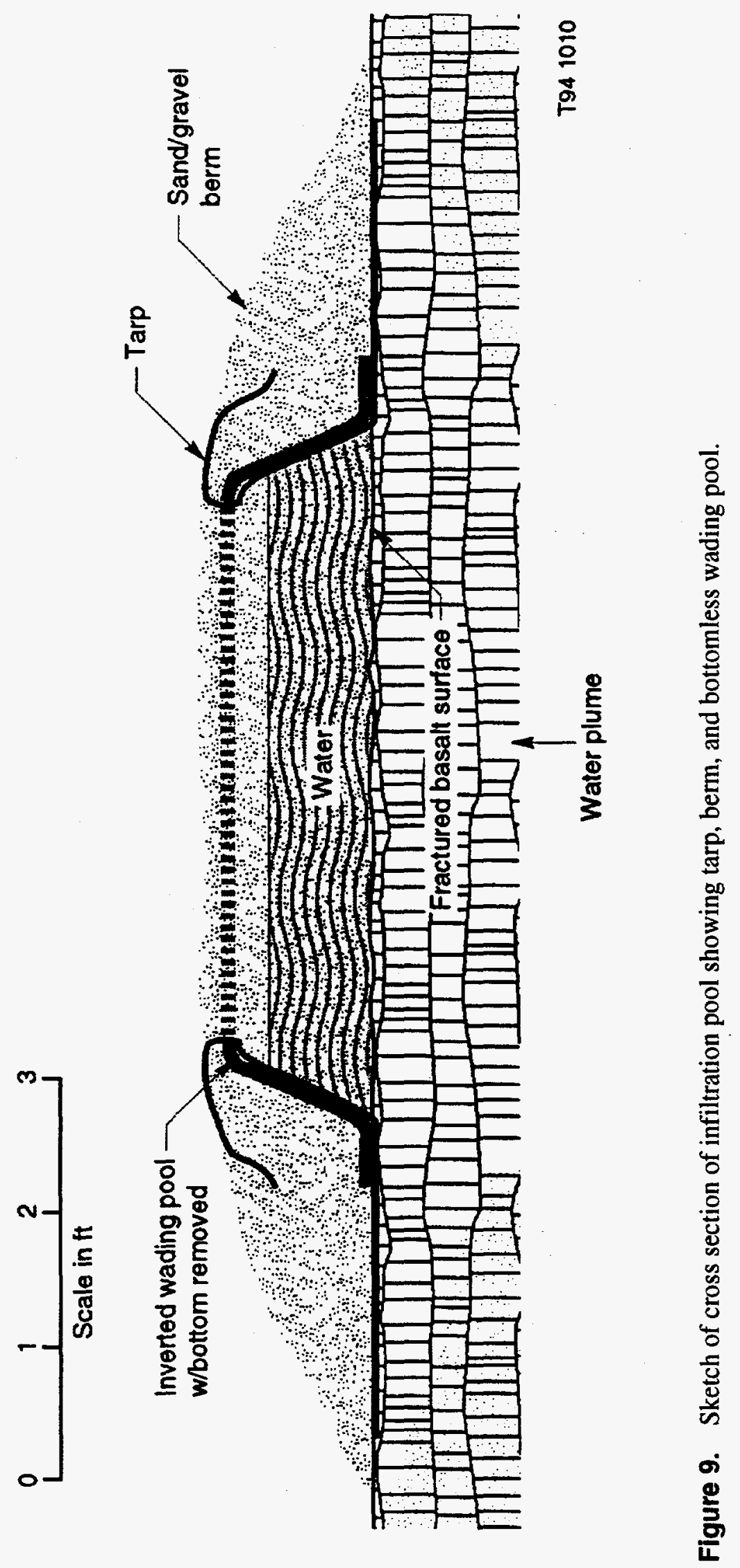



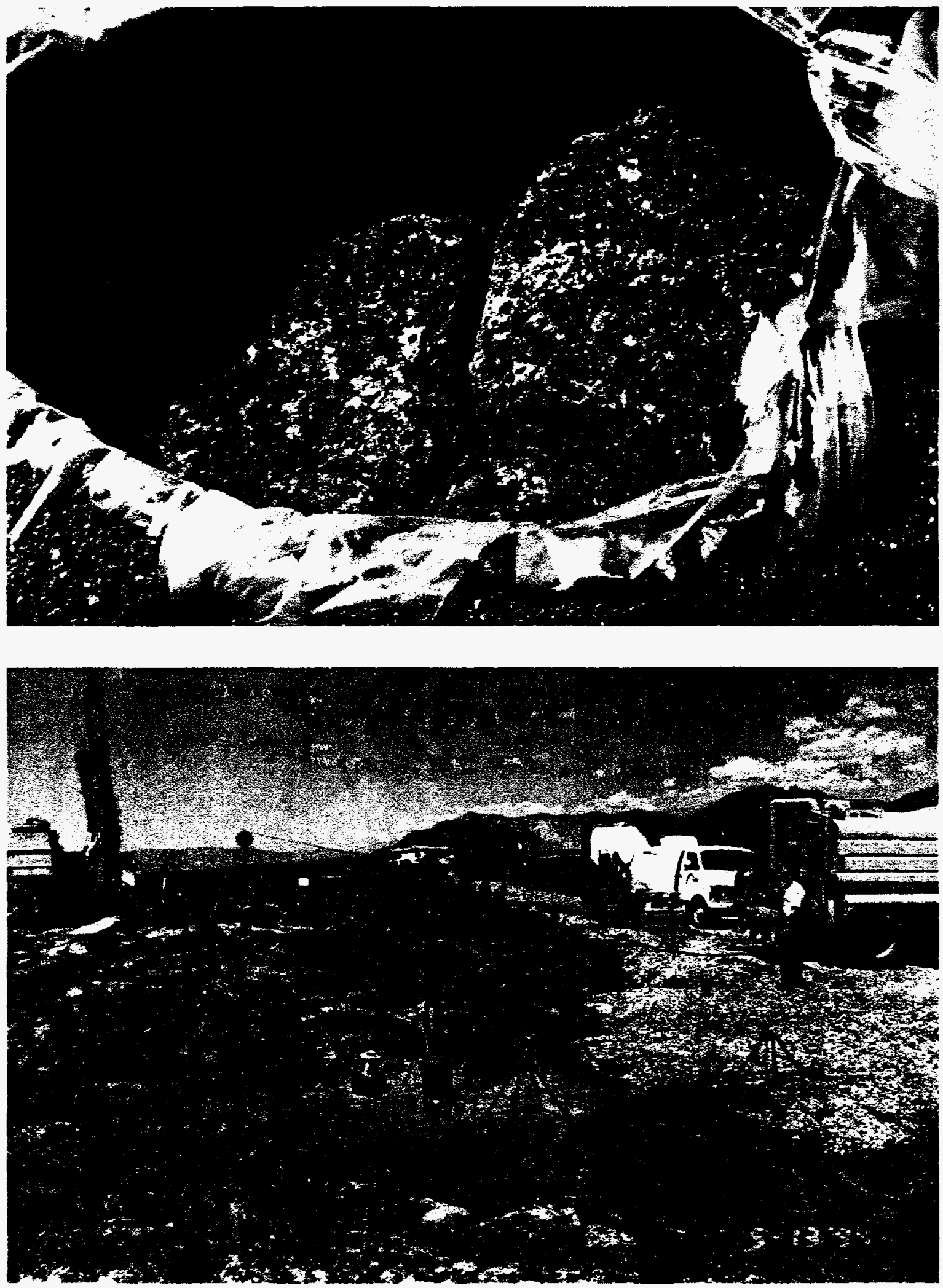

Figure 10. Upper view (10A) shows fractured basalt surface that is the bottom of the infiltration pool. Lower view (10B) shows the water truck in place and the start of the pool filling operation. 

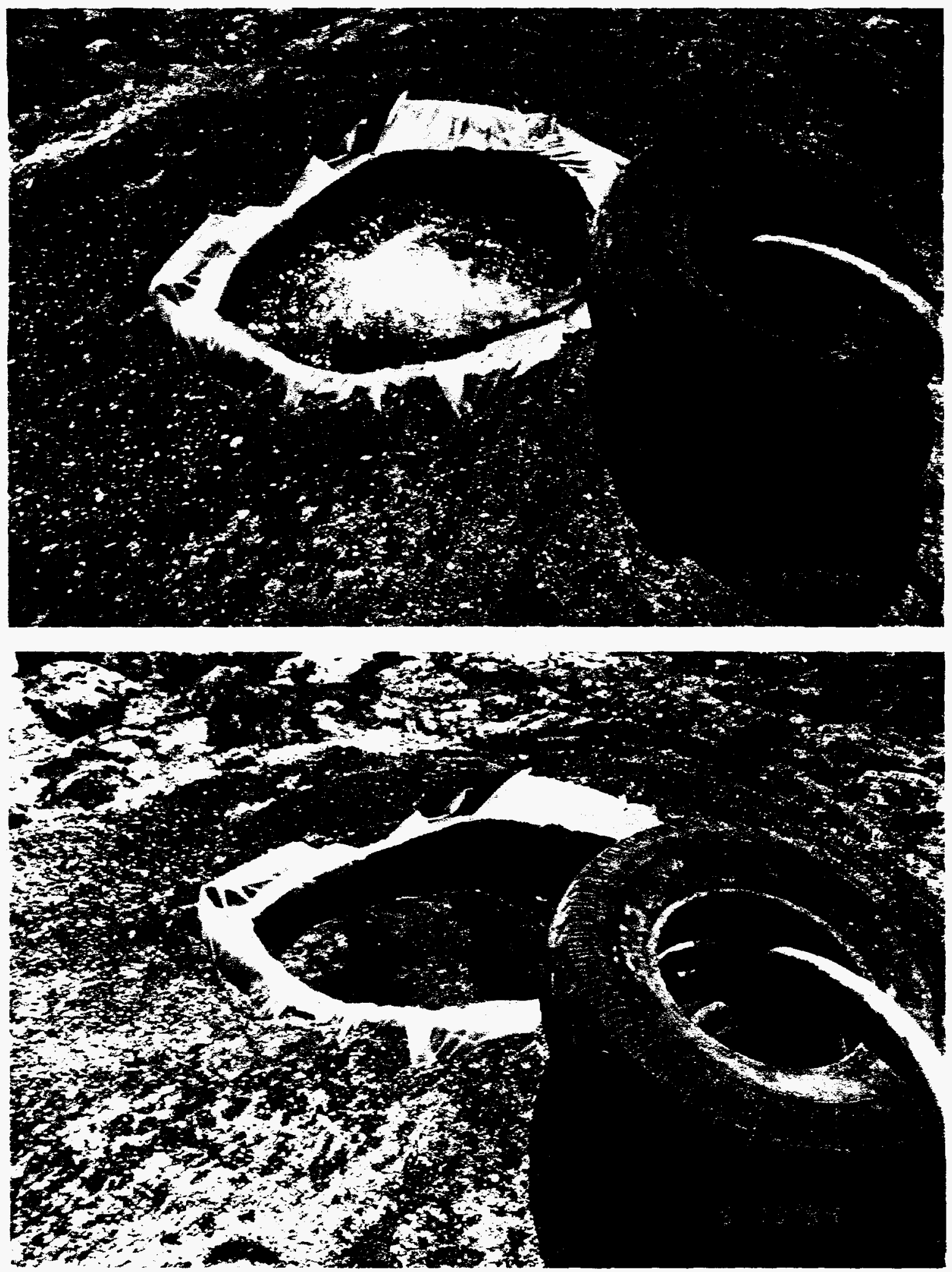

Figure 11. Upper view (11A) shows pool being filled. Lower view (11B) shows water infiltrating into the basalt. The low turbidity of the water, immediately after being agitated during the filling operation, suggests that little plugging is occurring from the suspended solids in the water. 


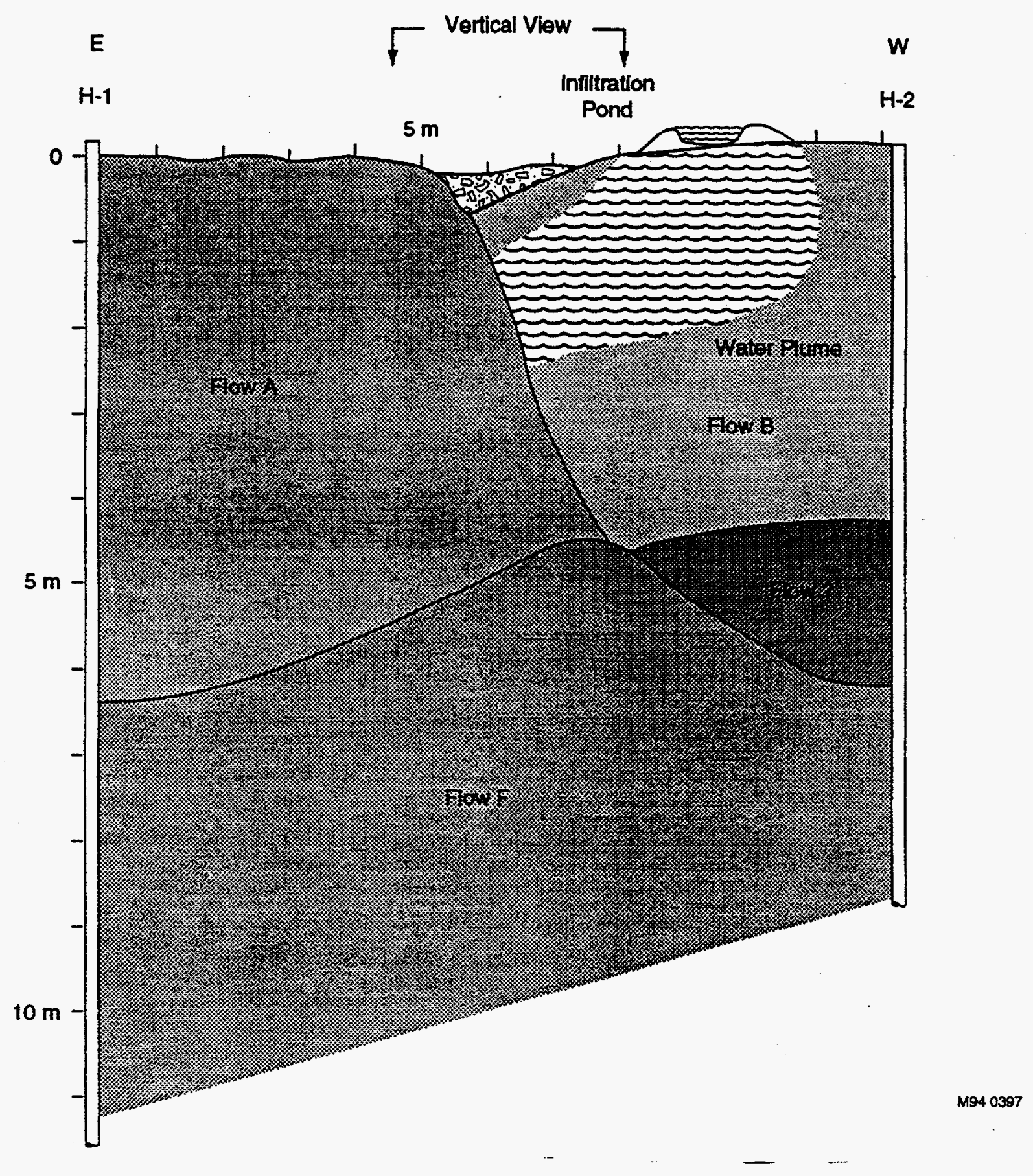

Figure 12. Modified sketch of flow cross section showing water infiltrating from pool and the resulting water filled fracture system. 